\title{
Opportunities for Ice Storage to Provide Ancillary Services to Power Grids Incorporating Wind Turbine Generation
}

\author{
Christopher Finley
}

\begin{abstract}
A thesis
submitted in partial fulfillment of the requirements for the degree of
\end{abstract}

Masters of Science in Engineering

University of Washington

2013

Program Authorized to Offer Degree:

Mechanical Engineering 

University of Washington

\begin{abstract}
Opportunities for Ice Storage to Provide Ancillary Services to Power Grids Incorporating Wind Turbine Generation
\end{abstract}

\author{
Christopher Finley \\ Chair of the Supervisory Committee: \\ Professor Ashley F Emery \\ Mechanical Engineering
}

Power generation using wind turbines increases the electrical system balancing, regulation and ramp rate requirements due to the minute to minute variability in wind speed and the difficulty in accurately forecasting wind speeds. The addition of thermal energy storage, such as ice storage, to a building's space cooling equipment increases the operational flexibility of the equipment by allowing the owner to choose when the chiller is run. The ability of the building owner to increase the power demand from the chiller (e.g. make ice) or to decrease the power demand (e.g. melt ice) to provide electrical system ancillary services was evaluated. 



\section{Table of Contents}

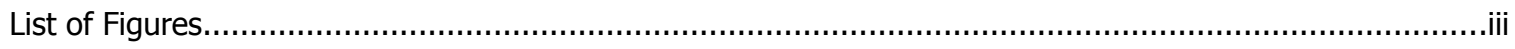

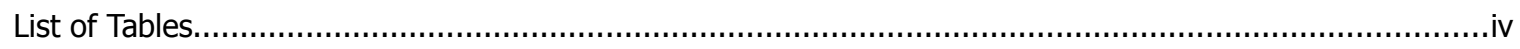

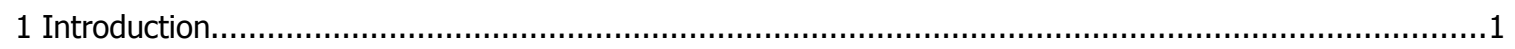

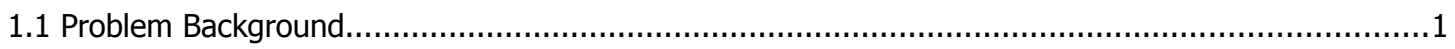

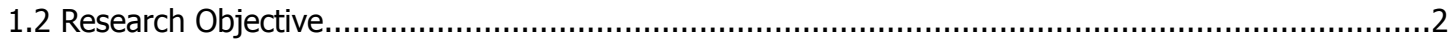

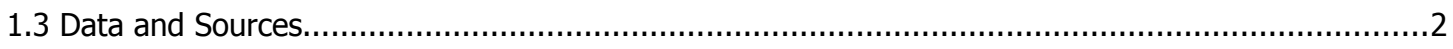

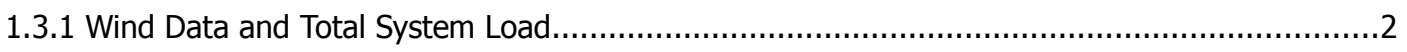

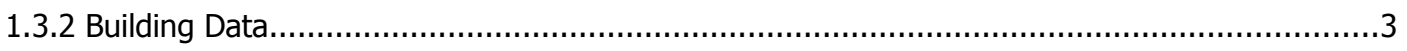

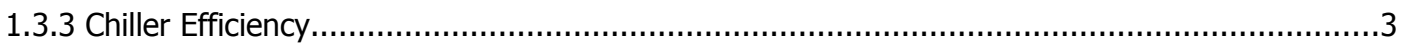

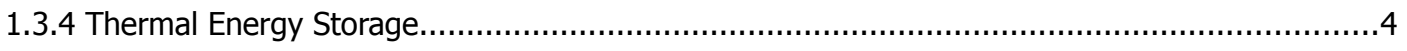

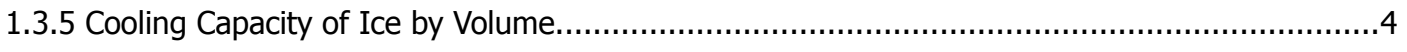

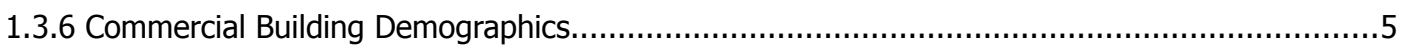

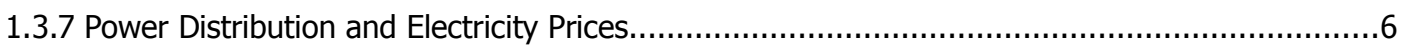

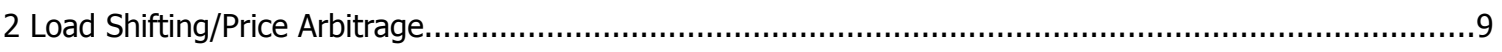

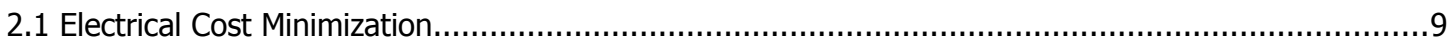

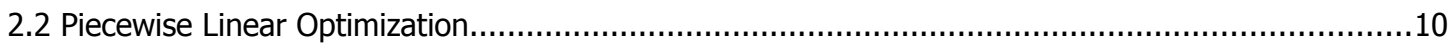

2.3 Decision Variables and Constraint Input Arguments to linprog()...............................................11

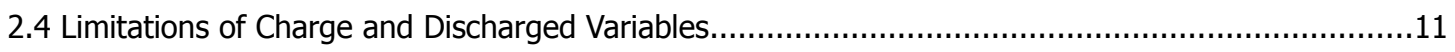

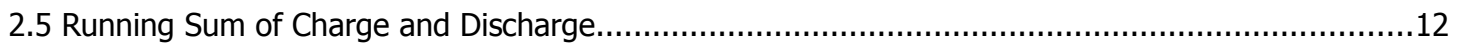

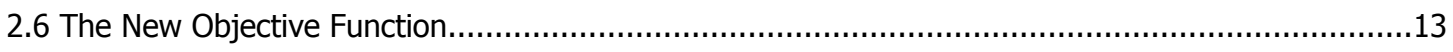

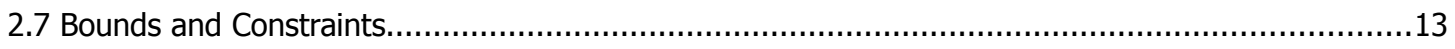

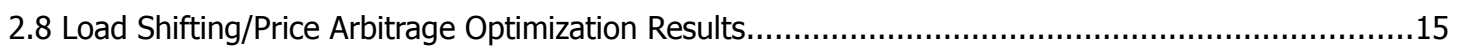

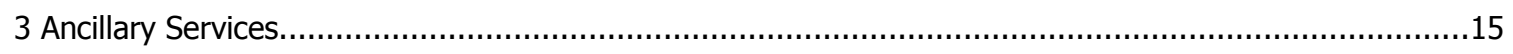

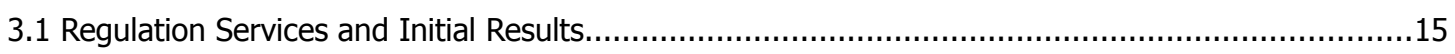

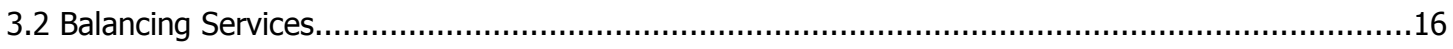

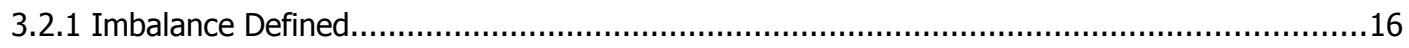

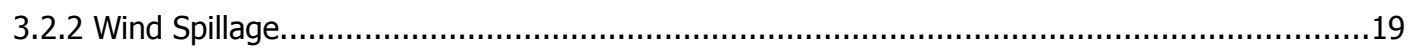

3.2.3 Linear Approach to Imbalance Minimization.............................................................. 19

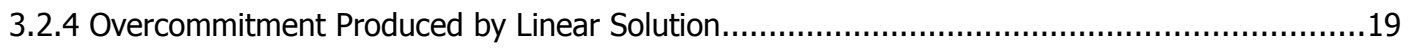

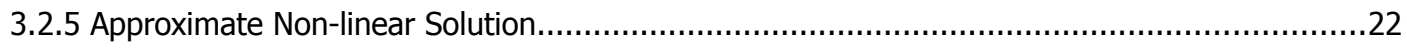

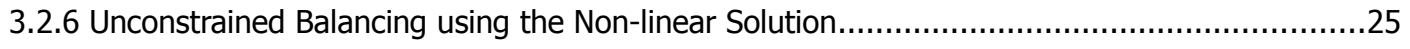

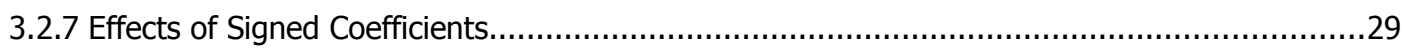

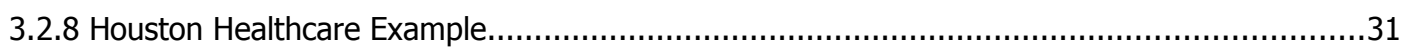

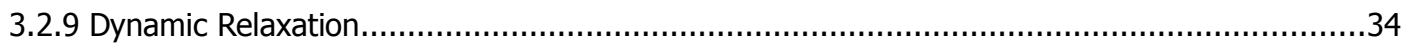

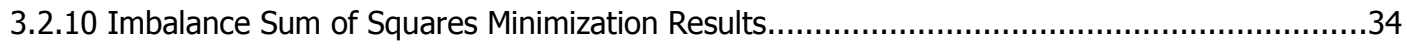

4 Economic Optimization of Combined Electricity Cost and Balancing Service Income............................36

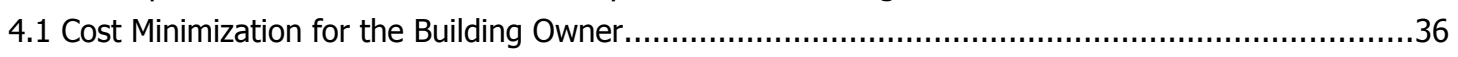

4.1.1 Combined Arbitrage and Balancing Price Test Case...........................................................

4.1.2 Combined Arbitrage and Balancing Unconstrained Storage................................................

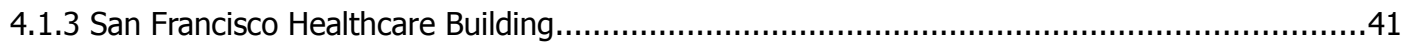


4.2 Combined Arbitrage and Balancing Service Results.......................................................44

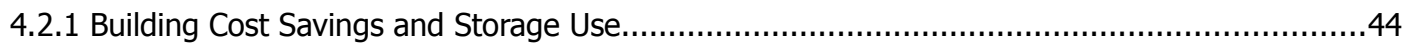

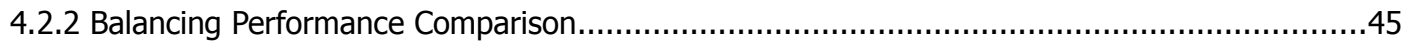

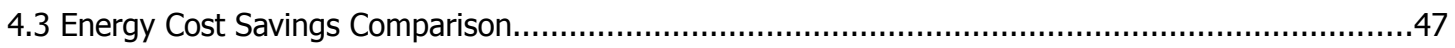

4.3.1 Time of Use Load Shifting for Summer San Francisco...........................................47

4.3.2 High Time of Use Price Differential's Effect on Cost Minimization.....................................49

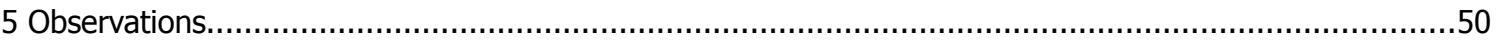

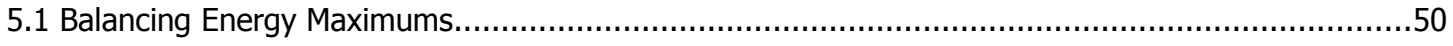

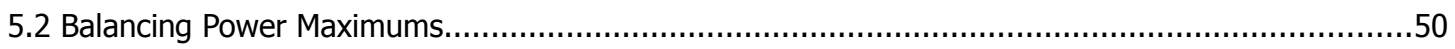

5.3 Economic Benefits of Providing Balancing Ancillary Services.............................................50

5.4 The Essential Characteristics of Using a Sum of Squares Versus a Constrained Linear Minimization. 50

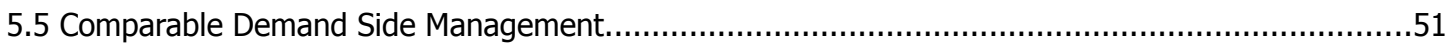

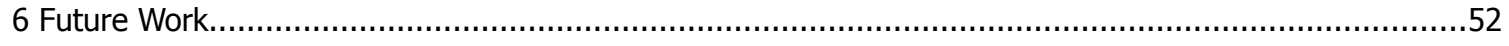

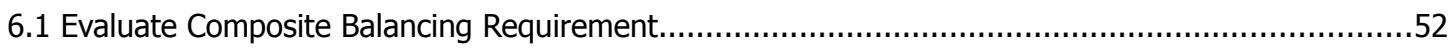

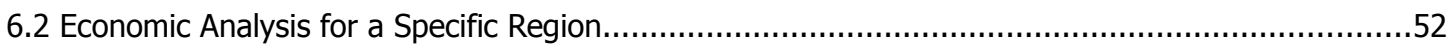

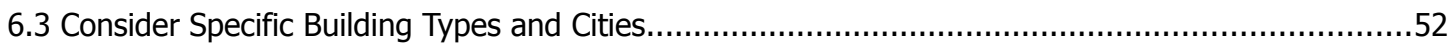

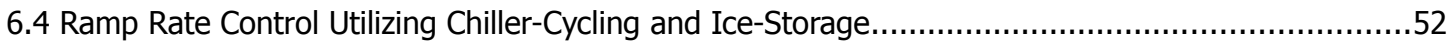

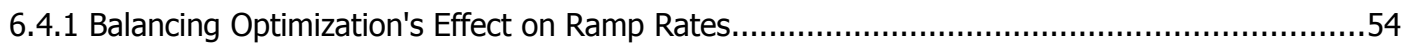

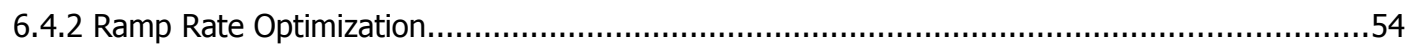

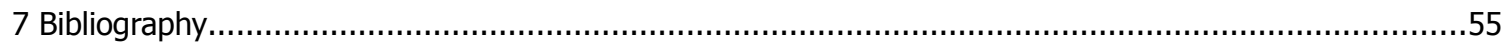




\section{List of Figures}

1. The balancing requirement for July using total system load and wind data.............................18

2. Overcommitment example, initial and net imbalances using linear optimization ........................20

3. Overcommitment example, balancing price for each interval.................................................21

4. Overcommitment example, storage operation for a single pass linear optimization.....................21

5. Iterative method example, imbalances for solution with one percent relaxation........................22

6. Iterative method example, storage operation for solution with one percent relaxation...............23

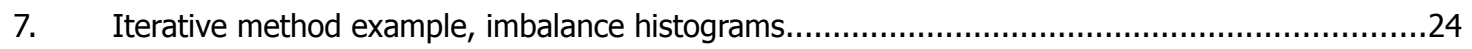

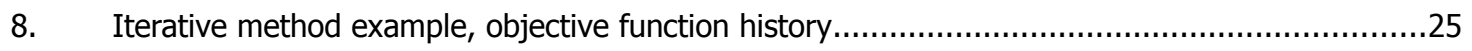

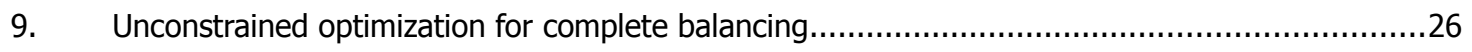

10. Unconstrained optimization with unequal coefficients of performance.....................................27

11. Signed coefficients, storage operation using signed coefficients with an iterative solution..........29

12. Signed coefficients example, imbalances using an iterative solution........................................30

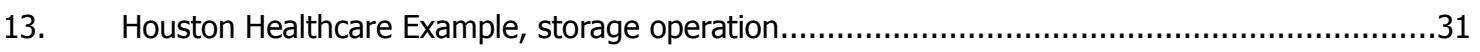

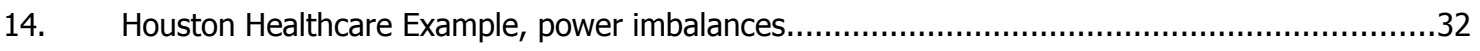

15. Houston Healthcare Example, histogram of imbalances...................................................3

16. Houston Healthcare Example, objective function value as iterations progress...........................33

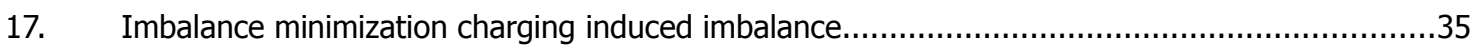

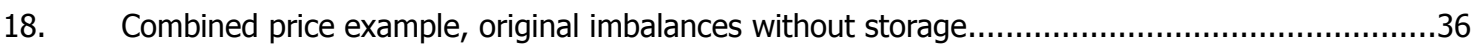

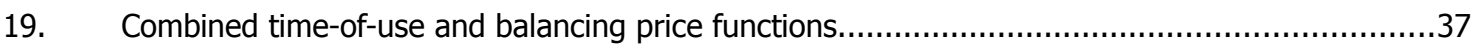

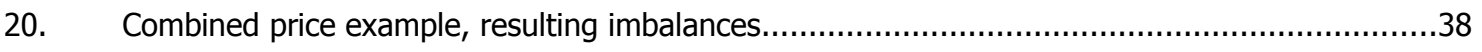

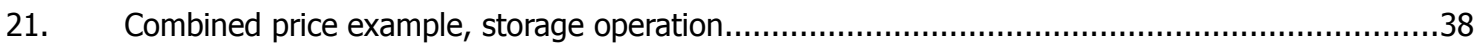

22. Combined price example, balancing results for unconstrained storage operation......................39

23. Combined price example, storage use for unconstrained storage...........................................40

24. San Francisco healthcare cooling load and storage use...................................................... 41

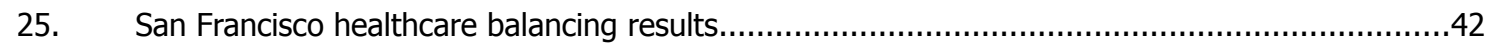

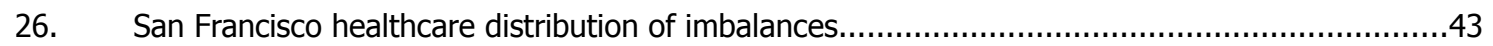

27. Net imbalances from combined price cost optimization versus balancing sum of squares...........46

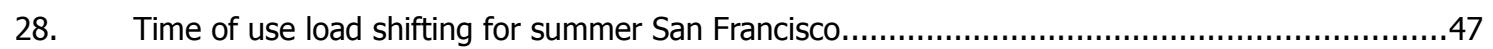

29. Storage use with load shifting for summer San Francisco..................................................48

30. Ramp rates for the total system load minus wind generation.............................................5

31. Resulting ramp rates after balancing optimization, 30 iterations.............................................54 


\section{List of Tables}

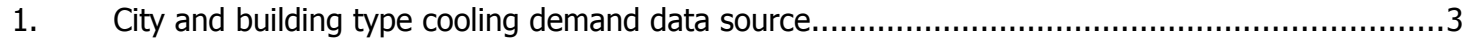

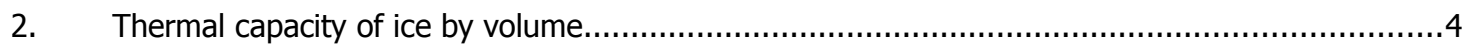

3. Building Demographics, Electricity Consumption and Expenditures.....................................

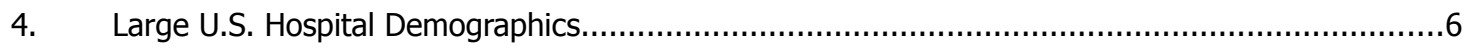

5. EIA average monthly retail electric bill information by state............................................

6. Storage Capacity Constraint using charge and discharge variables......................................

7. Charge State Using Sum of Charge and Discharge Variables.......................................13

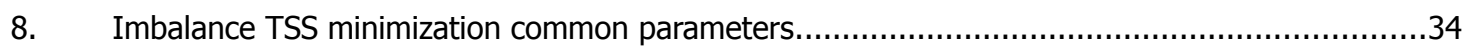

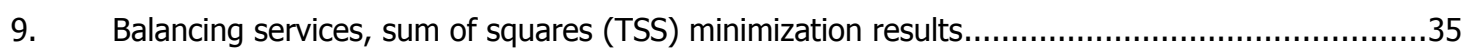

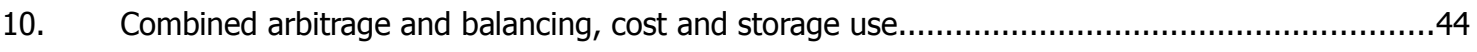

11. Balancing performance for combined arbitrage and balancing ......................................45

12. Cost minimization comparison with and without balancing ancillary services.........................49

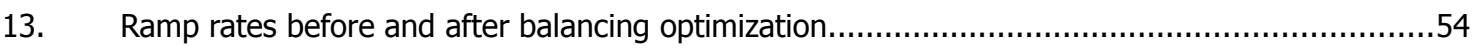




\section{Acknowledgments}

This research was made possible by funding and assistance from Pacific Northwest National Labs and by the extraordinary knowledge of its researchers. In particular, my thanks to Michael Kintner-Meyer and Kris Subbarao for their ideas and contribution. I have a special appreciation for my adviser, Professor Ashley Emery, for his guidance and exceptional experience. Professor Duane Storti holds my sincerest admiration for his intellect and my thanks for his endless support and encouragement. I am inspired by Professor John Kramlich's knowledge, professionalism and enthusiasm for his work. I want to recognize my professional heroes Professors Mark Ganter, Philip Malte and Richard Christie. Without them and the faculty and staff at the University of Washington, this work would not be possible. 


\section{Dedication}

To Kayla, Riessa and Annelli for their love, support and patience. 


\section{Introduction}

\subsection{Problem Background}

Power generation using wind turbines increases the electrical system balancing, regulation and ramp rate requirements due to the minute to minute variability in wind speed and the difficulty in accurately forecasting wind speeds at the time of generation dispatch planning (M. Kintner-Meyer et al. 2010; Y. V. Makarov et al. 2009; Y. V. Makarov et al. 2008). The difference between the actual power generation and actual load, the imbalance, is handled by a balancing service, which might be the addition or curtailment of power generation or the shedding of load. The balancing service can be characterized by the time it takes it to respond, with response times between a few minutes to several hours. The balancing requirement is expected to increase due to wind power generation. To accommodate $14.4 \mathrm{GW}$ of wind generation capacity (the projected generation capacity for 2019), the estimated balancing requirement for the Northwest Power Pool (NWPP) is 3900 MW upward capacity and 3700 MW downward capacity.(M. Kintner-Meyer et al. 2010) The installed wind generation capacity for 2013 was approximately 11 GW.(NWPP Corporation 2013) Balancing the differences between load and generation for shorter time frames (intrahour) naturally requires faster responding assets, such as hydro-electric turbines, gas-fired turbines, battery storage or demand response. The estimated intrahour balancing requirements for the 2019 NWPP are 1850 MW in either direction (M. Kintner-Meyer et al. 2010). Power regulation services maintain near instantaneous frequency requirements by matching power and demand on short time-scales, one or two minutes to less than one second. The characteristic time required for a generation asset to increase or decrease power output is its ramp rate. If wind power generation decreases suddenly with a rapid drop in wind speed, the balancing assets must come up to match power imbalance at a certain rate, termed the ramp rate requirement. Services providing balancing or regulation power are collectively called ancillary services.

The addition of thermal energy storage (TES), such as ice storage, to a building's space cooling equipment increases the operational flexibility of the equipment by allowing the owner to choose when the chiller is run. The owner may run the chiller to make ice when electricity rates are lowest. The stored ice could then be melted to cover building cooling loads when electricity prices are higher. This strategy is called load shifting for the purpose of price arbitrage ${ }^{1}$. Traditionally, this means making ice at night when electricity rates are lower and then cooling the building with

1 Arbitrage in this context is the practice of taking advantage of a price difference between markets to make a profit or reduce a cost. 
ice during the day when prices are higher. In this form no attention is paid to resolving any imbalances. However, the building owner could, by increasing the power demand from the chiller (e.g. make ice) or decreasing power (e.g. melt ice), compensate for the difference between the power grid's total load and generation, the imbalances. If the chiller responded to the imbalances on time frames of several minutes to several hours, the owner could sell this capability as a balancing service. However, if the electric motor that powers the chiller's compressor can respond on time-scales shorter than one or two minutes, that ability could be sold as a more valuable regulation service.

This paper develops a methodology for determining thermal energy storage's (TES) ability to shift loads for the purpose of price arbitrage or to provide ancillary services to the power grid operator though either balancing or regulation services. The method was tailored for environments containing wind power generation. Several test cases are demonstrated using sample wind data, total grid loads and building cooling loads.

\subsection{Research Objective}

The research's objective was to design a method and program a software toolkit for testing the ability of thermal energy storage to shift space cooling loads for the purpose of price arbitrage over weekly or even seasonal time-frames and explore the ability of TES to provide ancillary services, such as balancing and regulation services. The results of the load shifting/price arbitrage can be used as a baseline to understand the effects on electricity use, costs and benefits to the building owner when compared to providing ancillary services.

The project makes certain assumptions about the type of TES installed, the class of commercial building and its geographic location, and the utility power rate structures. The assumptions are for the purpose of demonstrating the effectiveness of the method and toolkit. The design allows the user to provide their own data and functions to handle specific situations.

\subsection{Data and Sources}

\subsubsection{Wind Data and Total System Load}

Wind generation and total system load data was provided by Pacific Northwest Nation Labs (PNNL) for the Bonneville Power Administration's (BPA) transmission control area. The wind generation data is for 2010 and provided in five minute increments.

Page 2 


\subsubsection{Building Data}

The cooling load data was provided by Pacific Northwest Nation Labs (PNNL) and comes from the study Interaction Between Dynamic Electric Rates and Thermal Energy Storage Control, 1252-RP (Sun et al. 2006). The cooling load data was simulated using SitePro for a variety of commercial buildings located throughout geographically diverse regions. Different cooling loads were generated for each day of the year based upon weather tapes. Because the weather tapes contain hourly temperature and humidity data, the simulations follow real-world cooling demands more closely than using monthly weekday and weekend averages. The building loads are generated at one hour intervals and assumed to be constant over the entire hour.

Building cooling load data from SitePro for four cities and three building types were chosen for use in this analysis.

Table 1: City and building type cooling demand data source

\begin{tabular}{l|c|c|c|}
\multicolumn{1}{|c|}{ Building Data } & Healthcare & Office & Hotel/Motel \\
\hline Chicago & SitePro & SitePro & SitePro \\
\hline Houston & SitePro & SitePro & SitePro \\
\hline New York & SitePro & SitePro & SitePro \\
\hline San Francisco & SitePro & SitePro & SitePro \\
\hline
\end{tabular}

\subsubsection{Chiller Efficiency}

The chiller's efficiency for the purpose of building cooling and ice making is a function of outdoor ambient wet-bulb temperature, the chiller's load normalized to the rated load, and the chilled water supply temperature. The efficiency correlation was derived from a simulated model for internal melt ice-on-coil thermal energy storage by Drees and Braun (1996). The model used a water-cooled centrifugal chiller. Plant power use includes the chiller, a constant-volume condenser water pump and single-speed cooling tower fans; the power use from the chilled-water pump is excluded from this relationship and must be treated separately.

$$
\begin{aligned}
& P_{c h} / P_{c h, \text { rated }}=0.2849893-0.2331356 \cdot T+0.12918 \cdot T^{2}+ \\
& 0.6808631 \cdot Q+0.02344963 \cdot Q^{2}+0.1532477 \cdot T \cdot Q \\
& T=\left(T_{w b}-T_{\text {chws }}\right) /\left(T_{w b, \text { rated }}-T_{\text {chws, rated }}\right) \\
& Q=Q_{c h} / Q_{c h, \text { rated }} \\
& T_{w b} \quad \text { : ambient wet bulb temperature }(F) \\
& T_{\text {chws }} \quad \text { : chilled-water supplied by the chiller }(F) \\
& T_{w b, \text { rated }}: \text { plant rated wet bulb ambient temperature }\left(75^{\circ} \mathrm{F}\right) \\
& T_{\text {chws,rated }}: \text { plant rated chilled-water supply temperature }\left(40^{\circ} \mathrm{F}\right)
\end{aligned}
$$


The toolkit developed for this paper uses a chilled-water supply temperature for building cooling of $50^{\circ} \mathrm{F}$ and a supply temperature of $25^{\circ} \mathrm{F}$ for ice making.

The efficiencies given by this correlation are conservative due to the poor partial-load performance caused by the constant-volume condenser water pump and single-speed cooling tower fans. The power requirements for these components remain fixed even as the cooling demand is reduced.

\subsubsection{Thermal Energy Storage}

Ice storage was chosen as the thermal energy storage mechanism. The maximum storage charge and discharged rates can be set independently; but for simplicity, the demonstration cases allowed the ice storage to charge at the chiller's rated power. The same thermal melting rate was used for ice storage discharge maximum.

\subsubsection{Cooling Capacity of Ice by Volume}

The building space requirements for keeping ice on-site must be factored into the building owner's cost-benefit analysis. Therefore, it is useful to consider the thermal capacity of ice in relation to its volume. When this report discusses thousands of megawatts of thermal storage, some insight can be gained by converting that value to a volume of ice.

$$
\begin{array}{ll}
333.6 \mathrm{~kJ} / \mathrm{kg} & \text { Enthalpy of fusion } \\
916.7 \mathrm{~kg} / \mathrm{m}^{3} & \text { Density of ice at } 0^{\circ} \mathrm{C} \\
3.6 \times 10^{6} \mathrm{~kJ} / \mathrm{MWh} & \text { Energy unit conversion }
\end{array}
$$

Table 2: Thermal capacity of ice by volume

$$
\begin{array}{c|c|c}
916.7 \mathrm{~kg} & 333.6 \mathrm{~kJ} & 1 \mathrm{MWh} \\
\hline \mathrm{m}^{3} & \mathrm{~kg} & 3,600,000 \mathrm{~kJ}
\end{array}=8.495 \times 10^{-2} \mathrm{MWh} / \mathrm{m} 3 \text { or } 11.77 \mathrm{~m}^{3} / \mathrm{MWh}
$$

The results of the economic analysis can be used by the building owners, in conjunction with implementation costs, to judge the value of utilizing ice storage. 


\subsubsection{Commercial Building Demographics}

The following demographic data for U.S. commercial buildings comes from the Commercial Buildings Energy Consumption Survey (CBECS) performed in 2003 and reported in 2006.(CBECS Energy Information Administration (EIA) 2003).

Table 3: Building Demographics, Electricity Consumption and Expenditures CBECS Table C13A. Total Electricity Consumption and Expenditures for All Buildings, 2003

\begin{tabular}{|c|c|c|c|c|c|c|}
\hline & $\begin{array}{c}\text { Number of } \\
\text { Buildings } \\
\text { (thousand) }\end{array}$ & \begin{tabular}{|c|} 
\\
Total \\
Floorspace \\
(million sq-ft)
\end{tabular} & \begin{tabular}{|c|} 
Mean \\
Floorspace \\
per Building \\
(thousand sq- \\
ft) \\
\end{tabular} & \begin{tabular}{|c|} 
Total \\
Electricity \\
Consumption \\
(million MWh) \\
\end{tabular} & \begin{tabular}{|c|} 
Mean \\
Electricity \\
Consumption \\
per Building \\
(MWh) \\
\end{tabular} & $\begin{array}{c}\text { Total } \\
\text { Electricity } \\
\text { Expenditures } \\
\text { (million } \\
\text { dollars) }\end{array}$ \\
\hline All Buildings using Electricity & 4,617 & 71,658 & 14.7 & 1,043 & 226 & 82,783 \\
\hline \multicolumn{7}{|l|}{ Building Floorspace (sq-ft) } \\
\hline 1,001 to 5,000 & 2,418 & 6,479 & 2.7 & 115 & 48 & 10,547 \\
\hline 5,001 to 10,000 & 893 & 6,645 & 7.4 & 86 & 96 & 8,199 \\
\hline 10,001 to 25,000 & 799 & 12,495 & 15.6 & 142 & 178 & 12,172 \\
\hline 25,001 to 50,000 & 254 & 9,098 & 35.9 & 116 & 457 & 9,179 \\
\hline 50,001 to 100,000 & 146 & 10,265 & 70.3 & 153 & 1,048 & 11,694 \\
\hline 100,001 to 200,000 & 73 & 10,171 & 138.7 & 172 & 2,356 & 11,962 \\
\hline 200,001 to 500,000 & 26 & 7,370 & 288.4 & 112 & 4,308 & 7,862 \\
\hline Over 500,000 & 8 & 7,660 & 937.6 & 147 & 18,375 & 11,167 \\
\hline \multicolumn{7}{|l|}{ Principal Building Activity } \\
\hline Education & 384 & 9,871 & 25.7 & 109 & 284 & 8,111 \\
\hline Food Sales & 221 & 1,237 & 5.6 & 61 & 276 & 4,627 \\
\hline Food Service & 297 & 1,654 & 5.6 & 63 & 212 & 5,176 \\
\hline Health Care & 129 & 3,163 & 24.6 & 73 & 566 & 4,882 \\
\hline Inpatient & 8 & 1,905 & 241.4 & 52 & 6,500 & 3,198 \\
\hline Outpatient & 121 & 1,258 & 10.4 & 20 & 165 & 1,684 \\
\hline Lodging & 142 & 5,096 & 35.8 & 69 & 486 & 5,288 \\
\hline Mercantile & 657 & 11,192 & 17.0 & 215 & 327 & 18,883 \\
\hline Retail (Other Than Mall) & 443 & 4,317 & 9.7 & 62 & 140 & 5,132 \\
\hline Enclosed and Strip Malls & 213 & 6,875 & 32.2 & 153 & 718 & 13,751 \\
\hline Office & 824 & 12,208 & 14.8 & 211 & 256 & 17,050 \\
\hline Public Assembly & 274 & 3,935 & 14.4 & 49 & 179 & 3,943 \\
\hline Public Order and Safety & 71 & 1,090 & 15.5 & 17 & 239 & 1,216 \\
\hline Religious Worship & 370 & 3,754 & 10.1 & 18 & 49 & 1,628 \\
\hline Service & 601 & 3,982 & 6.6 & 44 & 73 & 3,485 \\
\hline Warehouse and Storage & 464 & 9,425 & 20.3 & 72 & 155 & 5,034 \\
\hline Other & 76 & 1,729 & 22.7 & 39 & 513 & 3,049 \\
\hline Vacant & 106 & 1,846 & 17.3 & 4 & 38 & 412 \\
\hline
\end{tabular}


Several of the real-world optimizations will use building sizes of 250 thousand square feet and aggregate the load and response of one thousand buildings. Given that the survey indicates 107 thousand buildings greater than 100 thousand square feet in size, this assumption seems reasonable. The large annual electrical consumptions, exceeding $2000 \mathrm{MWh}$ annually, indicates a good potential for load shifting.

Large hospital demographics are examined more carefully in Table 4. The twenty-four hour operation and year round cooling loads means these buildings have high electricity consumption.

\begin{tabular}{|c|c|c|c|c|}
\hline & $\begin{array}{l}\text { Number of } \\
\text { Buildings }\end{array}$ & $\begin{array}{c}\text { Total } \\
\text { Floorspace } \\
\text { (million sq-ft) }\end{array}$ & $\mid \begin{array}{c}\text { Mean Floorspace } \\
\text { per Building } \\
\text { (thousand sq-ft) }\end{array}$ & \begin{tabular}{|c} 
Electric \\
Consumption per \\
Building (MWh)
\end{tabular} \\
\hline \multicolumn{5}{|c|}{ Building Floorspace (sq-ft) } \\
\hline 200,001 to 500,000 & 1,494 & 468 & 312.9 & 10,796 \\
\hline 500,001 to $1,000,000$ & 1,034 & 725 & 701.0 & 20,962 \\
\hline Over $1,000,000$ & 511 & 766 & $1,498.6$ & 37,403 \\
\hline \multicolumn{5}{|l|}{ Census Region } \\
\hline Northeast & 793 & 434 & 547.3 & 14,358 \\
\hline Midwest & 575 & 399 & 694.1 & 20,285 \\
\hline South & 1,170 & 802 & 685.5 & 21,317 \\
\hline West & 500 & 323 & 644.5 & 17,807 \\
\hline
\end{tabular}

\subsubsection{Power Distribution and Electricity Prices}

Electricity prices in four major cities were obtained from several sources. The transmission and distribution (T\&D) charges were included. The T\&D charges often varied by month, in these cases average or estimated values were used. Charges based on the peak monthly power consumption were not included. Fixed monthly charges for facilities or equipment were not included. Time of use pricing was used when the information was available. 
The U.S. Energy Information Administration (EIA) average monthly retail electric rate for commercial buildings was used to as a check against the utility rates obtained (U.S. Energy Information Administration 2013). In the case of Chicago and Houston rates, the actual average charges for EIA were higher than those calculated from the utility ratebook. This may be caused by the difficulty in estimating facility and demand charges.

\begin{tabular}{|c|c|c|c|c|}
\hline $\begin{array}{c}\text { Avg } \\
\text { Commercial } \\
\text { Bill }\end{array}$ & $\begin{array}{l}\text { Number of } \\
\text { Customers }\end{array}$ & $\begin{array}{l}\text { Avg Monthly } \\
\text { Consumption } \\
\text { (KWh) }\end{array}$ & $\begin{array}{l}\text { Avg Retail Price } \\
\text { (c/kWh) }\end{array}$ & $\begin{array}{l}\text { Avg Monthly Bill } \\
\text { (dollars) }\end{array}$ \\
\hline Illinois & 586,611 & 7,354 & 11.79 & $\$ 867.11$ \\
\hline Texas & $1,411,826$ & 6,698 & 10.75 & $\$ 719.72$ \\
\hline New York & $1,032,105$ & 6,251 & 16.84 & $\$ 1,052.45$ \\
\hline California & $1,807,261$ & 5,765 & 12.54 & $\$ 722.88$ \\
\hline
\end{tabular}

\subsubsection{Chicago}

Originally, the rates for Chicago were drawn from the Commonwealth Edison Company (ComEd) ratebook. Attempting to include all of the applicable fees and tariffs resulted in a total electric rate that was unrealistically low. Therefore, the U.S. EIA average rate of 11.79 cents/kWh was used instead.

\subsubsection{Houston}

The U.S. EIA average of 10.75 cents per $\mathrm{kWh}$ was used at a flat rate.

\subsubsection{New York}

The rate for New York was obtained in two pieces from Con Edison. An energy electricity rate of 15.19 cents/kWh was quoted over the phone for large commercial buildings. The delivery charges vary monthly, but an online tool provides average charges over the past year. (Consolidated Edison 2013) The delivery charges allows the customer to chose a time of use schedule over a flat rate.

$$
\begin{array}{lll}
15.19 & \text { Energy charge flat rate } & \\
6.55 & \text { Peak delivery charge: } & 10 \mathrm{am} \text { to } 10 \mathrm{pm}, \text { Monday through Friday } \\
4.897 & \text { Off-peak deliver: } & 10 \mathrm{pm} \text { to } 10 \mathrm{am}, \text { Monday through Friday } \\
& & \text { All day Saturday, Sunday, and holidays }
\end{array}
$$

The final electricity rate is the sum of the energy charge and delivery charge. 


\subsubsection{San Francisco}

Rates from Pacific Gas and Electric (PG\&E) were used. PG\&E offers time of use pricing with separate schedules for summer and winter. The summer partial-peak was treated as a peak load period.

Summer, May-October (cents/kWh):

14.70 Peak: 12:00 noon to 6:00 pm, Monday through Friday

14.22 Partial-Peak: 8:30 am to 12:00 noon, Monday through Friday

6:00 pm to 9:30 pm, Monday through Friday

12.39 Off-Peak: 9:30 pm to 8:30 am Monday through Friday

All day Saturday, Sunday, and holidays

Winter, November-April (cents/kWh):

$10.91 \quad$ Peak: $\quad$ 8:30 am to 9:30 pm, Monday through Friday

9.47 Off-Peak: $\quad 9: 30$ pm to 8:30 am, Monday through Friday

All day Saturday, Sunday, and holidays

For all cities, the final electricity rate is the sum of the energy and deliver charges. 


\section{Load Shifting/Price Arbitrage}

The addition of ice storage to a building's space cooling equipment allows the owner to shift the use of electrical power from high priced to lower priced times. The goal of this electrical price arbitrage is to minimize the total price paid for electricity while meeting the building cooling requirements. Increasing the ice storage capacity allows the owner to shift more energy and choose electric power prices further from the time of use. Load shifting is done without knowledge of the state of the power grid; no attempt is made to alleviate imbalances.

\subsection{Electrical Cost Minimization}

The purpose of this minimization is to define a thermal storage operation plan that minimizes the total cost of electricity for building space cooling with ice storage. The function has foreknowledge of electricity prices and cooling loads. The pos subscript keeps only positive values and sets negative ones to zero.

$$
\text { Cost of electricity }=\sum_{i=1}^{\text {Nhours }} p_{i} \cdot E_{\text {cool }, i}\left(l_{\text {bldg }, i}-\left(s_{i-1}-s_{i}\right)_{\text {pos }}\right)+p_{i} \cdot E_{\text {chg }, i}\left(s_{i}-s_{i-1}\right)_{\text {pos }}+p_{i} \cdot E_{\text {dis }, i} \cdot\left(s_{i-1}-s_{i}\right)_{\text {pos }}
$$

Equation 1: Minimization using storage state variables

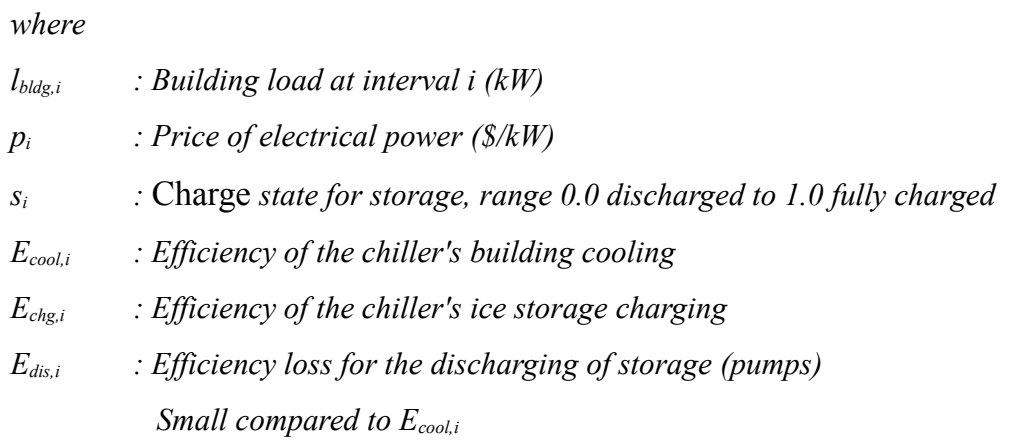

The $\left(\mathrm{s}_{\mathrm{i}-1}-\mathrm{s}_{\mathrm{i}}\right)$ term gives the change in the storage state from one time interval to the next. $\mathrm{A}$ positive change indicates that ice was melted to provide space cooling. The melting of ice is considered the discharge of stored energy because it reduces chiller electrical power that would have been required to meet cooling loads. A positive $\left(\mathrm{s}_{\mathrm{i}}-\mathrm{s}_{\mathrm{i}-1}\right)$ term signals ice making; the charging of the ice storage. The storage capacity is normalized to one and has units of kilowatt·hour-thermal. 


\subsection{Piecewise Linear Optimization}

The cost of electricity function from Equation 1 is rewritten below with the constant cost terms pulled out and the controllable variables grouped together.

$$
\text { Cost of electricity }=\sum_{i=1}^{N \text { hours }} p_{i} \cdot l_{\text {bld }, i}+\sum_{i=1}^{N \text { hours }} p_{i}\left[E_{\text {chg }, i} \cdot \max \left(0, s_{i+1}-s_{i}\right)+\left(E_{\text {cool }, i}-E_{\text {dis }, i}\right) \cdot \min \left(0, s_{i+1}-s_{i}\right)\right]
$$

Equation 2: Minimization using storage state variables, decision variables grouped

Without considering constraints yet, the $\left(\mathrm{s}_{\mathrm{i}+1}-\mathrm{s}_{\mathrm{i}}\right)$ terms can range from -1.0 to 1.0. Positive values indicate ice-making. The efficiency of ice making $\left(\mathrm{E}_{\mathrm{chg,i}}\right)$ is lower efficiency than building cooling $\left(E_{\text {cool, }, i}\right)$ because the chiller's working fluid temperature must be lower to freeze water than to cool the building. The energy cost to discharge the ice; for instance, power to run the water pumps, reduces the energy saved due to the offset building cooling. The discharge cost is considered a fixed percentage of the discharged storage in this formulation.

If the efficiencies are assumed to be constant over the entire time interval (i), charging the storage will have one cost and discharging the storage will provide a different cost, but both are linear functions of the decision variables $c_{i}$ and $d_{i}$. The cost function is thus, a piecewise linear equation and might be solved with a linear optimizer. The charging segment is given the decision variable $c_{i}$, while discharging is given $d_{i}$.

$$
\begin{aligned}
& \text { Cost of electricity }=\sum_{i=1}^{N \text { hours }} p_{i} l_{\text {bldg }, i}+\sum_{i=1}^{N \text { hours }} p_{i}\left[E_{c h g, i} \cdot c_{i}+\left(E_{d i s, i}-E_{c o o l, i}\right) \cdot d_{i}\right] \\
& \text { Equation 3: Electricity cost minimization using charge and discharge } \\
& \text { variables } \\
& \text { where } \quad: \text { Charging of the storage in interval } i \\
& c_{i} \quad: \text { Discharging of the storage in interval } i \\
& d_{i} \quad \text { both }_{i} \text { and } d_{i} \text { are normalized to the thermal energy storage capacity }
\end{aligned}
$$

The non-linear component of the efficiencies arise from the non-linear, partial-load efficiency of the chiller. The chiller compressor generally becomes less efficient at lower partial-loads; but this behavior is highly dependent upon the equipment. Cooling systems with variability-speed compressor motors and water-pumps perform well at partial-load. In this analysis, these nonlinearities were ignored. The desire to examine ice storage benefits over weekly to season periods guides the decision to choose an optimization algorithm capable of handling a large number of decision variables. By taking the prices $\left(\mathrm{p}_{\mathrm{i}}\right)$ and the efficiencies ( $\mathrm{E}_{\mathrm{dis}}, \mathrm{E}_{\mathrm{cool}}, \mathrm{E}_{\mathrm{chg}}$ ) as 
constants, the minimization problem is linear in $c_{i}$ and $d_{i}$. Running a single full-year optimization involves 8760 hours per year times two decision variables per hour or 17,520 variables to optimize. Matlab's Linear Interior Point Solver (LIPSOL) based optimization function linprog() was chosen as the basis for solving the optimization problem.

\subsection{Decision Variables and Constraint Input Arguments to linprog()}

The linear solver, $\operatorname{linprog}\left(\right.$ ), finds a set of values for the decision variables ( $x$ ) so that $\mathrm{f}^{\mathrm{T}} \cdot \mathrm{x}$ is minimized. The resulting values for the decision variables may be bound by upper and lower limits, inequality constraints and equality constraints. The objective function (f) is specified as a vector of linear coefficients.

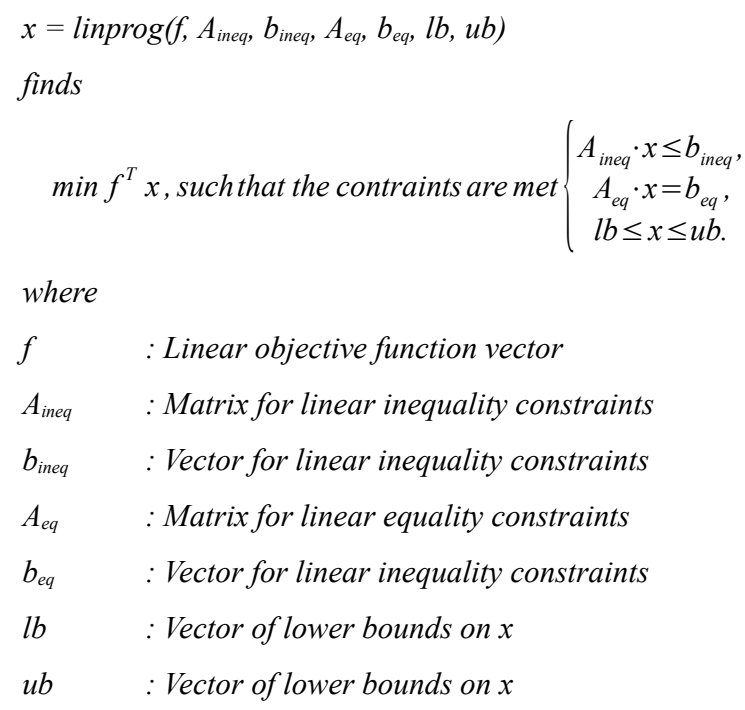

The decision variables in Equation 3 are the charge and discharge amounts for each interval.

$$
x=\left[c_{1}, c_{2}, c_{3}, \ldots c_{n}, d_{1}, d_{2}, d_{3}, \ldots d_{n}\right] \text {, where there are } n \text { intervals }
$$

The objective function (f) contains the linear coefficients to the decision variables. The coefficients are primarily set by the price of electricity during the interval and the efficiency of the chiller. The outdoor ambient wet-bulb temperature affects the chiller's efficiency; hence, the temperature in each interval must be considered.

\subsection{Limitations of Charge and Discharged Variables}

The optimization was originally coded using one charge and one discharge variable for each interval. Charging increases the use of electricity for that interval while discharging decreases the use of electricity by the chiller for space cooling. Subject to constraints, the electricity price in 
each interval drives which action should be taken.

Naturally, charging beyond the storage capacity can not occur and discharging from empty storage is not possible. These constraints requires bounding the storage state in each interval. However, determining the storage's state of charge at interval (i) requires taking the initial charge state (Init), adding each of the charges and subtracting each of the discharges from previous intervals.

Table 6: Storage Capacity Constraint using charge and discharge variables

\begin{tabular}{|c|c|c|}
\hline Interval & Charge/Discharge Variables & Bound \\
\hline 1 & Init $+c_{1}-d_{1}$ & $\leq$ storage_capacity \\
\hline 2 & Init $+c_{1}-d_{1}+c_{2}-d_{2}$ & $\leq$ storage_capacity \\
\hline$\ldots$ & $\ldots$ & $\leq$ storage_capacity \\
\hline $\mathrm{n}$ & Init $+c_{1}-d_{1}+c_{2}-d_{2}+\ldots+c_{n}-d_{n}$ & $\leq$ storage_capacity \\
\hline
\end{tabular}

Specifying the lower and upper storage state bounds necessitates adding two large lower triangular matrices to the inequality constraint matrices. When looking at long-term optimizations, over 3 months, the optimizer runs out of memory.

The constraint matrices were loaded into sparse matrix data structures; however, the triangular nature of the constraints still caused the algorithm to use more memory than available.

\subsection{Running Sum of Charge and Discharge}

The decision variables charge $\left(\mathrm{c}_{\mathrm{i}}\right)$ and discharge $\left(\mathrm{d}_{\mathrm{i}}\right)$ were replaced with variables representing the running sum of charges $\left(\mathrm{cs}_{\mathrm{i}}\right)$ and sum of discharges $\left(\mathrm{ds}_{\mathrm{i}}\right)$. The charge amount $\left(\mathrm{c}_{\mathrm{i}}\right)$ is the difference between the current sum and the sum in the next interval $\left(\mathrm{cs}_{\mathrm{i+1}}-\mathrm{cs}_{\mathrm{i}}\right)$. The charge amount must be zero or positive. The discharge amount $\left(\mathrm{d}_{\mathrm{i}}\right)$ can be derived from $\left(\mathrm{ds}_{\mathrm{i}+1}-\mathrm{ds}_{\mathrm{i}}\right)$; likewise, it is always zero or positive. The new decision vector follows.

$$
x=\left[c s_{1}, c s_{2}, c s_{3}, \ldots c s_{n}, c s_{n+1}, d s_{1}, d s_{2}, d s_{3}, \ldots d s_{n}, d s_{n+1}\right],
$$

over $n$ intervals and $n+1$ charge/discharge sums

The state of charge (s) for any interval (i) is given by $\left(\mathrm{cs}_{\mathrm{i}}-\mathrm{ds}_{\mathrm{i}}\right)$. The storage state in any interval $\left(\mathrm{s}_{\mathrm{i}}\right)$ is found by subtracting the sum of discharges $\left(\mathrm{ds}_{\mathrm{i}}\right)$ from the sum of charges $\left(\mathrm{cs}_{\mathrm{i}}\right)$.

$$
s_{i}=c s_{i}-d s_{i}
$$


The upper and lower limits on the storage capacity now involves just two variables, regardless of the interval. Specifying an upper limit on the charge state requires a diagonal, first difference matrix; instead of a lower triangular matrix.

Table 7: Charge State Using Sum of Charge and Discharge Variables

\begin{tabular}{|c|c|c|}
\hline Interval & Charge/Discharge Variables & Bound \\
\hline 1 & Init $+c s_{1}-d s_{1}$ & s storage_capacity \\
\hline 2 & Init $+\mathrm{Cs}_{2}-\mathrm{ds} \mathrm{s}_{2}$ & s storage_capacity \\
\hline$\ldots$ & $\ldots$ & s storage_capacity \\
\hline $\mathrm{n}$ & Init $+c s_{n}-d s_{n}$ & s storage_capacity \\
\hline
\end{tabular}

Specifying the storage limit constraints using charge and discharge sums and storing the matrices in a sparse data structure saves memory and allows for optimizing of the thermal storage use over an entire year.

\subsection{The New Objective Function}

The charge and discharge decision variables are replaced with running sum of charges $\left(\mathrm{cs}_{\mathrm{i}}\right)$ and sum of discharges $\left(\mathrm{ds}_{\mathrm{i}}\right)$. The objective function is rewritten below.

$$
\begin{aligned}
& \qquad c_{i} \text { is replaced with }\left(c s_{i+1}-c s_{i}\right) \\
& \qquad d_{i} \text { is replaced with }\left(d s_{i+1}-d s_{i}\right) \\
& \text { Cost of electricity }=\sum_{i=1}^{N \text { hours }} p_{i} \cdot l_{b l d g, i}+\sum_{i=1}^{N h o u r s} p_{i}\left[E_{c h g, i} \cdot\left(c s_{i+1}-c s_{i}\right)+\left(E_{d i s, i}-E_{c o o l, i}\right) \cdot\left(d s_{i+1}-d s_{i}\right)\right] \\
& \begin{array}{l}
\text { Equation 7: Electricity cost minimization using sum of charge and sum of discharge } \\
\text { variables }
\end{array}
\end{aligned}
$$

The goal is to minimize this objective function, that is the cost of electricity for building space cooling.

\subsection{Bounds and Constraints}

\subsubsection{Upper and Lower Bounds}

The lower bound for both $\mathrm{cs}_{\mathrm{i}}$ and $\mathrm{ds}_{\mathrm{i}}$ is 0.0 , indicating that no charging or discharging has occurred. The charge/discharge sums can grow by the maximum respective charging/discharging rates. An upper bound for $\mathrm{cs}_{\mathrm{i}}$ in interval $\mathrm{i}$ is the maximum charge rate times interval number. Likewise, the upper bound for $\mathrm{ds}_{\mathrm{i}}$ is the maximum discharge rate time the interval number. 


\subsubsection{Initial Charge State}

The initial charge state can be fixed by constraining $\mathrm{cs}_{1}$ to the desired initial state with $\mathrm{ds}_{1}$ set to zero. Alternately, $\mathrm{cs}_{1}$ can be left undefined and the optimizer will find the optimal starting charge state.

\subsubsection{Charge State Constraints}

The storage's charge state in any interval (i) is given by $\mathrm{cs}_{\mathrm{i}}-\mathrm{ds}_{\mathrm{i}}$. The storage capacity constraints are listed below.

Maximum storage capacity

$$
c s_{i}-d s_{i} \leq 1.0
$$

Storage state may not be negative

$$
c s_{i}-d s_{i} \geq 0.0
$$

\subsubsection{Charging and Discharging Rate Constraints}

\section{Lower limits}

$$
\begin{aligned}
& c s_{i+1}-c s_{i} \geq 0 \\
& d s_{i+1}-d s_{i} \geq 0
\end{aligned}
$$

Upper Limits

$$
\begin{aligned}
& c s_{i+1}-c s_{i} \leq \text { max_charge_rate } \\
& d s_{i+1}-d s_{i} \leq \text { max_discharge_rate }
\end{aligned}
$$

\subsubsection{Discharge May Not Exceed Load}

$$
d s_{i+l}-d s_{i} \leq l_{b l d g, i}
$$

\subsubsection{Chiller Capacity}

The chiller must be able to meet any building cooling load not met by the ice storage. This also limits the storage charge rate.

$$
\begin{aligned}
& \text { chiller_rate_max } \geq \text { charge_rate }+ \text { load-discharge_rate } \\
& \text { rearranged and written in terms of the decision variables } \\
& \left(c s_{i+1}-c s_{i}\right)-\left(d s_{i+1}-d s_{i}\right) \leq \text { chiller_rate_max }-l_{\text {bldg,i }}
\end{aligned}
$$

\subsubsection{Final Charge State Equals Initial State}

$$
\left(c s_{1}-d s_{1}\right)-\left(c s_{n+1}-d s_{n+1}\right)=0
$$

There will be $n+1$ states for $n$ charge/discharge sums. 


\subsection{Load Shifting/Price Arbitrage Optimization Results}

The cost savings from load shifting are used as a baseline for comparing the ability of ice storage to offer ancillary services in addition to load shifting. The results are used in Section 4.3 Energy Cost Savings Comparison. In all of the real-world examples, the maximum ice storage was equal to the cooling needed for eight hours at the annual peak demand.

The load shifting optimization could be run for an entire year using one hour intervals. Although, the initial and final storage states are required by constraints to be the same, the value can be freely chosen. Once balancing was introduced, the intervals were changed to five minutes. Fullyear optimizations were not possible due to memory limits with the computers and the version of $M A T L A B^{\circledR}$ used for this research. These could be up upgraded, but because the constraint matrices grow quickly, the added number of decision variables was expected to be small. This thesis ran month-long optimizations for January and July for each objective function used. The start and end storage state had to match, but could take any value. Obtaining full-year results can be achieved by running the target month plus a few extra weeks and allowing the final state to be chosen freely. The results from the extra weeks are discarded; they provide look-ahead for the optimization, but are not used. The end of month storage state would become the initial storage state for the next month. The thermal storage capacity ( 8 hours at peak cooling) is small compared to the cooling load over several weeks, thus it is unlikely that conditions beyond the two extra weeks would change the optimal value at the month's end.

\section{Ancillary Services}

\subsection{Regulation Services and Initial Results}

The addition of ice storage makes it possible to turn off the chillers without impacting building cooling. Can the chillers be cycled on and off (short cycling) to match the power regulation need of the electric distribution system? Power regulation occurs on a minute by minute basis. The air conditioning system would respond automatically (automatic load control) similar to AGC (automatic generation control) infrastructure.

The full-cycle shutdown/restart times for centrifugal compression chillers with variable-speed drives are approximately 8 to 17 minutes. Leaving the system running while varying the chiller output between the operating minimum and maximum, typically $25 \%$ to $100 \%$ of the design load would provide faster responses, about 75 seconds to 6 minutes, while removing the mechanical 
and thermal stresses associated with a full stop and restart. The efficiency of the chiller increases with reduction in load; however, the full air conditioning plant efficiency decrease slightly with reduced load.

The 75 second to 6 minute response times for chiller are sufficient for real-time balancing services. However, for the purposes of providing regulation services, a closer look at the mechanical properties of individual chiller models is required. Operational requirements belonging to the power market into which the regulation service is bid should also be examined. Future research on this topic would be useful because regulation services command higher prices.

\subsection{Balancing Services}

A building's centrifugal compression chiller and ice storage can be operated to consume excess power generation or to reduce the system load when there are generation shortages. Because the chiller can power up or down between the operating minimum and maximum states within 6 minutes, this capability can be sold on the power markets as a balancing service. This section examines the ability of building chillers with ice storage to provide balancing services using historical power grid loads and wind turbine power generation. Building cooling requirements and physical limits on the ice storage are considered. The current section uses ice storage to provide the maximum balancing possible regardless of the building owner's electricity price contract. These results provide a best-case baseline for comparing the balancing that can be provided when the chiller is operated for economic benefit as will be done in the economic optimization in Section 4 Economic Optimization of Combined Electricity Cost and Balancing Service Income.

\subsubsection{Imbalance Defined}

Balancing power compensates for differences between the actual load $\left(L_{a}\right)$ and the actual generation $\left(\mathrm{G}_{\mathrm{a}}\right)$.

$$
b=L_{a}-G_{a}
$$

Power generation must be scheduled $\left(\mathrm{G}_{\mathrm{s}}\right)$ in advance and so the load must be predicted $\left(\mathrm{L}_{\mathrm{p}}\right)$. Any inability to perfectly predict the load introduces some deviations for which balancing will need to compensate.

$$
L_{a}=L_{p}+L_{d e v}
$$

In addition, deviations from the scheduled generation occur when power generation units fail or when power is provided by non-controllable resources such as wind or solar.

$$
G_{a}=\left(G_{s}+G_{d e v}\right)+\left(G_{\text {wind }, p}+G_{\text {wind,dev }}\right)+\left(G_{\text {solarp } p}+G_{\text {solarddev }}\right)
$$


Putting this together provides a more detailed definition of balancing.

$$
b=\left(L_{p}+L_{d e v}\right)-\left(G_{s}+G_{d e v}\right)+\left(G_{\text {wind,p }}+G_{\text {wind,dev }}\right)+\left(G_{\text {solarp }}+G_{\text {solar dev }}\right)
$$

The scheduled generation $\left(\mathrm{G}_{\mathrm{s}}\right)$ equals the predicted load minus the predicted generation from the non-controllable resources.

$$
G_{s}=L_{p}-G_{\text {wind }, p}-G_{\text {solarp } p}
$$

Substituting equation (5) into equation (4) and reducing leads to the intuitive result that the balancing power requirement is equal to the sum of the deviations from the predicted load and predicted generation.

$$
b=L_{d e v}-G_{d e v}-G_{\text {wind,dev }}-G_{\text {solar,dev }}
$$

A schedule made far in advance of reliable wind, cloud cover or temperature data will result in significant imbalances. Schedules made near the time of the actual load and generation will have been adjusted based on better predictions, thus the balancing requirements near the time of power use will be lower, but these services must be able to respond on shorter notification.

The ability to offset building cooling loads using ice storage allows control of the load deviation term $\left(\mathrm{L}_{\mathrm{dev}}\right)$. Controlling the load deviation in a way that minimizes the balancing requirement is a benefit to the power grid and is monetized as an ancillary service called balancing power. This section looks specifically at the ability to compensate for wind generation deviations. Even though power generation failure from dispatchable units and variability from solar power is treated as zero, the power grid will require sufficient additional balancing to handle these deviations. Load management using ice storage could also provide some of the non-wind balancing; however, that ability was not examined here.

The actual load $\left(\mathrm{L}_{\mathrm{a}}\right)$ for the BPA control area along with the actual wind generation data $\left(\mathrm{G}_{\mathrm{wind,a}}\right)$ was provided by PNNL. The balancing requirement can only be determined after a scheduled generation $\left(\mathrm{G}_{\mathrm{s}}\right)$ is estimated.

$$
b=L_{a}-G_{\text {wind }, a}-G_{s}
$$

To demonstrate that this is indeed the sum of the load and generation deviations, substitute the following identities into equation 7 and reduce.

$$
\begin{aligned}
& L_{a}=\left(L_{p}+L_{d e v}\right) \\
& G_{\text {wind,a }}=\left(G_{\text {wind, } p}+G_{\text {wind,dev }}\right) \\
& G_{s}=\left(L_{p}-G_{\text {wind, } p}\right) \\
& \text { substituting and reducing leads to equation } 6 \text { for the wind-only case. } \\
& b=L_{d e v}-G_{\text {wind,dev }}
\end{aligned}
$$


Once a reasonable value for the scheduled generation is determined, the combined load, wind generation deviations and balancing requirement can be determined from the available data. Choosing a generation schedule that too closely matches the actual load and wind generation would produce a balancing requirements that are unrealistically small.

This thesis will take the monthly average of the load minus wind generation to be the scheduled generation. Any variation from this average is considered an imbalance. This is very inclusive definition of balancing and means that base-load power generation could be set to a fixed output for the entire month and the controllable building cooling load will try to compensate for any deviations. This provides a difficult test for the ice storage because it assumes no ability to predict load or wind generation and includes daytime peak loads as a deviation from the scheduled generation. Figure 1 shows the imbalances in megawatts for July by 5 minute interval.

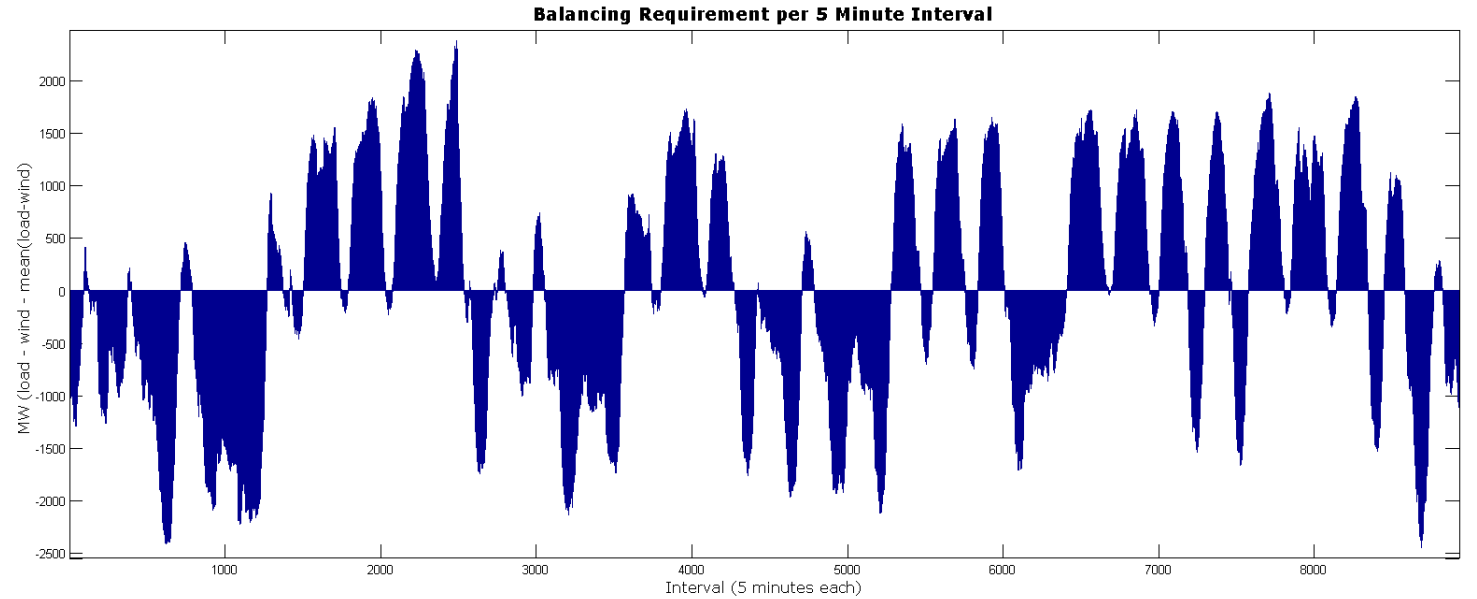

Figure 1: The balancing requirement for July using total system load and wind data from BPA, Section 1.3.1 Wind Data and Total System Load.

Realistically, traditional load-following resources can handle much of the hour to hour variations. Using the controllable chiller to provide only intrahour balancing greatly reduces the energy storage capacity requirements (by greater than $90 \%$ ) while almost cutting the chiller power capacity requirements in half (Y. Makarov, Kintner-Meyer, and Illian 2010) 


\subsubsection{Wind Spillage}

Balancing requirements caused by over-generation can be reduced by controlling the wind turbines to generate less power than the available wind resource would allow. This action is called wind spillage and can curtail the peaks of the imbalances. However, since the undergeneration troughs are not affected by wind spillage, the upward balancing requirements stays the same. Non-intuitively, this approach increases the capacity requirements of energy storage used to balance energy shortages. (M. Kintner-Meyer et al. 2010, B.15)

\subsubsection{Linear Approach to Imbalance Minimization}

The electrical price arbitrage problem from Section 2 Load Shifting/Price Arbitrage minimized the use of chiller power when electricity prices were high and then used power to make ice while prices were low. The coefficients for the linear optimization were the electricity prices. To minimize imbalances, the chiller must reduce energy use during positive imbalances and increase the energy use during negative imbalances. The thought was to achieve this with the same method used in the load shifting problem, basing the linear coefficients on the imbalances, instead of the electricity prices. Complete balancing would reduce the balancing requirement signal to the mean of the imbalances. However, since the imbalances are the deviations from the month's load minus wind generation mean, the mean of the imbalances is zero. A solution that provided zero balancing requirements would be the minimization solution.

\subsubsection{Overcommitment Produced by Linear Solution}

When examining the use of ice storage for load shifting and electricity price arbitrage, it was assumed that the electric prices were not affected by the operation of the ice storage. However, to provide balancing services, the chiller's capacity must be sufficient to affect the imbalances. Using a linear optimization to find an ice storage operation plan to minimize imbalances results in the overcommitment of the chiller or overuse of the ice. These overcommitments can cause large net imbalances in the opposite direction. 
The overcommitment effect is demonstrated in Figure 2: Overcommitment example. The top bar graph shows the original imbalances. During the initial intervals, there is excess wind generation which can be used to charge the ice storage. The wind generation drops off starting at interval 16. The bottom bar graph shows the net imbalance with the use of ice storage. Over-use of the chiller is seen in interval 2 and interval 10. Intervals 17 and 19 show the uneven use of ice storage during the low wind generation period.
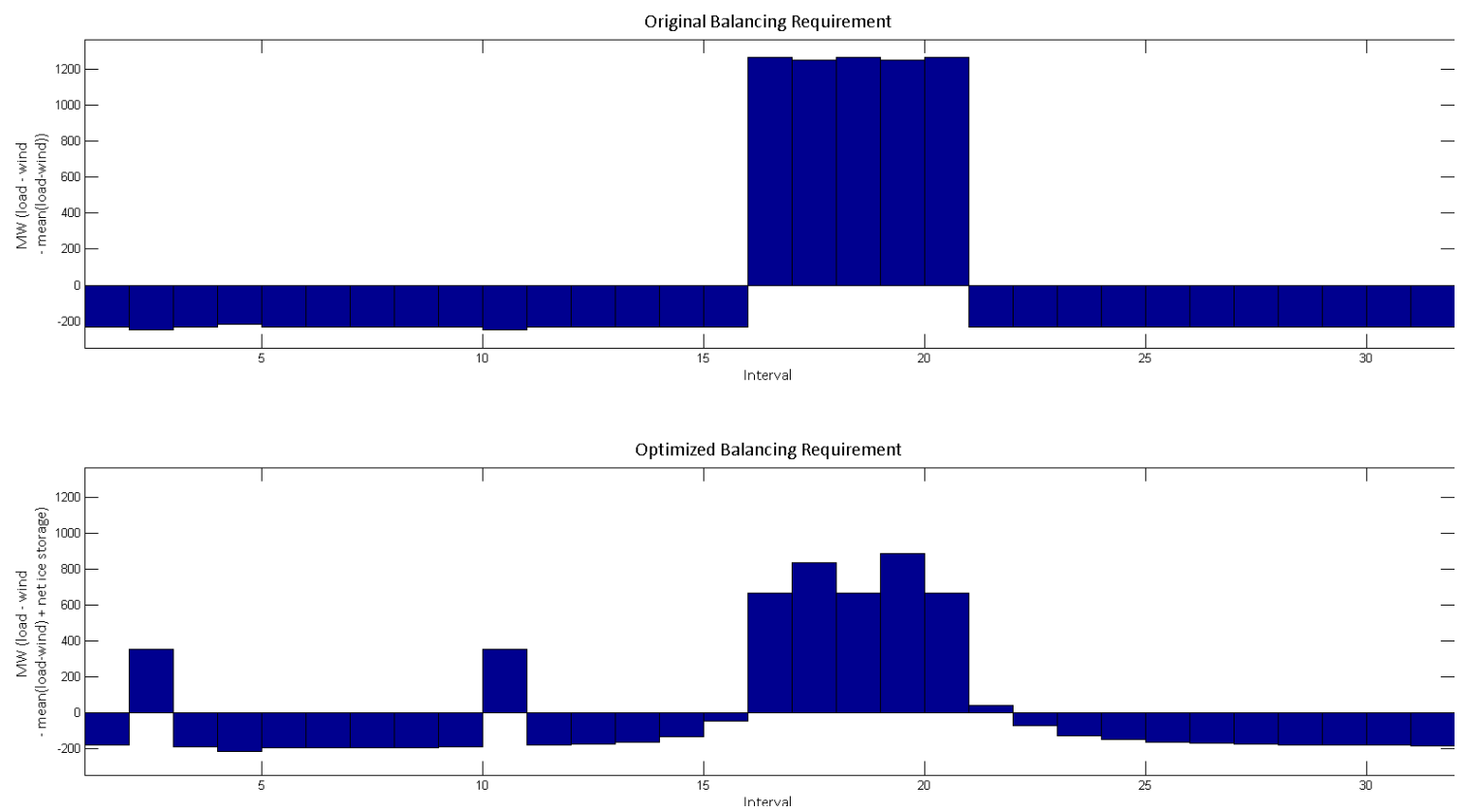

Figure 2: Overcommitment example, initial and net imbalances using linear optimization

The overcommitment of the chiller is caused by slightly lower prices for intervals 2 and 10 . The prices are the coefficients to the charge and discharge decision variables and are directly proportional to the imbalances; Figure 3 shows the prices for the Overcommitment example. 


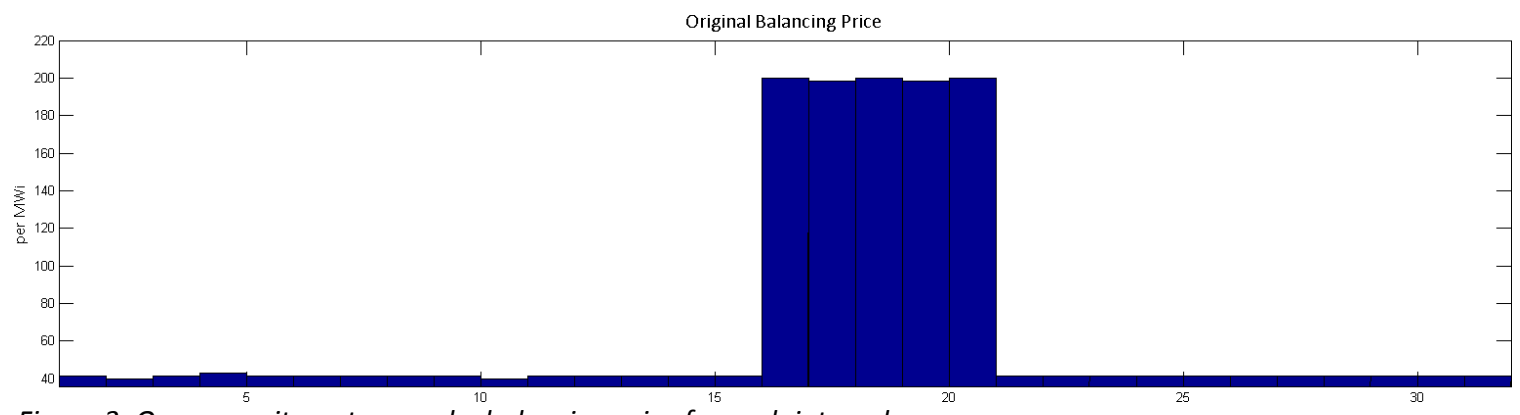

Figure 3: Overcommitment example, balancing price for each interval

Because the prices are lowest during interval 2 and 10, the chiller is used to full capacity. The difference can be very small; for example, $\$ 40.0 / \mathrm{MWh}$ in interval 2 versus $\$ 41.6 / \mathrm{MWh}$ in interval 3 , and the chiller will still be used at full capacity. The original imbalance in interval 2 was small and negative, but a greater imbalance is created in the opposite direction by the charging of the ice storage.

Figure 4 shows the building cooling load, storage charging and discharging and the storage state. The building has a constant cooling load which simplifies the test case and provides some load in each interval that may be offset with ice discharge.

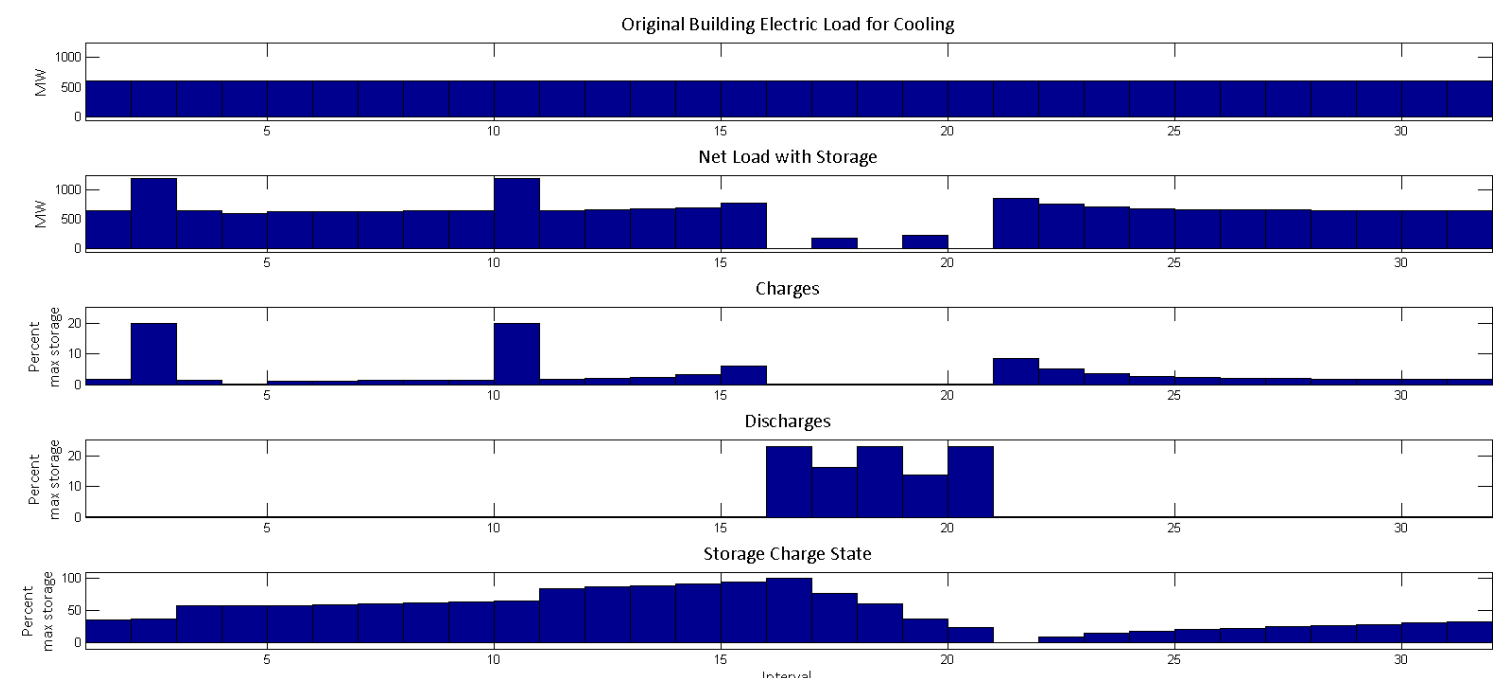

Figure 4: Overcommitment example, storage operation for a single pass linear optimization a) cooling load, b) net load, c) charging, d) discharging and e) storage charge state 


\subsubsection{Approximate Non-linear Solution}

The overcommitment problem assumed that the incentive for balancing was proportional to the magnitude of the imbalances. Doing this makes the problem non-linear by running the linear solution, but only committing to a percentage of the chiller and ice operation. The coefficients and constraints are adjusted to account for the commitment and the linear optimization is run again. With this method, it was possible to achieve a realistic solution.

The coefficients to the linear solution in Section 2 Load Shifting/Price Arbitrage were the prices for electricity in each interval. Because the non-linear optimization is minimizing the sum of the squares and not minimizing the cost of electricity, the coefficient are based upon the imbalance in each interval. In the context of the non-linear imbalance minimization, the term "coefficients" will be used instead of "price".

The same test case was rerun using this iterative method. Between each iteration, one percent of the linear plan was committed. The original and net imbalances are shown in Figure 5 . The final imbalances are shown after 500 iterations.

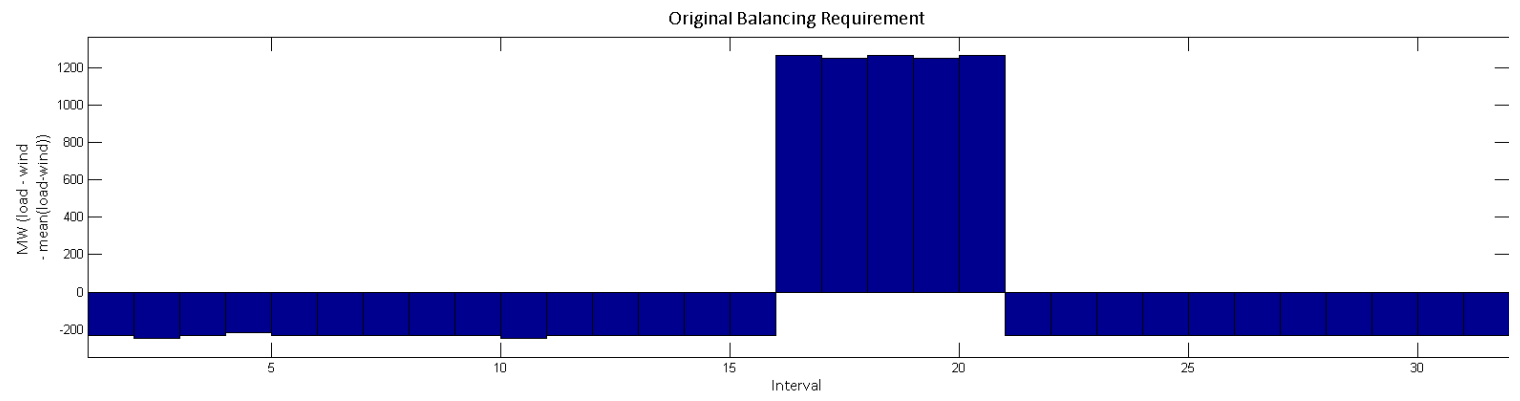

Optimized Balancing Requirement

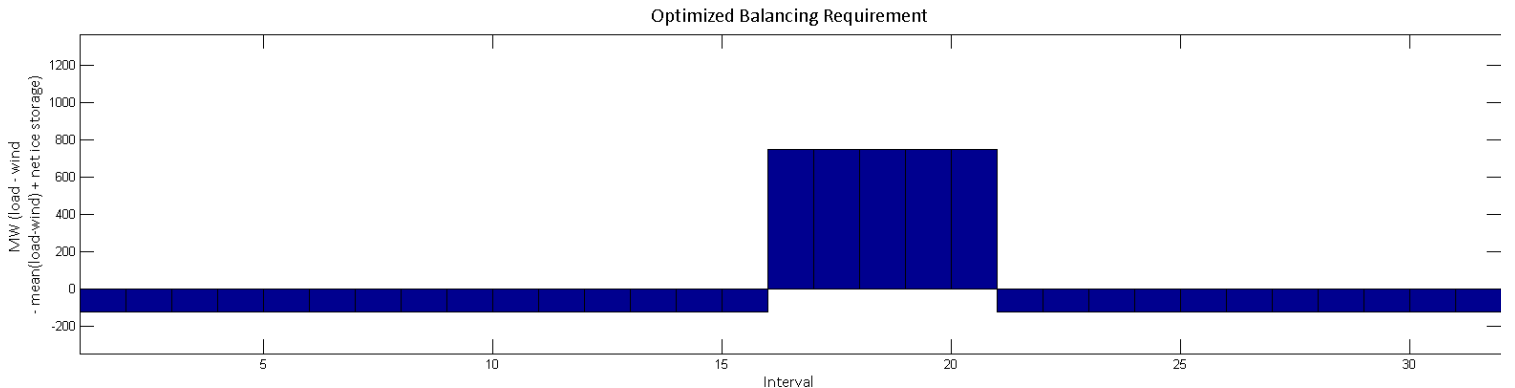

Figure 5: Iterative method example, imbalances for solution with one percent relaxation

The overcommitment of the chiller no longer occurs during the storage charging intervals 1 through 15 . When the wind generation drops from intervals 16 through 20, the ice storage is discharged in a way that levels the imbalances. 
Building cooling load, storage charging and discharging and the storage state for the iterative approach are shown in Figure 6. The charging and discharging is more uniform.

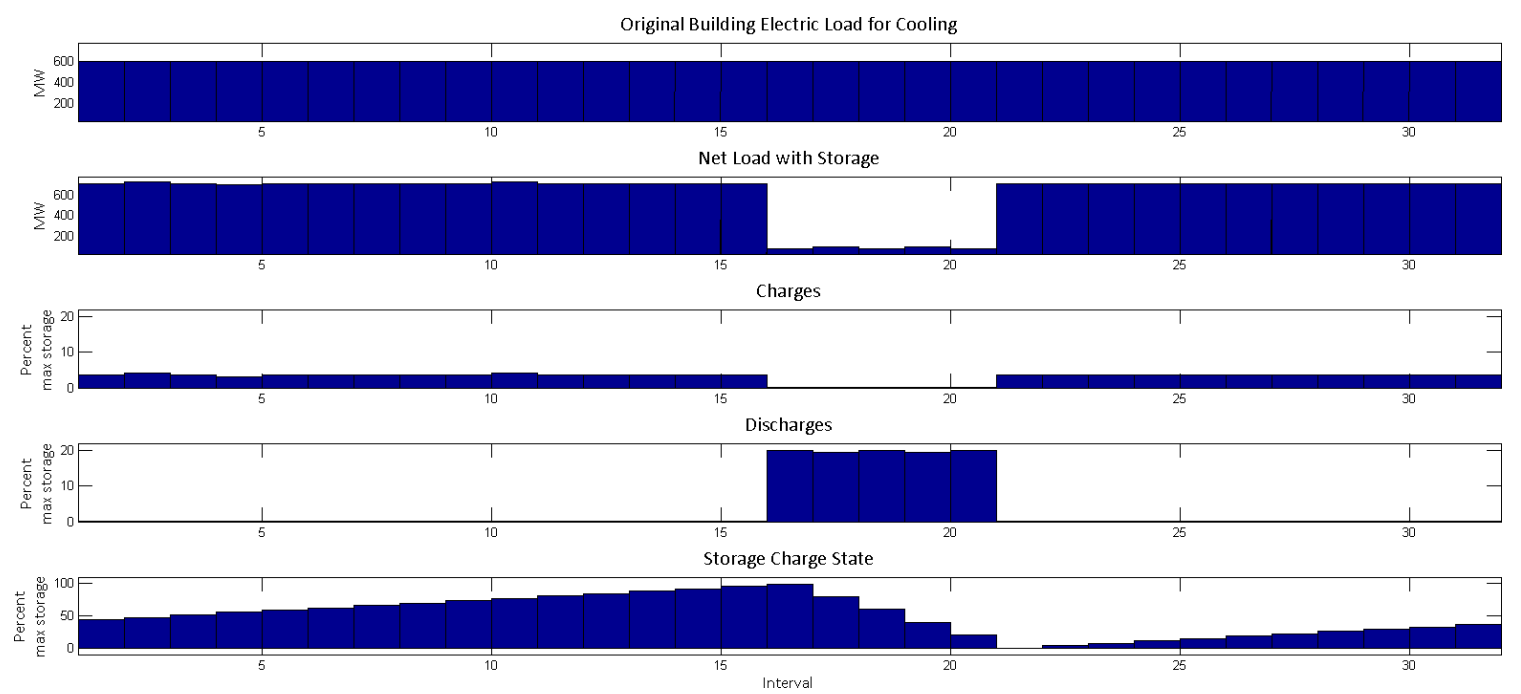

Figure 6: Iterative method example, storage operation for solution with one percent relaxation a) cooling load, b) net load, c) charging, d) discharging and e) storage charge state

The ice storage is charged evenly over intervals 1 to 15 with excess wind generation. The ice storage is discharged to reduce the under-generation imbalances to equal values for intervals 16 through 20 . The chiller would have provided additional balancing except that the storage capacity constraint was reached. A second constraint, the building cooling load (Figure $6 \mathrm{~b}$ ), is about to be reached as shown in intervals $16-20$. Once the building cooling load is completely offset by ice storage, no additional upward balancing can be provided. 
A histogram of the imbalances are shown in Figure 7. The top histogram shows the original distribution of the imbalances. The magnitudes are split between two types of imbalances; a $1200 \mathrm{MW}$ excess load and a $200 \mathrm{MW}$ excess generation. The middle histogram shows the distribution after the single linear optimization. The bottom histogram is the result of the iterative optimization.
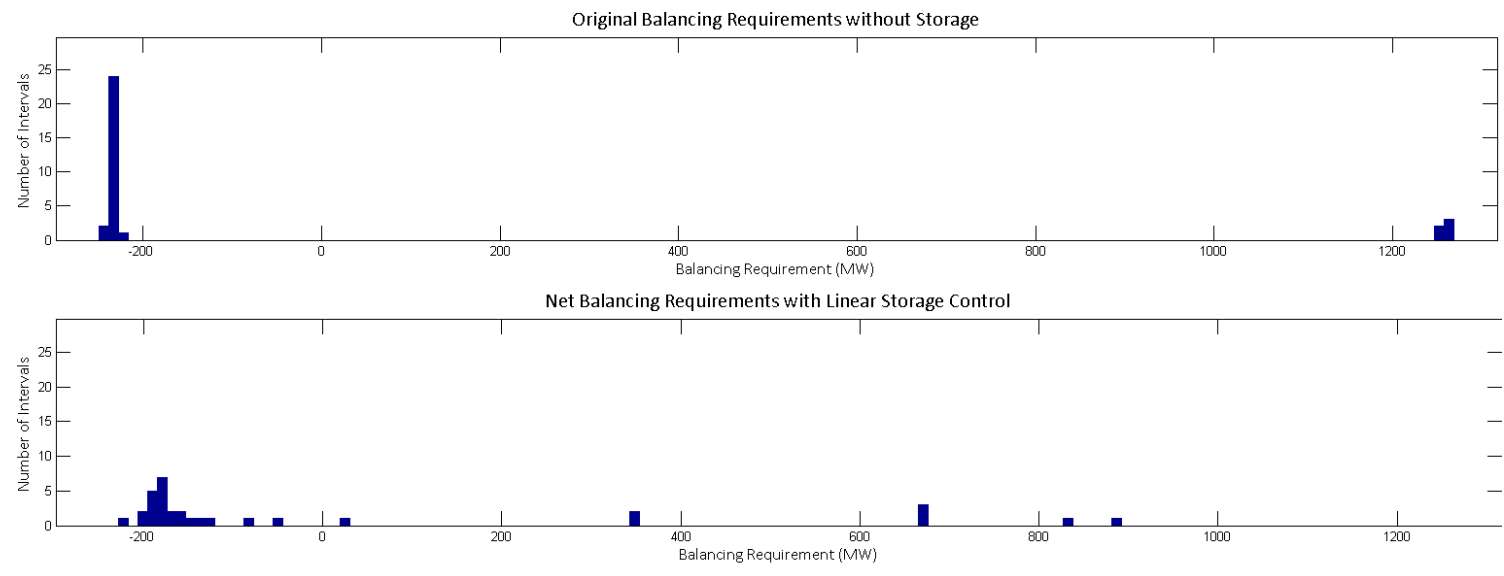

Net Balancing Requirements with Iterative Storage Control

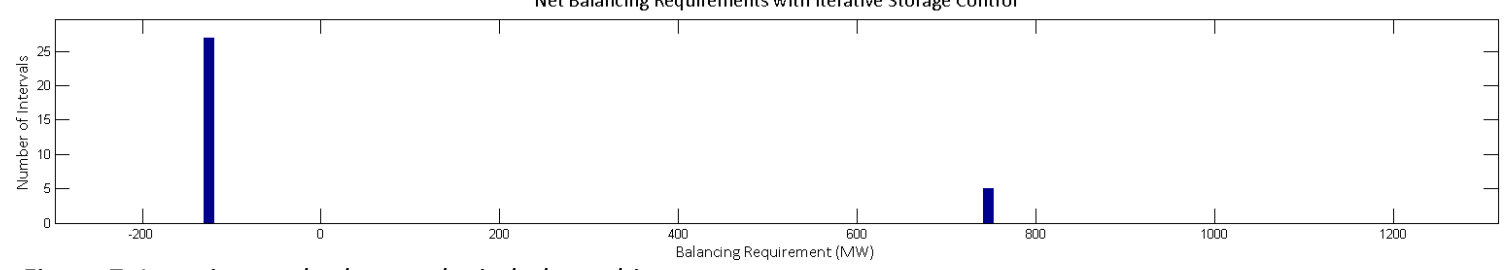

Figure 7: Iterative method example, imbalance histograms

(top) original imbalance without storage, (middle) imbalances resulting from linear storage control, (bottom) imbalances resulting from iterative method storage control. 
The iterative method approximates a quadratic optimization. In the linear optimization, the imbalance is multiplied by the coefficient, but the coefficient is a linear function of the imbalance. If the coefficient is reevaluated after each partial commitment of storage, the result is an optimization of the imbalances squared. The objective function for the iterative method is quantified as Minimize $\mathrm{k} \cdot \Sigma\left(\mathrm{b}_{\mathrm{i}}\right)^{2}$, where $\mathrm{k}$ is a constant and $\mathrm{b}_{\mathrm{i}}$ is the imbalance in each interval $\mathrm{i}$. This objective function value is plotted against the iteration number in Figure 8.

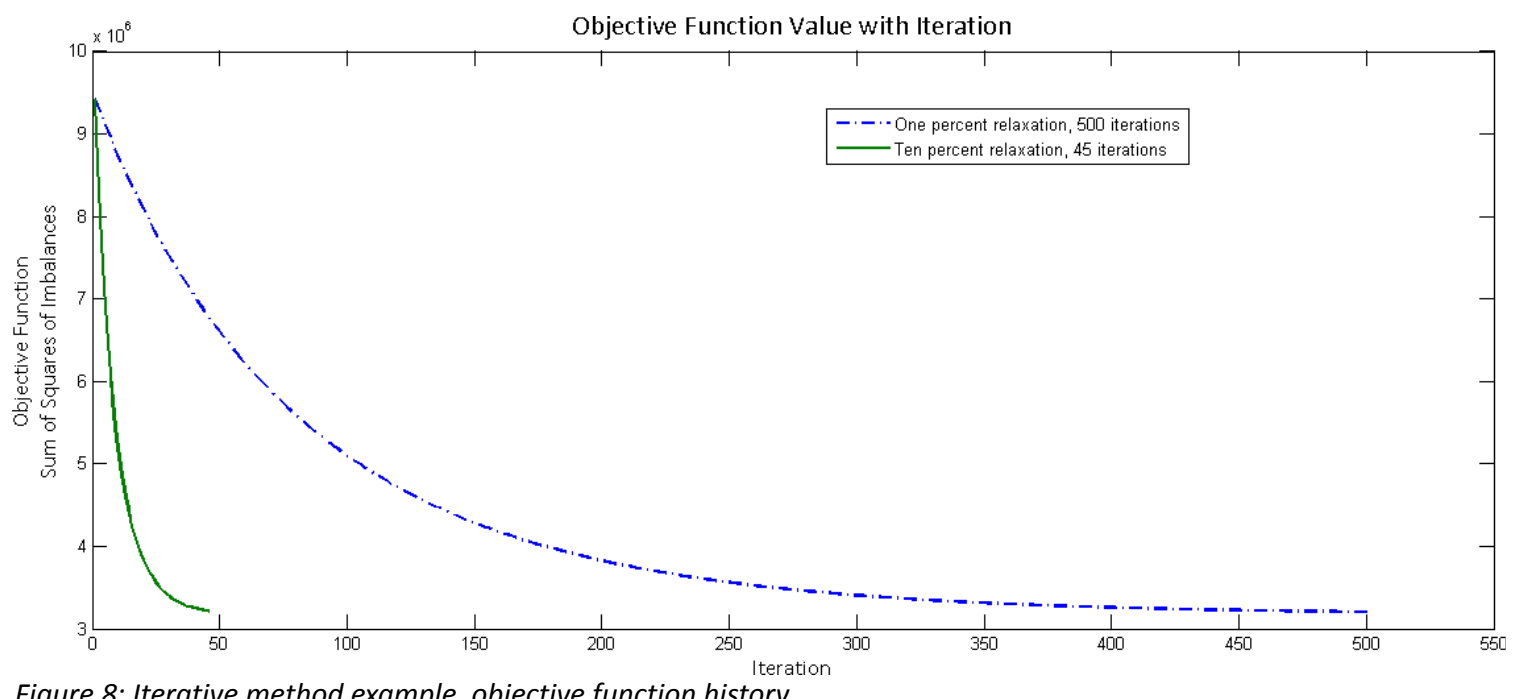

Figure 8: Iterative method example, objective function history

The objective function value is reduced by $66.01 \%$ by iteration 500 when using a relaxation variable of one percent. The relaxation variable can be changed from one percent to ten percent and the objective function value is still be reduced by $65.89 \%$ over 45 iterations.

\subsubsection{Unconstrained Balancing using the Non-linear Solution}

The method of iterating on linear solutions to approximate a quadratic solution for the purpose of minimizing the sum of squares of the imbalances was tested with a case designed without problem constraints on chiller or ice storage. This means that a solution should exist for the management of the ice storage that equalizes all of the final imbalances. 
Figure 9 below shows the original imbalances (top) and the net imbalances after the optimal use of the ice storage (bottom). The chiller's coefficient of performance for ice making and building cooling were the same value. The storage efficiency was $100 \%$ for this text case.

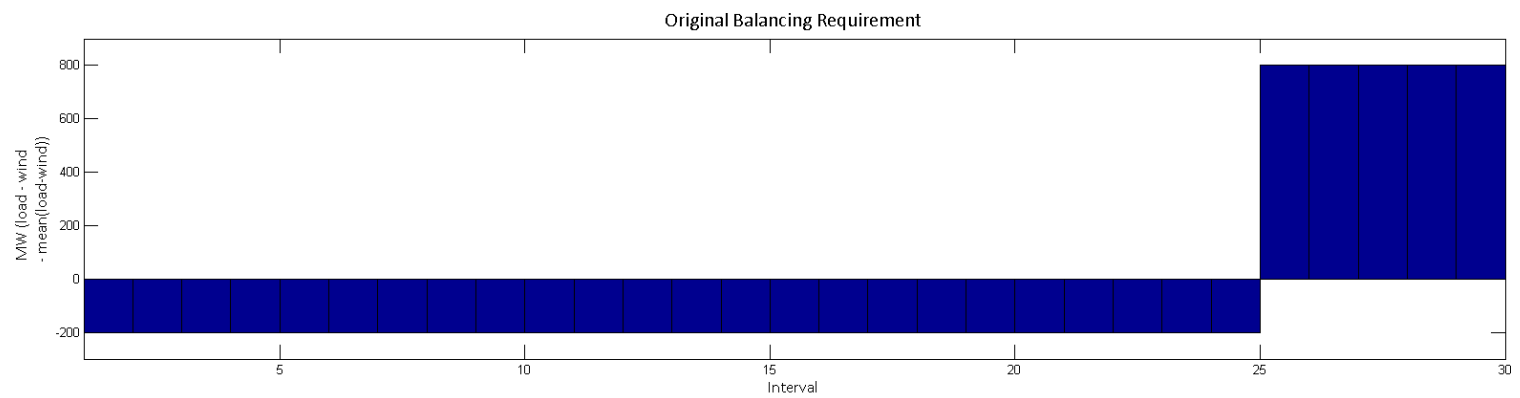

Optimized Balancing Requirement

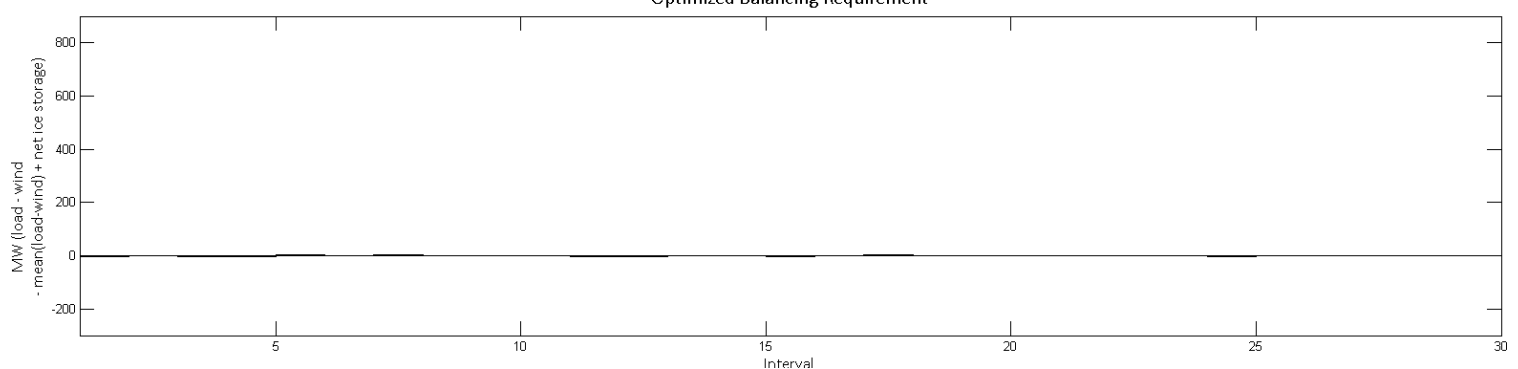

Figure 9: Unconstrained optimization for complete balancing

The solution results in zero balancing needed over the entire modeled period; this is expected because the scheduled generation $\left(G_{s}\right)$ is the mean of the load minus the wind power. The original sum of squares of the imbalance was $4.8 \mathrm{e} 6$. The resulting sum of squares was 78 , producing an error of 0.0016 percent. The error is associated with oscillations across the optimal value and are proportional to the relaxation. The solution for Figure 9 was obtained with 1750 iterations at $0.1 \%$ relaxation. When the relaxation is changed to $1.0 \%$, the error increases to 0.89 percent.

\subsubsection{Unconstrained Optimization with Unequal Coefficients of Performance}

The troughs in the imbalance are raised by making ice. The peaks are reduced by offsetting the electric load on the building chiller with the melting of ice. When the coefficients of performance for ice making and building cooling are the same, the minimized sum of squares occurs when the imbalances in each interval are the same, i.e., a flat graph. However, the coefficients of performance normally differ. Ice-making consumes more power because the chilled fluid temperature is lower for making ice than for cooling the building. There should be a point in the 
minimization where making ice to later offset building cooling will increase the square of the imbalance in one interval more than it will decrease the square of an imbalance in another interval.

The same test case run again with different ice making and building cooling coefficients of performance ( $\mathrm{COP}_{\text {cool }}$ of 5 and a $\mathrm{COP}_{\text {ice }}$ of 3 ). The relaxation was $0.03 \%$ with 2750 iterations. The initial imbalances and the net imbalances after optimization are shown in Figure 10.
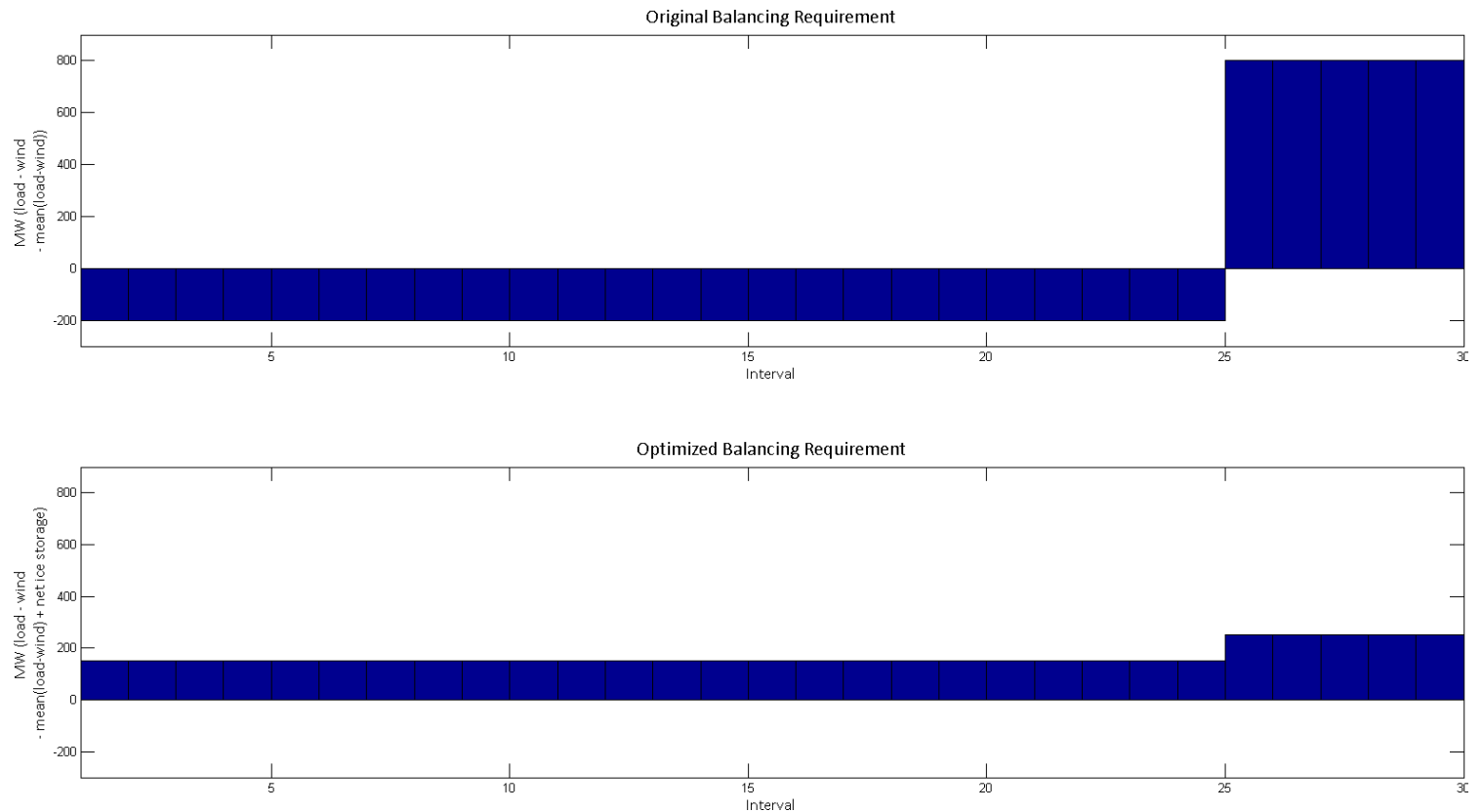

Figure 10: Unconstrained optimization with unequal coefficients of performance.

The use of power to make ice and the melting of ice to offset building cooling does not continue until the imbalances are equal. The imbalances up to interval 24 are very close to $151.9 \mathrm{MW}$ while the imbalances from interval 25 on are $252.1 \mathrm{MW}$. Does this operation minimize the sum of squares of the imbalances? Consider making a little more ice in interval 24 for the purpose of offsetting some building cooling in interval 25 . At some point the lower efficiency for making ice will increase the sum of squares by more than can be offset through reduced load. Does this result represent this zero-gain point?

\subsubsection{Zero-gain Point Determined Analytically}

This zero-gain point can be determined analytically by considering a simple two-interval problem. There is a balancing requirement in the first interval $\left(b_{1}\right)$ that is greater than the balancing requirement in the second interval $\left(b_{2}\right)$. After the use of ice storage, the imbalance in the first 
interval will be reduced by the chiller power offset with ice melting while the imbalance in the second interval is increased by the power consumed to make ice.

$$
\begin{aligned}
& N e t_{b l}=b_{1}-P_{\text {saved }} \\
& \mathrm{Net}_{b 2}=b_{2}+P_{\text {ice }}
\end{aligned}
$$

The thermal energy $(T)$ discharged in one interval must then be charged in the next, so that the net change in storage is zero. The goal is to minimize the sum of the final imbalances, as stated in Equation 33.

$$
\begin{aligned}
& \text { minimize }\left(\mathrm{Net}_{b 1}^{2}+\mathrm{Net}_{b 2}^{2}\right)=\text { minimize }\left(\left(b_{1}-\frac{T}{C O P_{\text {cool }}}\right)^{2}+\left(b_{2}+\frac{T}{C O P_{i c e}}\right)^{2}\right) \\
& \text { Equation 33: Minimized imbalances with differing coefficients of performance }
\end{aligned}
$$

The optimal use of the thermal storage can be found by multiplying out sum of squares and taking the derivative. Setting the derivative to zero to find the minimum produces Equation 34 for $\mathrm{T}$.

$$
T=\left(\frac{C O P_{c o o l} \cdot C O P_{i c e}}{C O P_{c o o l}^{2}+C O P_{i c e}^{2}}\right) \cdot\left(b_{1} \cdot C O P_{i c e}-b_{2} \cdot C O P_{c o o l}\right)
$$

Equation 34: Optimal use of thermal storage for two interval problem

This relationship is used to test the result from Figure 10. The coefficients of performance for building cooling and ice making are substituted into Equation 34 ( $\mathrm{COP}_{\text {cool }}$ of 5 and a $\mathrm{COP}_{\text {ice }}$ of 3 ). The imbalance from interval 25 is $252.1 \mathrm{MW}$ as $b_{1}$ with the imbalance from interval $24 a_{2} b_{2}$ at 151.9MW. The result for $\mathrm{T}$ is $-1.4 \mathrm{MW}$.t indicating that slightly less ice storage should be used for an optimal result. The error in the optimization is less than $1 \%$.

Problems that result in full or near-full balancing require smaller step sizes. The problem from Figure 10 uses a step size of only $0.03 \%$. The storage charging for the first 24 intervals should all be equal in the optimal result. Even a slight differences in their values would cause one interval to charge the storage more and another to charge a less, but only the direction is known and not the magnitude. This behavior causes the coefficients in the first 24 intervals to oscillate around the optimal value. Larger step sizes result in greater total error. 


\subsubsection{Effects of Signed Coefficients}

The coefficients assigned to imbalances in the Section 3.2.5 Approximate Non-linear Solution were all greater than zero and were linearly proportional to the magnitude of the imbalance. The following example uses signed coefficients, with credits for consuming excess generation and costs for power use during positive load intervals. When the credits became available, a new feature appears in the optimized solution; ice will be discharged to meet building cooling while the ice is also created using the chiller. Because ice making has a lower efficiency than building cooling, the results are an increased use of power during time intervals with excess generation. Because credits are granted for power use during excess generation, the power loss due to inefficiencies are counted as a credit to the objective function.

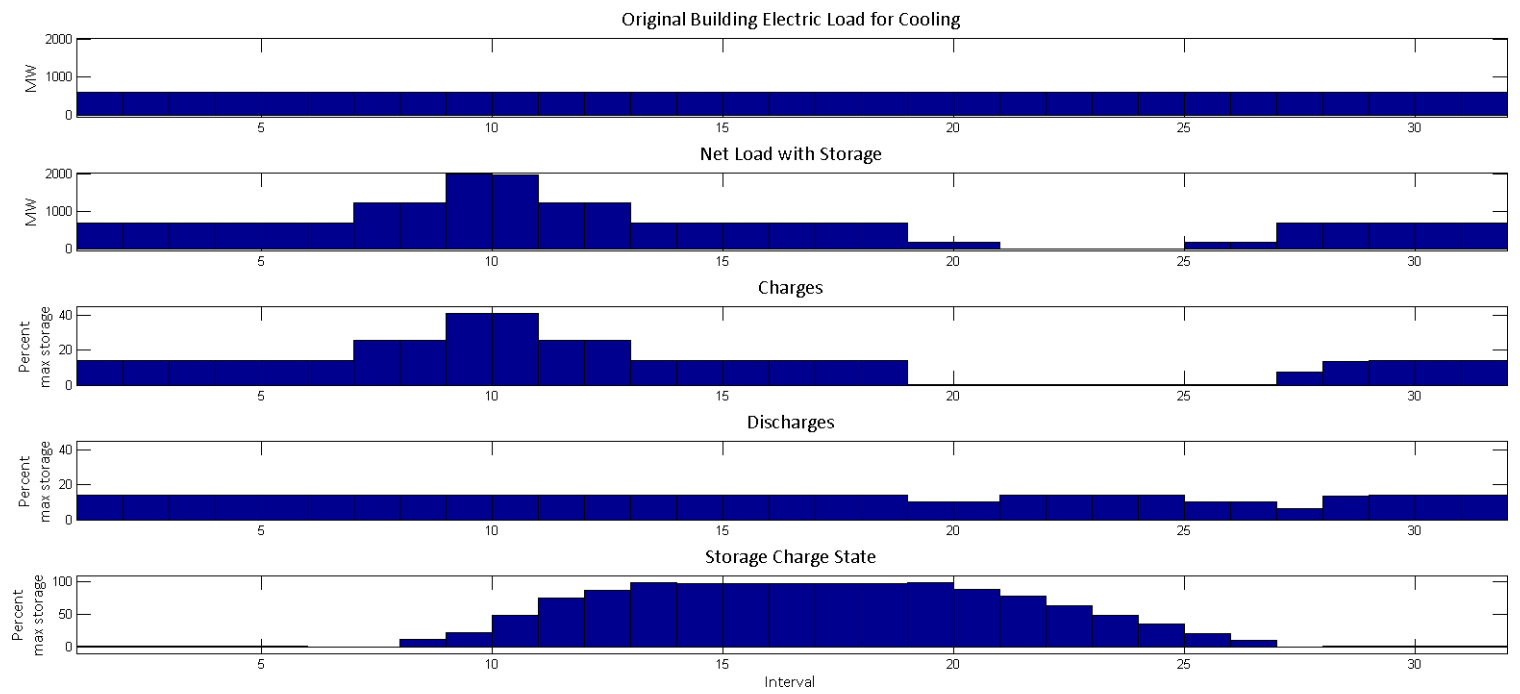

Figure 11: Signed coefficients, storage operation using signed coefficients with an iterative solution a) cooling load, b) net load, c) charging, d) discharging and e) storage charge state

Figure 11 shows storage use for the signed coefficients example. The ice storage is simultaneously charged and discharged for much of the optimized schedule. The optimization with signed coefficients reduced the sum of squares objective function value by $82.18 \%$ over the initial state's objective value. The same test case using all-positive coefficients reduces the objective function by $78.63 \%$.

Using signed coefficients improves the final balancing result by taking advantage of the power loss caused by simultaneously charging and discharging during intervals with excess generation. However, many ice storage storage systems cannot physically charge and discharge at the same 
time. Additionally, the signed coefficients provides credits for using power when excess power is available. Operating in this manner would only be beneficial if the value of the balancing services exceeds the actual cost of the electrical power. It is more realistic to assume that power costs during excess generation would be very low or zero. For these reasons, the realistic data optimizations will use all positive coefficients.
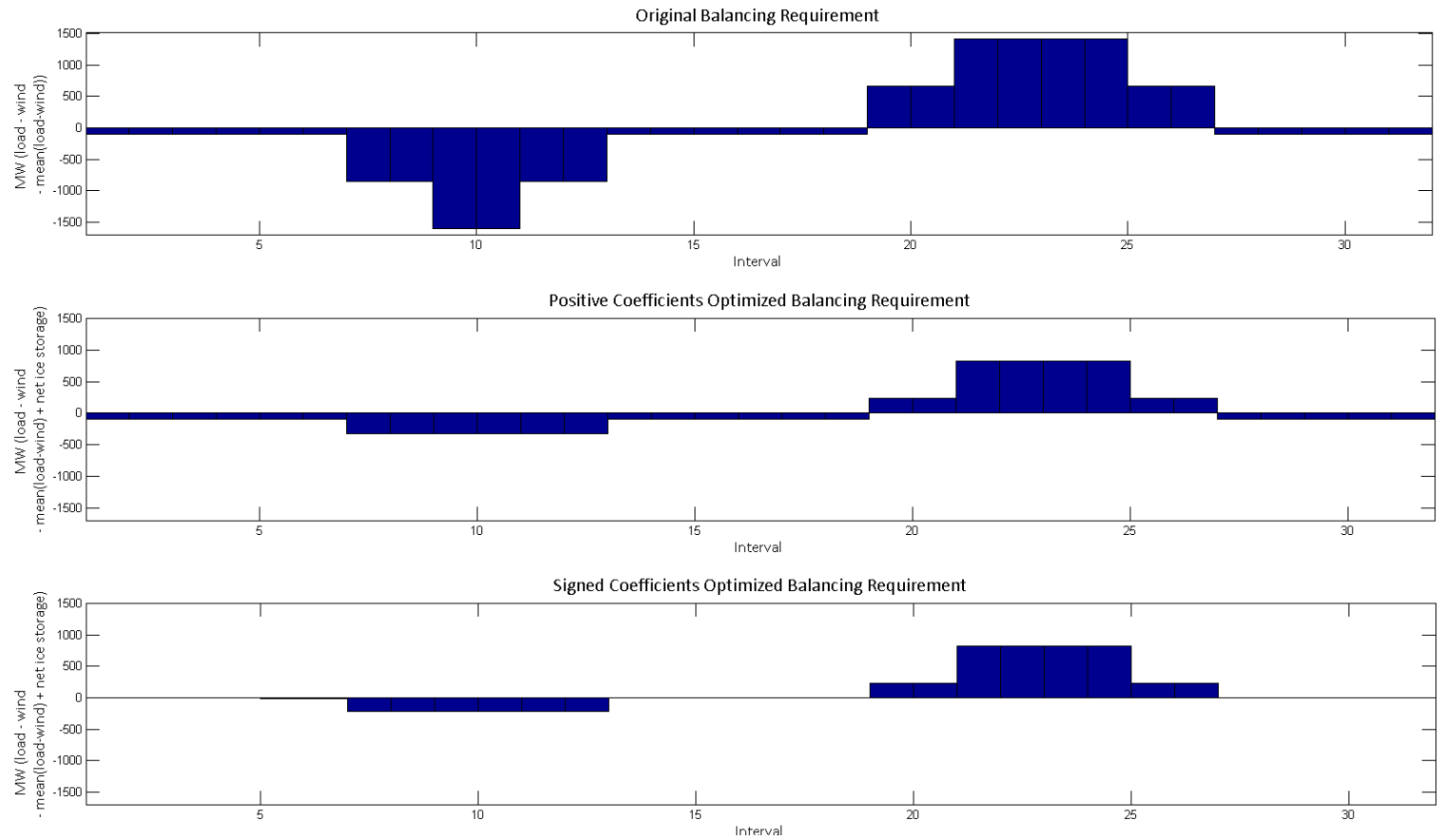

Figure 12: Signed coefficients example, imbalances using an iterative solution (top) original imbalances, (middle) positive coefficients net imbalances, (bottom) signed coefficients net imbalances

Figure 12 shows the net imbalance achieved with ice storage while using signed coefficients (bottom) compared to the net imbalances achieved by using all-positive coefficients (middle). Greater balancing is achieved with signed coefficients during the intervals with excess power generation (7 through 12). This is achieved by taking advantage of the storage efficiency costs and simultaneous charging and discharging the ice storage. 


\subsubsection{Houston Healthcare Example}

An optimized storage management plan is determined for the first four weeks of the year using the realistic data sets for a Houston healthcare building. The source of the wind generation data is described in Section 1.3.1 Wind Data and Total System Load. The cooling load data was simulated using SitePro for healthcare category buildings located in Houston (2005). The data source is described in Section 1.3.2 Building Data. The cooling load used in this optimization represents 1000 buildings of 250,000 sq-ft each.

The building's ice storage capacity was 49,591 (MWh.t) which was designed to offset 8 hours 20 minutes of thermal cooling at the building's peak thermal load (taken from the entire year's data). The compression chiller was designed to handle 1.75 times the building's maximum cooling load. The total rated power for all chillers was 1,925 (MW.e). The chiller's coefficient of performance are constant at 6.28 for building cooling and 5.41 for ice making.

The iterative linear optimization used a relaxation of one percent over 550 iterations. Two decision variables per state with 8065 states were needed. The problem involves 16,130 decision variables total. The coefficients for the imbalances were all positive.

The building's cooling load, ice storage state and charging and discharging are shown in Figure 13 below.

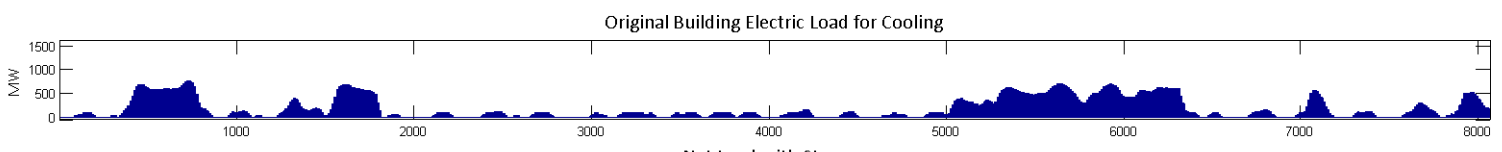
Net Load with Storage
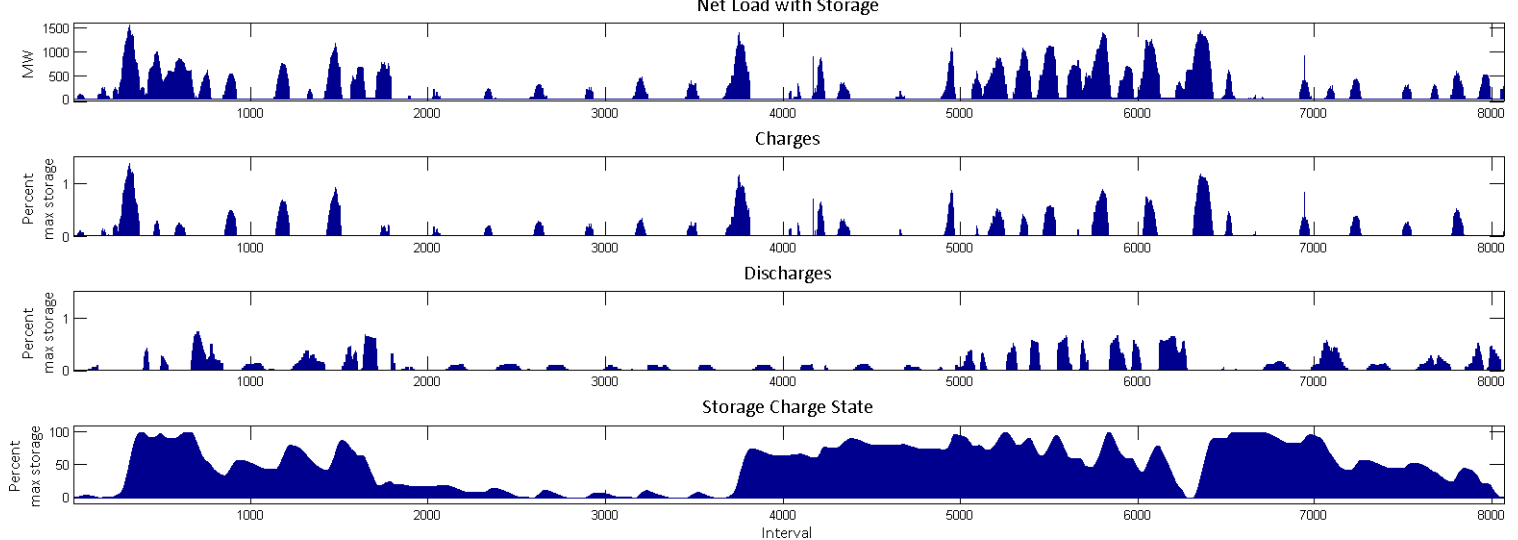

Figure 13: Houston Healthcare Example, storage operation

a) cooling load, b) net load, c) charging, d) discharging and e) storage charge state 
Figure 14 shows the imbalances without ice storage (top graph) and the net imbalances with optimized use of the ice storage (bottom).
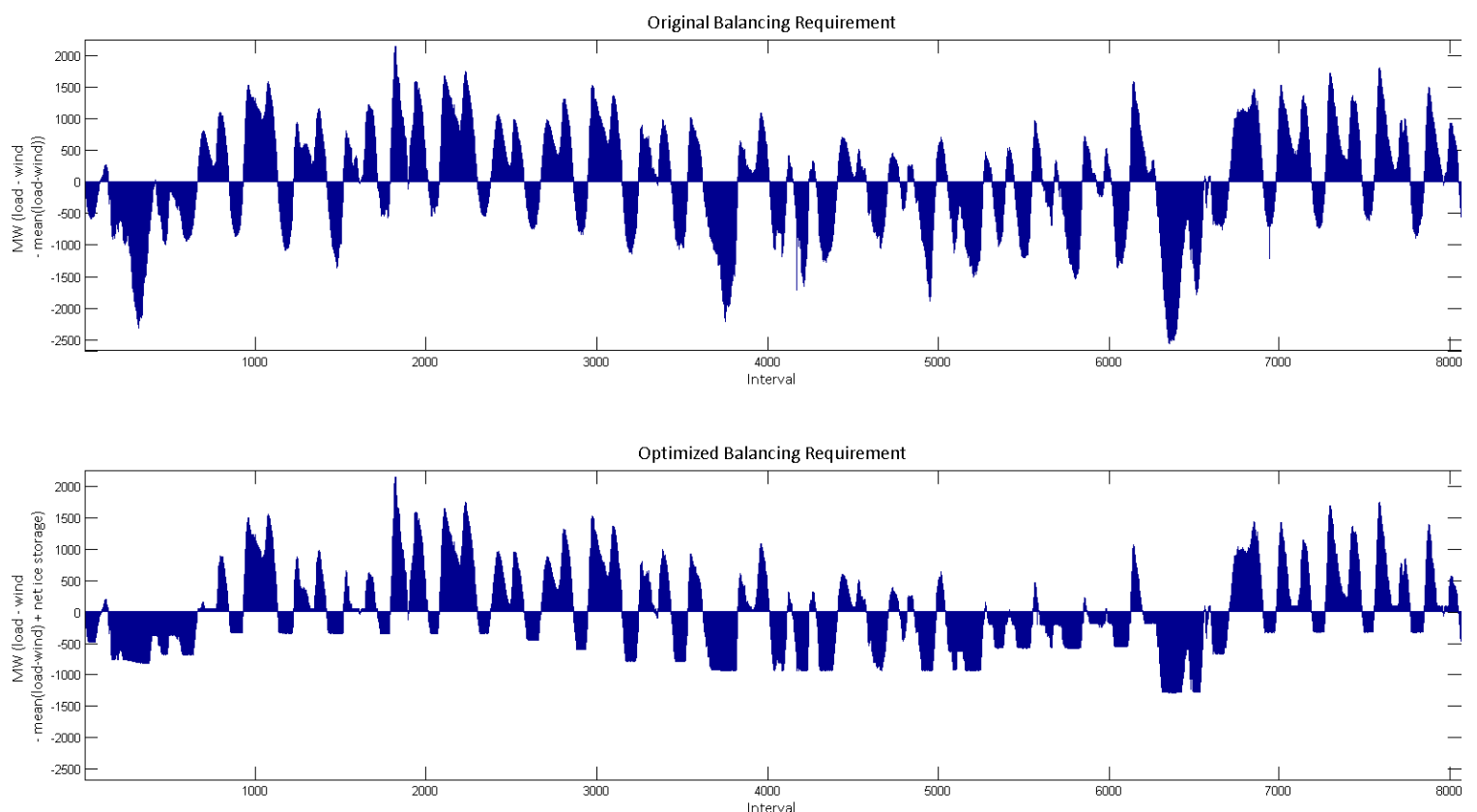

Figure 14: Houston Healthcare Example, power imbalances

(top) original imbalances, (bottom) net imbalances with storage

The troughs, representing by excess generation, are filled by the chiller's maximum power draw of 1,925 (MW.e). The high loads are not reduced as consistently because the ice storage can only offset the loads normally used to meet building cooling needs. The sum of squares of the imbalances was reduced by $37.8 \%$. 
Histograms of the original imbalances (top) and resulting net imbalances (bottom) are shown in Figure 15. The number of intervals with excess power generation or excess load are reduced.
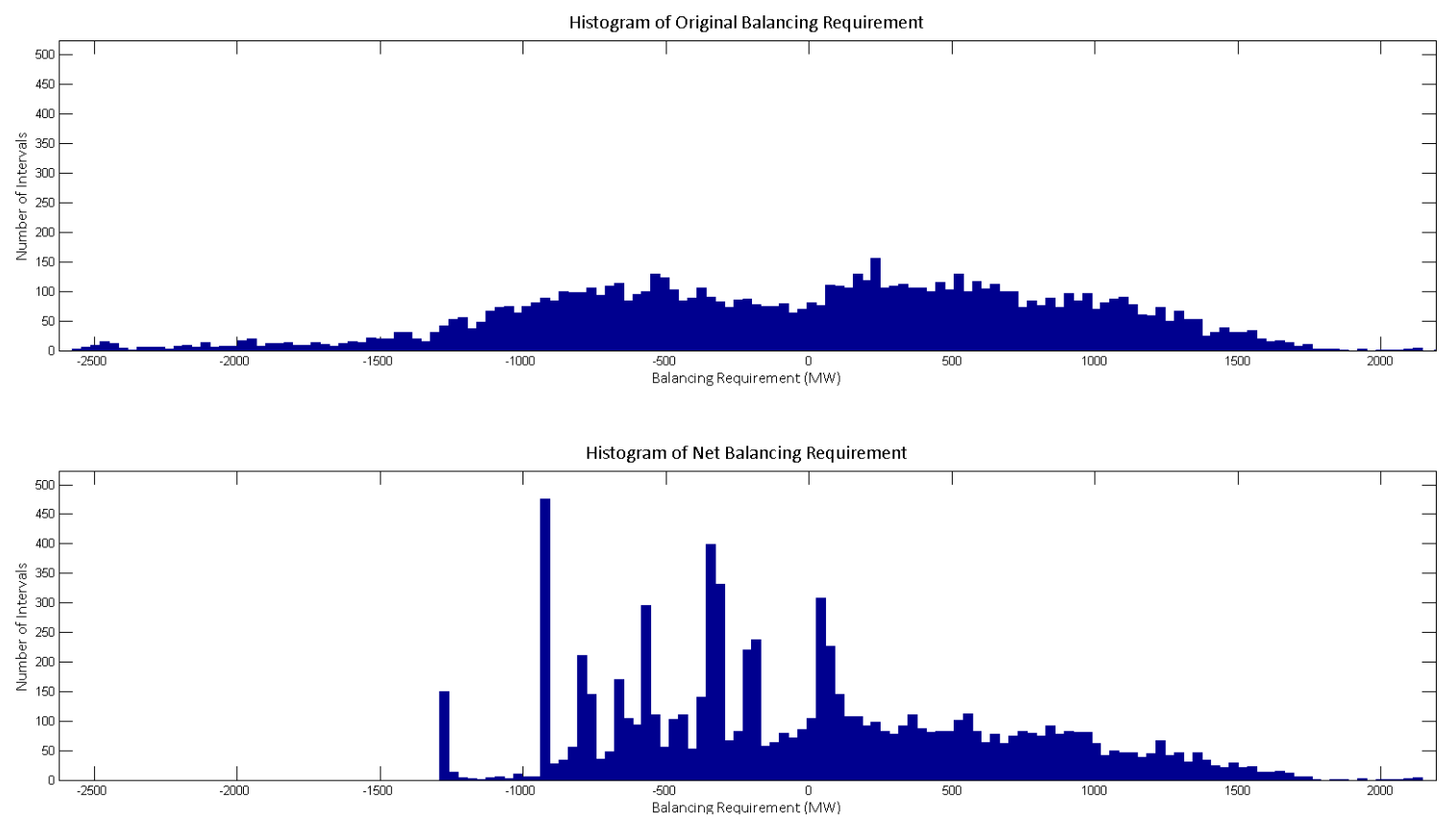

Figure 15: Houston Healthcare Example, histogram of imbalances (top) without storage, (bottom) with storage

The objective function value for the Houston Healthcare optimization is plotted over the 550 iterations at one percent relaxation.

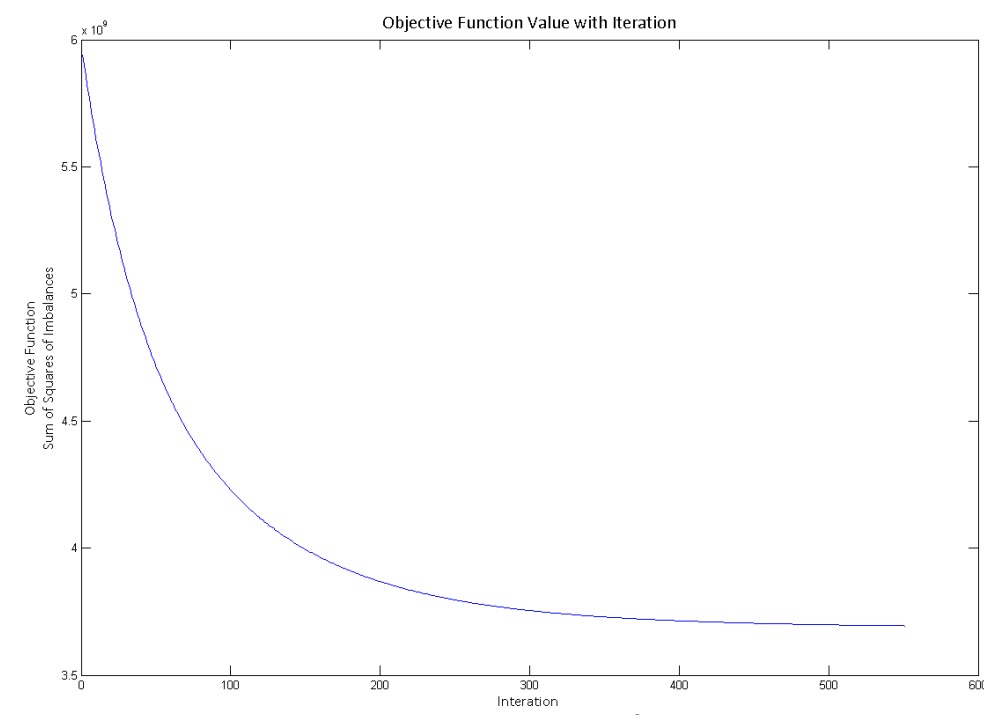

Figure 16: Houston Healthcare Example, objective function value as iterations progress

Page 33 


\subsubsection{Dynamic Relaxation}

The optimization time can be reduced by increasing the relaxation to $10 \%$ of the linear solution on each iteration. Within 60 iterations, solutions were found that were within one percent of the solution found by running 550 iterations at $1 \%$ relaxation. Ultimately, for the compiled results, a dynamic relaxation was used over 80 iterations. The initial commitment was $14 \%$ which was reduced linearly to $0.1 \%$ at iteration number 50 . It stayed at $0.1 \%$ until the final $80^{\text {th }}$ iteration. This method was not conclusively better than the other methods, but seemed to balance time and accuracy well.

\subsubsection{Imbalance Sum of Squares Minimization Results}

An optimization of the building's thermal storage use was run for each of the selected cities and building types in Section 1.3.2 Building Data. The optimal storage use minimized the sum of squares of the imbalances. An optimization for summer (July) and winter (January) was run for each building. The thirty-one day period involved 17,858 decision variables. Longer periods could be run, but full-year optimizations consumed more computing memory than available.

The common parameters for the optimization are listed in Table 8.

Table 8: Imbalance TSS minimization common parameters

8928 Number of intervals

5 min Interval duration

1.75x (MW) Chiller oversize relative to maximum annual load

8 hours Ice storage capacity at the building's annual maximum cooling load

6.28 Chiller COP for building cooling

5.41 Chiller COP for ice making

$2 \%$ Cooling loss due to storage equipment (pumps, etc)

250,000 Building size (sq-ft)

1000 Number of buildings

The capacity of the ice storage changed for each city/building combination is based upon the annual maximum building cooling load. Because imbalance was considered any deviation from the mean building load and wind generation for the month, the amplitude and integral of the imbalances was large; thus a large number of buildings were required to provide both balancing power and energy storage. 
The results included in Table 9 are the minimum sum of squares for the imbalances that can be achieved using building cooling with ice storage to provide balancing. No consideration was made for the price of electricity. The building's space-cooling load was still met by the chiller. The sum of squares (TSS) reduction is listed in the first results column. The total balancing energy for the month, provided by charging or discharging the ice storage, is listed in the second column. A few building types had low or no cooling load for January.

Not all charging or discharging of the ice storage went to correct imbalances. During some intervals, it was advantageous to make sufficient ice that a positive imbalance was created. The stored ice could be used at a later time to offset even greater imbalances, this can be seen in intervals 1730 through 1805 in Figure 17 below.
Table 9: Balancing services, sum of squares (TSS) minimization results

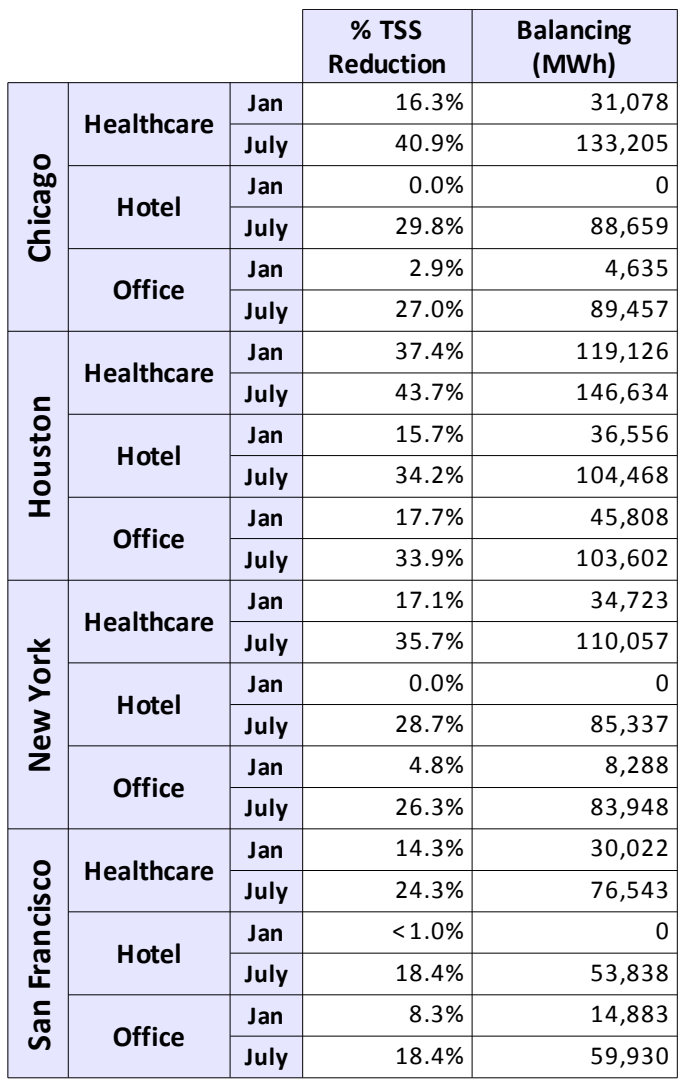
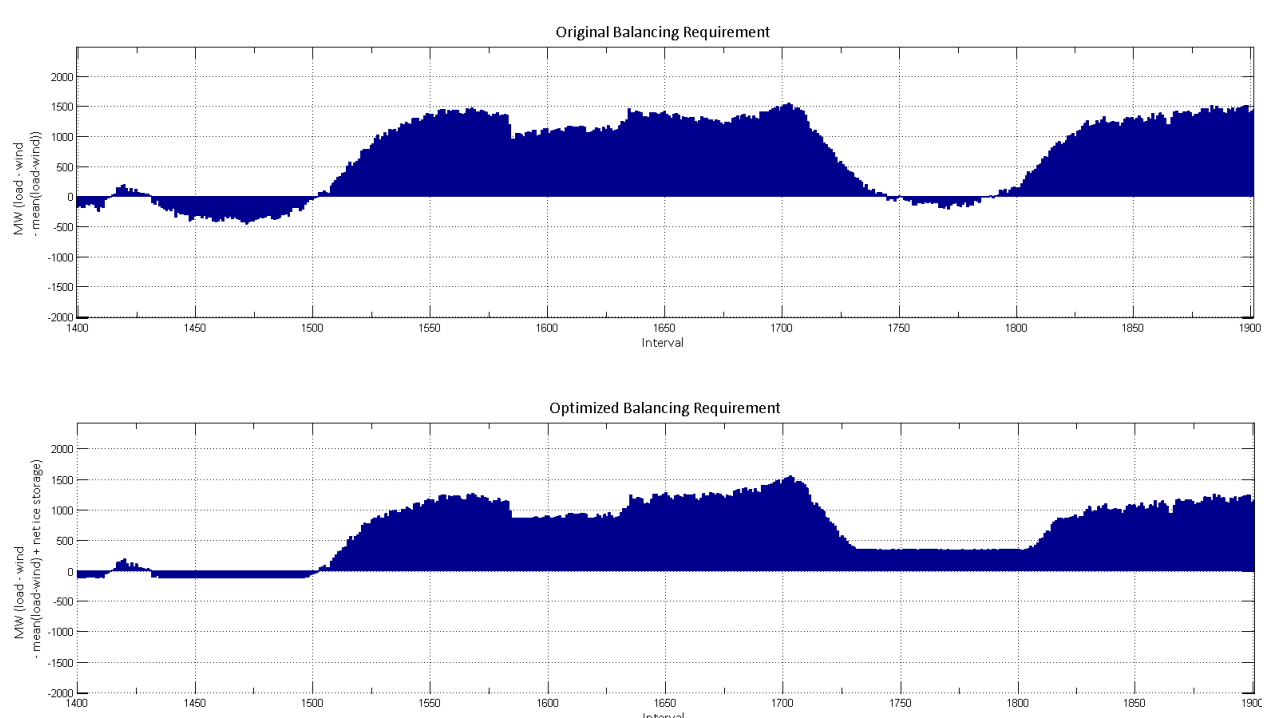

Figure 17: Imbalance minimization charging induced imbalance 


\section{Economic Optimization of Combined Electricity Cost and Balancing Service Income}

\subsection{Cost Minimization for the Building Owner}

The opportunity for the building owner to reduce overall costs for space cooling are examined. The ice storage use was optimized to take advantage of both price arbitrage through load shifting and cost recovering by providing a balancing ancillary service.

The electricity rates are specific to region from which the building simulation took place, see 1.3.7 Power Distribution and Electricity Prices. For this analysis, the market clearing price for balancing service is proportional to the initial imbalance in that interval. In a real market, the balancing price would also depend upon the mix of generation assets, constraints upon the generation, constraints on the transmission systems, the variability of other intermittent resources, in addition to many other factors.

This clearing price is not changed as the imbalance is reduced, thus the problem remains linear. The mean price for winter months was $\$ 30.89$ per $\mathrm{MWh}$ and for summer months was $\$ 39.67$ per MWh. To prevent overcommitment of the chiller, an additional constraint was added that prevents charge or discharge power from contributing to an imbalance.

\subsubsection{Combined Arbitrage and Balancing Price Test Case}

A simple test case run to demonstrate minimization of electricity costs while capturing some benefit by providing balancing services. The first intervals start with a high wind generation imbalance, followed by a dropping of the wind generation to zero which creates a high load period.

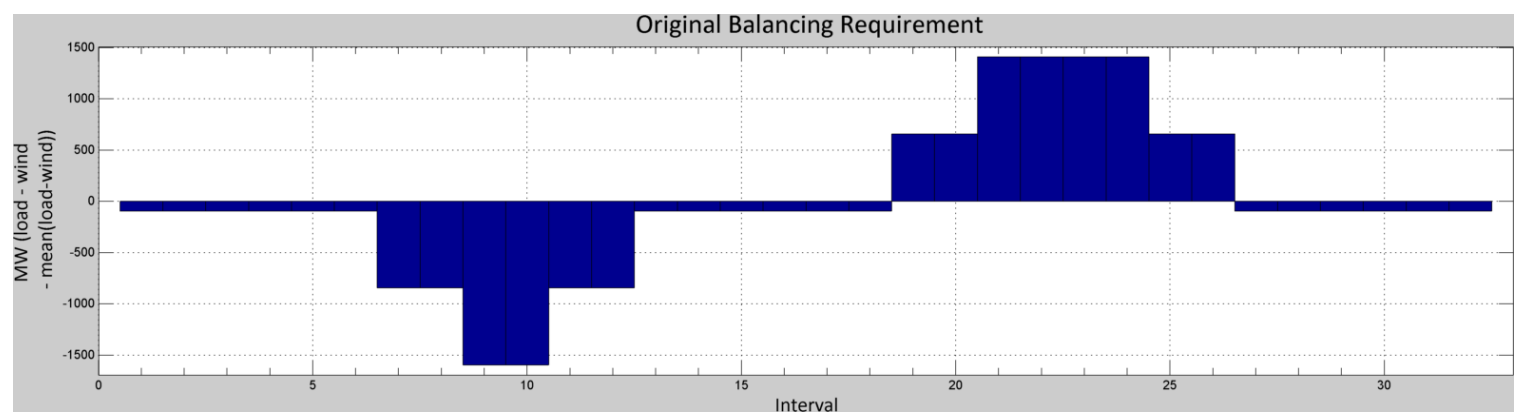

Figure 18: Combined price example, original imbalances without storage 
The time of use price for this simple case is a flat rate, shown in Figure 19 as the dotted line. The time of use price is what the building owner pays for electricity. The building owner receives a credit for providing balancing that is proportional to the initial magnitude of the imbalance (the dashed line). Adding the two price functions provides the combined electricity rate (the solid line) which applies to energy used to make ice or chiller power reduced by cooling with ice.

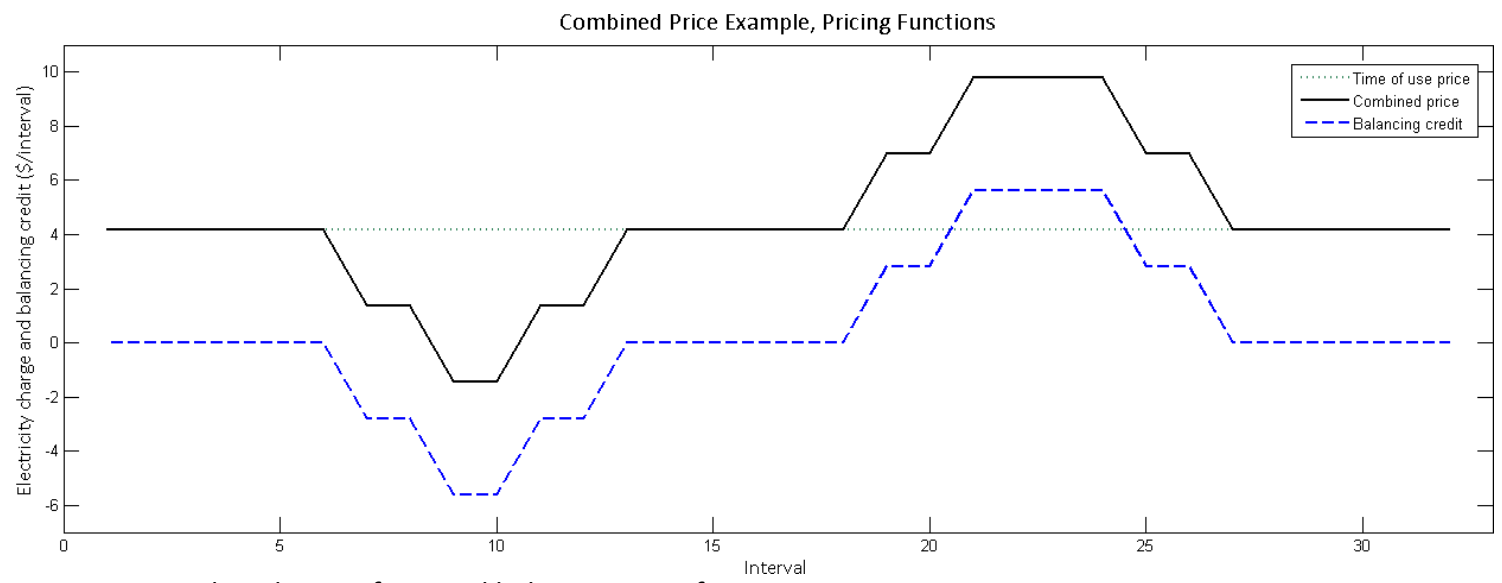

Figure 19: Combined time-of-use and balancing price functions

The credit appears as a negative price when there is excess wind; thus reducing the price of electricity and encouraging ice making. When there is not enough generation for the load, the credit appears as a positive adjustment to the price to encourage ice melting.

Owner cost $=\sum_{i=1}^{N \text { hours }} p_{i} \cdot l_{\text {bldg }, i}+\sum_{i=1}^{\text {Nhours }} p *_{i}\left[c_{i}-d_{i}\right]$
$\begin{aligned} & \text { Equation 35: Electricity price combined with balancing } \\ & \text { credit }\end{aligned}$
$\begin{aligned} & \text { where } \\ & c_{i} \quad: \text { Charging power used for ice-making in interval } i \\ & d_{i} \quad: \text { Displaced chiller power from ice-melting in interval } i \\ & p_{i} \quad: \text { Time-of-use electricity rate in interval } i \\ & p^{*} \quad: \text { Combined electricity rate with balancing credit in interval } i \\ & l_{\text {bldg, } i} \quad: \text { Chiller's electrical cooling load in interval } i\end{aligned}$

The combined price is only applied to the storage charge and discharge power. The first summation in Equation 35 is what that owner would pay for electricity without the addition of thermal storage. The second summation provides an adjustment to the base cost for providing balancing services and possibly shifting the load to other time periods. Discharging $\left(d_{i}\right)$ is negative, introducing a credit $\left(\mathrm{P}^{*}{ }_{i}\right)$ that includes a refund for the chiller power that would normally be used, plus a credit for providing the balancing service. Discharging is contingent 
upon adding cost by having charged ice $\left(\mathrm{c}_{\mathrm{i}}\right)$ during an earlier interval.

The net imbalances after running the example case are displayed in Figure 20. Most of the ice making was done during intervals 9 and 10 because these had the lowest (actually negative) prices for electricity. Some of the excess load in intervals 21 through 24 was offset, but there was insufficient building load to reduce the positive imbalance to zero.

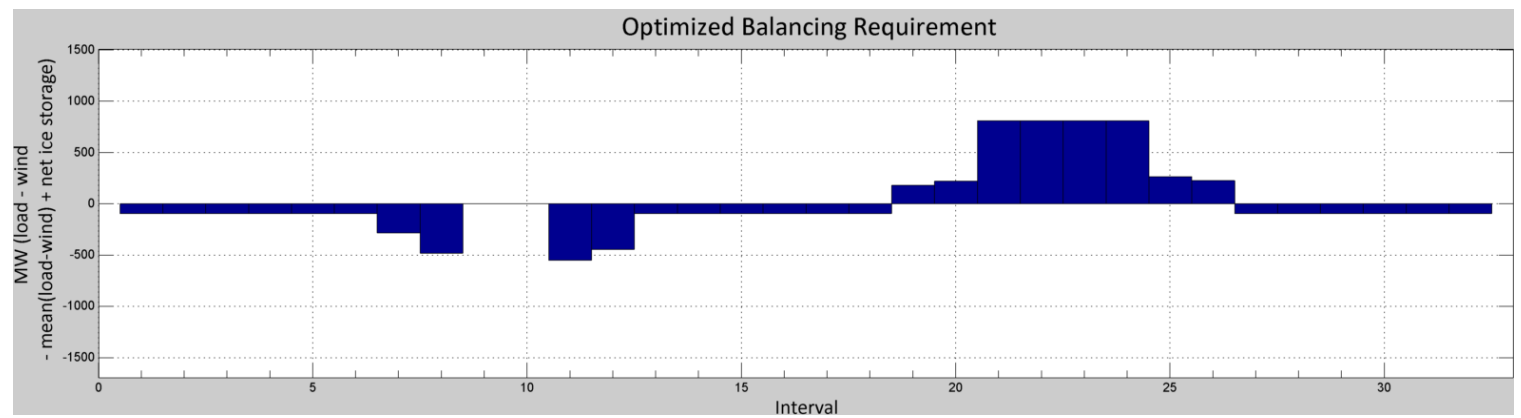

Figure 20: Combined price example, resulting imbalances

Unlike the balancing sum of squares minimization from Section 3.2 , the imbalances are not filled evenly; however, other balancing services would be expected to provide the difference. The added constraint affects interval 9 and 10 which prevents imbalances of the opposite sign from being created by the ice storage.

Building cooling loads and ice storage operation are shown in the figure below.

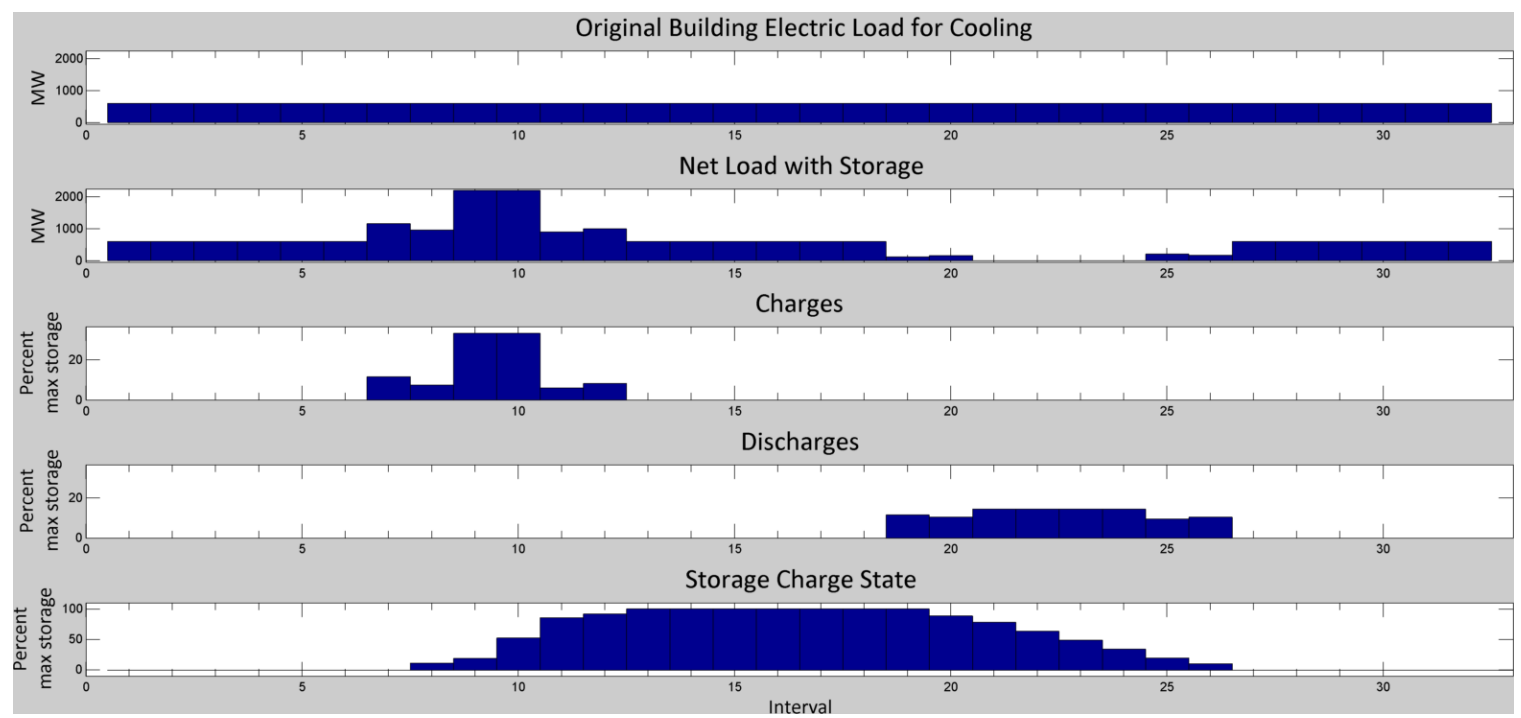

Figure 21: Combined price example, storage operation

a) cooling load, b) net load, c) charging, d) discharging and e) storage charge state 


\subsubsection{Combined Arbitrage and Balancing Unconstrained Storage}

An example case was run in order to demonstrate the validity of the algorithm. The building cooling still needed to be fulfilled by ice melt or chiller. The parameters removed the storagerelated or building cooling constraints; however, imbalances in the opposite direction were still prevented by the new constraint on the objective function.
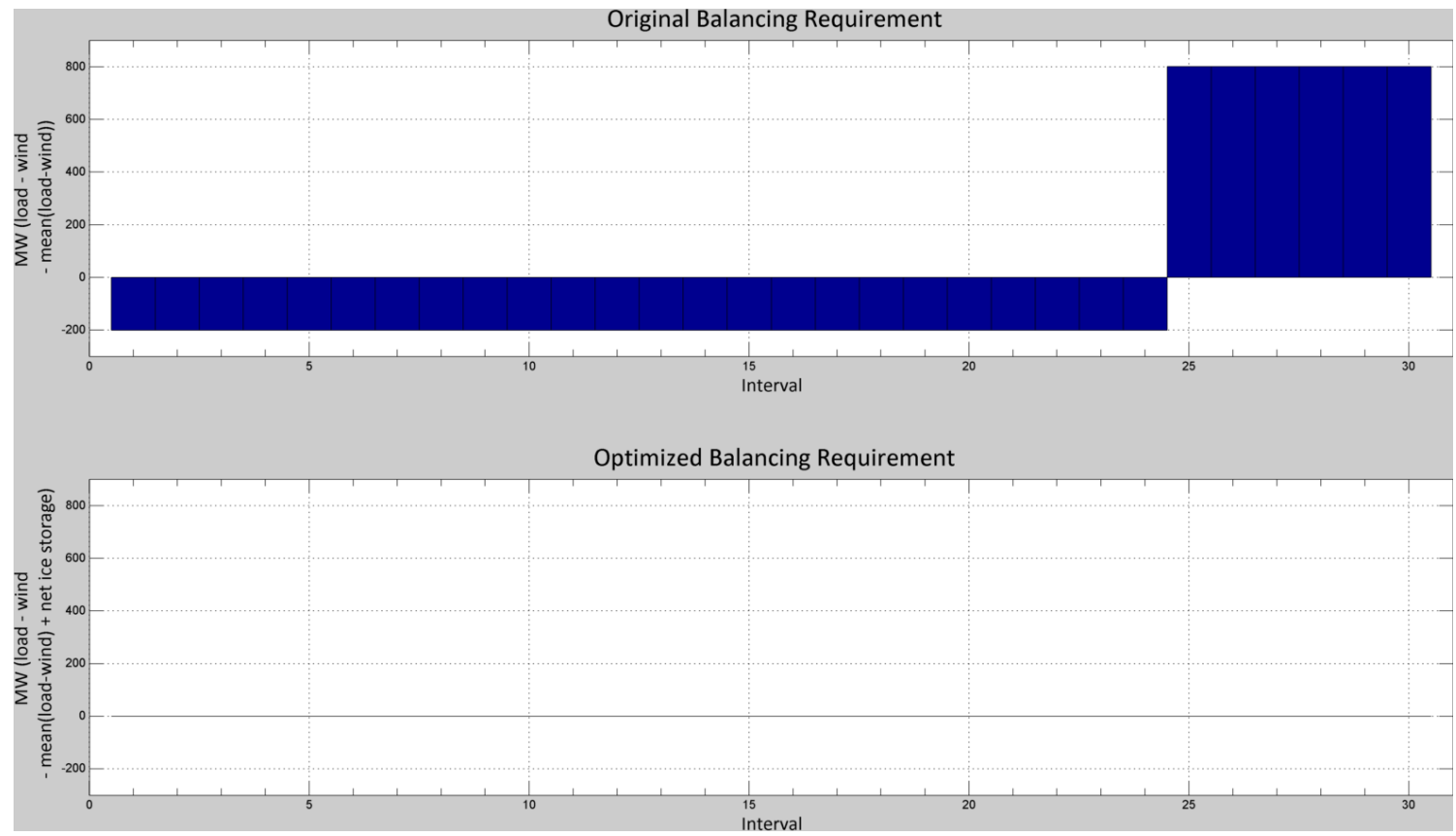

Figure 22: Combined price example, balancing results for unconstrained storage operation

A small constant imbalance caused by excess wind begins the case. At interval 25 , the wind generation stops, creating a large load imbalance. The use of ice storage is able to fully correct the imbalances because the coefficients of performance for ice making and building cooling are identical in this test. These results are expected and help verify the functioning of the algorithm. 
Figure 23 contains the storage operation solution for the balancing problem in Figure 22. The simultaneous charging and discharging occurs because the coefficients of performance are identical. In this example, only the difference between the two matter. Simultaneous charging and discharging does not occur with the real-world optimizations because the coefficients of performance are different.

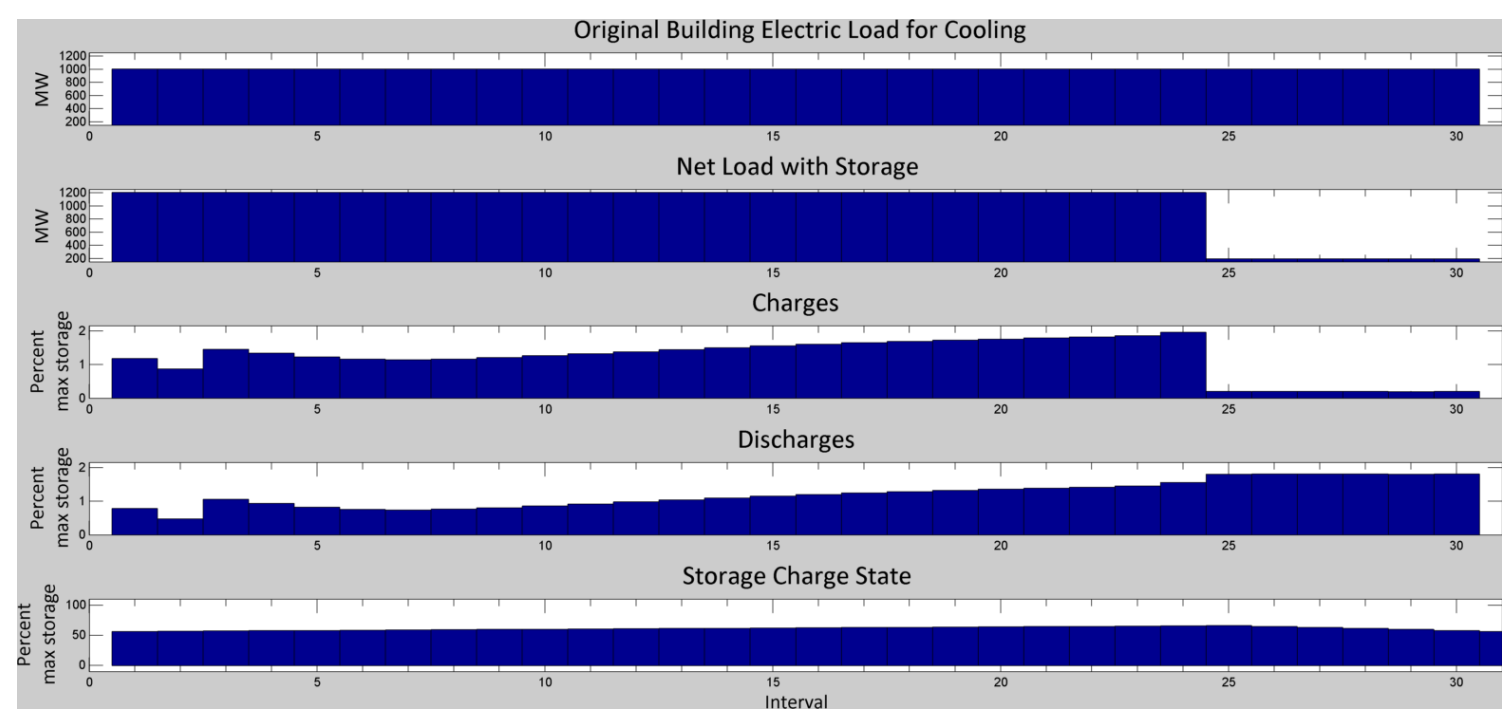

Figure 23: Combined price example, storage use for unconstrained storage

a) cooling load, b) net load, c) charging, d) discharging and e) storage charge state 


\subsubsection{San Francisco Healthcare Building}

An optimal storage plan was determined for a 250,000 sq-ft Healthcare building in San Francisco operated in July. The initial electrical costs for building cooling were $\$ 12,076$ for the month. Time of use rates were 0.147 dollars per kWh for peak hours and 0.124 dollars per kWh off-peak, as listed in 1.3.7 Power Distribution and Electricity Prices. The mean value of balancing services, both upward and downward, was $\$ 39.68$ per $\mathrm{MWh}$.
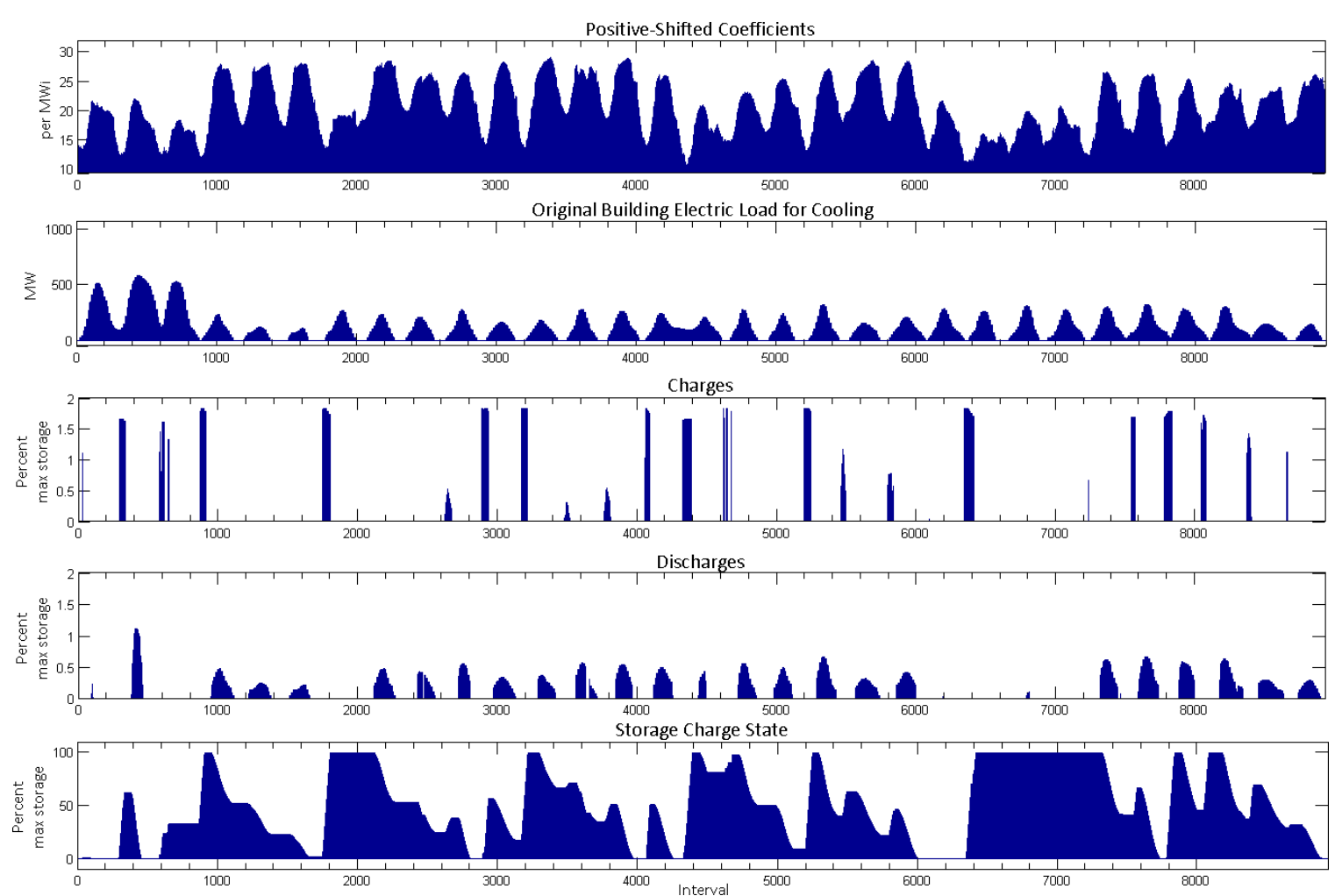

Figure 24: San Francisco healthcare cooling load and storage use

a) price coefficients b) cooling load, c) charging, d) discharging and e) storage charge state

The results of the ice storage use are seen above. Comparing the original cooling load with the discharges shows that much of the building cooling is provided by ice melting. The ice making opportunities correspond to the intervals pf low electricity prices. The resulting cost for the month was $\$ 7,051$ which includes the credits for selling balancing service. The net savings were $\$ 5,016$. 
The effects on the imbalances for the month are shown in Figure 25 below. All the power used for making ice and all the load reduction from ice melting must provide balancing due to the constraints. If the use of storage is not economically beneficial, the building will run the chiller to provide building space-cooling and the ice storage will not be used.
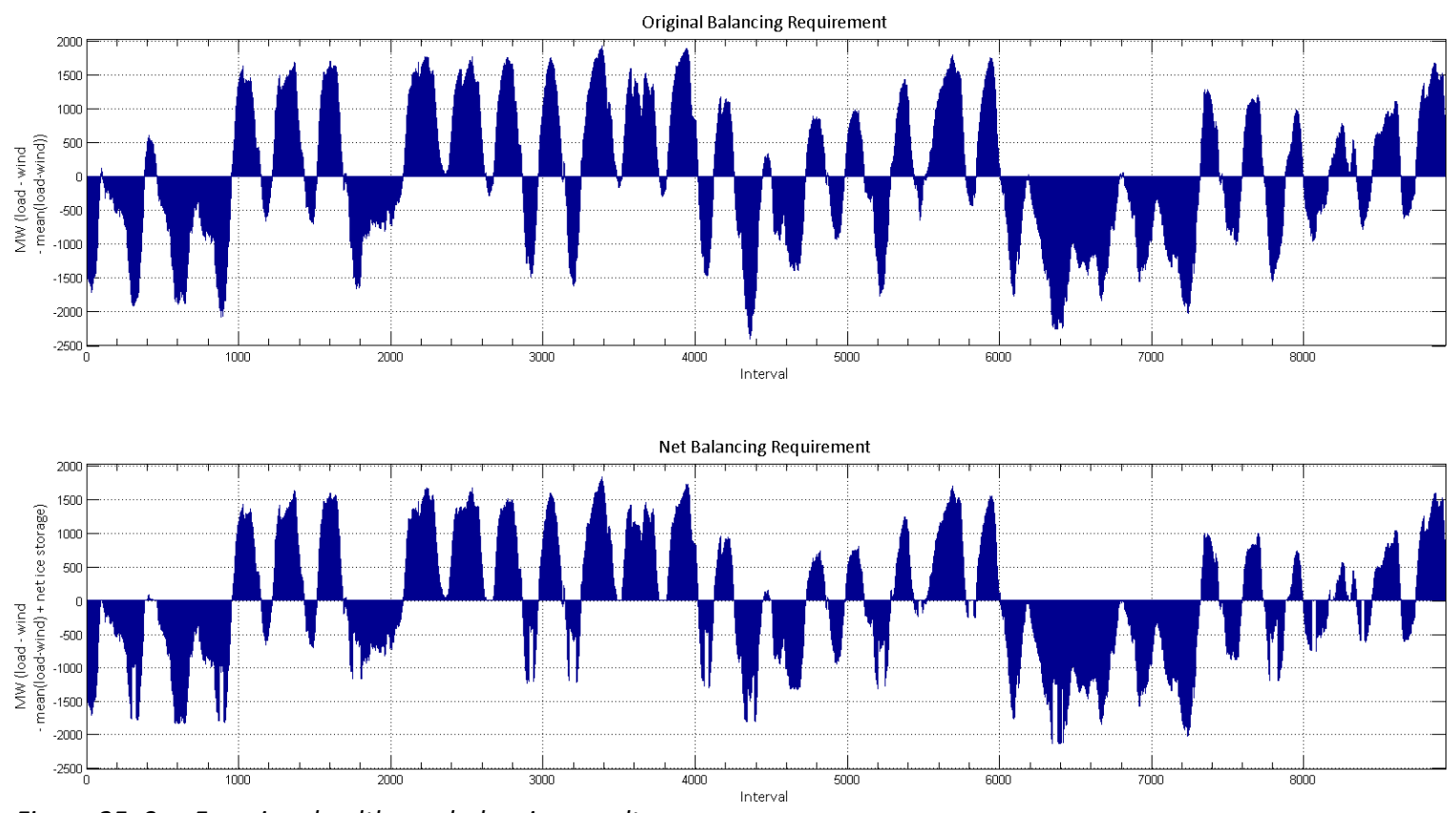

Figure 25: San Francisco healthcare balancing results

Unlike the balancing optimization, the economic one does not evenly reduce imbalances; it chooses the intervals with the highest balancing price discharge. The remaining balance would be provided by traditional sources. 
The distribution of imbalances with and without ice storage are shown in Figure 26 below. The number of intervals that have a specific balancing requirement determine the bar height. The balancing requirements are sorted into bins along the $x$-axis. The cost minimization using combined arbitrage and a balancing credit tends to provide balancing for the peak requirements as can be seen by the removal of the red intervals from the end. There is a strong tendencies to reduce imbalances to zero, as evident by the large number of net imbalances at zero in the blue results histogram.

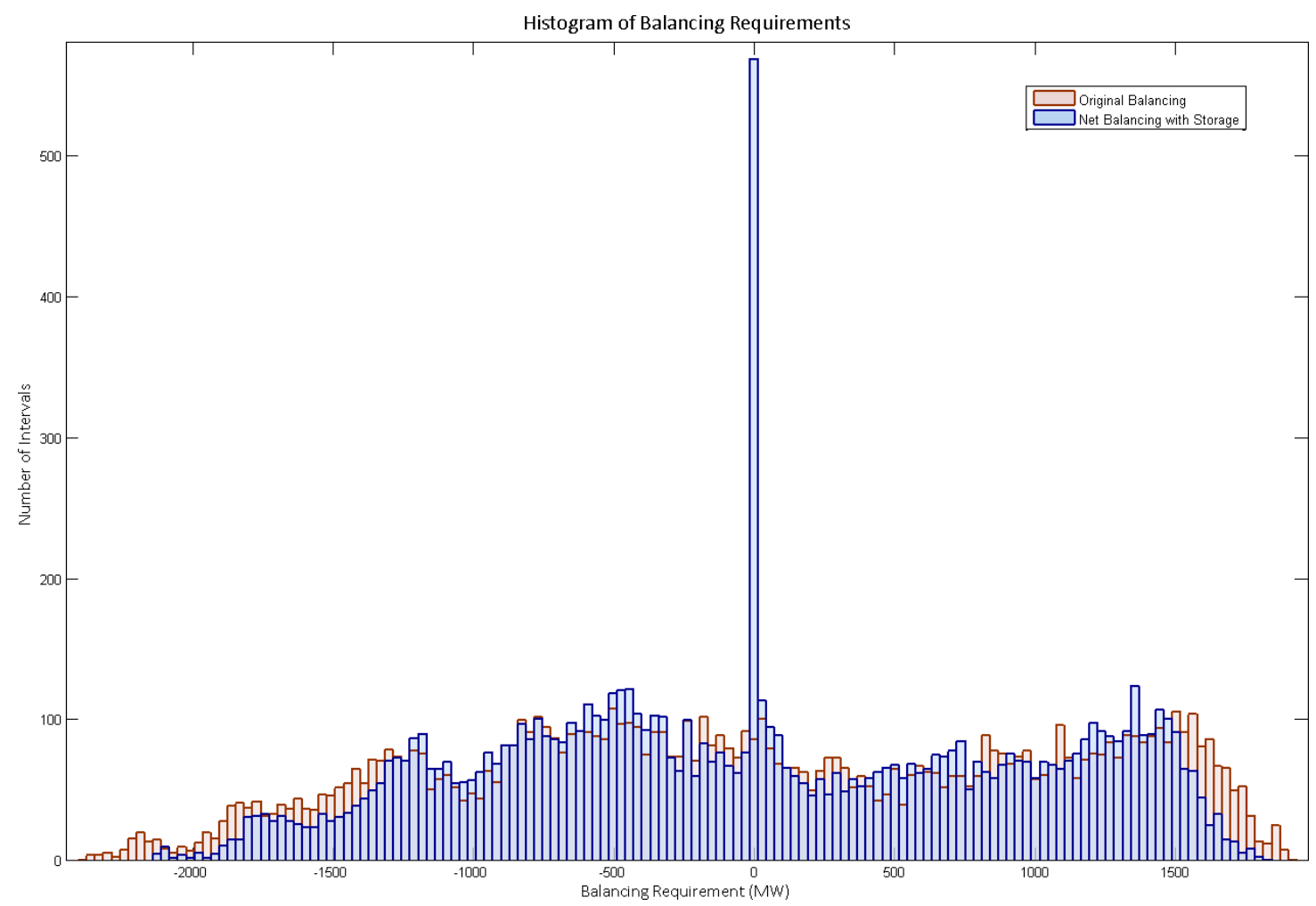

Figure 26: San Francisco healthcare distribution of imbalances 


\subsection{Combined Arbitrage and Balancing Service Results}

The optimal ice storage operation for minimizing the building owner's costs were determined for each of the three building types in four cities.

\subsubsection{Building Cost Savings and Storage Use}

Generally, months and buildings with high cooling demands provided the greatest opportunity to reduce costs by providing ancillary services. The building's region was a determining factor as expected. However, the type of building also plays an significant role. Even in the cool-summer Mediterranean climate of San Francisco, healthcare buildings require year-round space-cooling.

Table 10: Combined arbitrage and balancing, cost and storage use

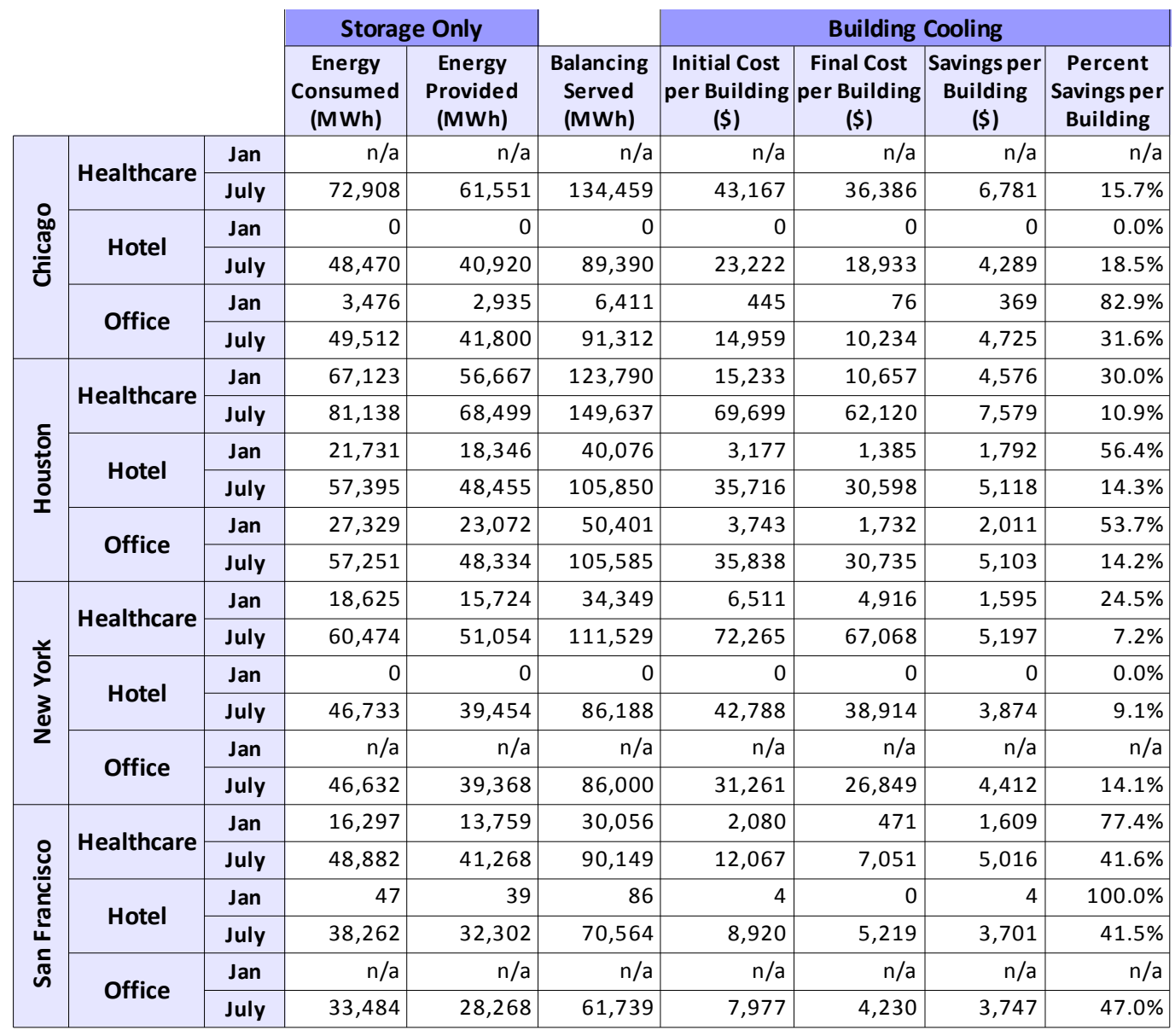

The energy consumed by storage use was always greater than the energy provided owing to the different coefficients of performance and efficiency losses. 


\subsubsection{Balancing Performance Comparison}

The ability to provide balancing power when minimizing building costs is compared in Table 11 to only minimizing the sum of squares (TSS). In three cost minimization cases, the linear solver was unable to provide a solution, given the constraints.

Table 11: Balancing performance for combined arbitrage and balancing

\begin{tabular}{|c|c|c|c|c|c|c|}
\hline & & & \multicolumn{2}{|c|}{ \% TSS Reduction } & \multicolumn{2}{|c|}{ Balancing Served (MWh) } \\
\hline & & & Combined & Balancing & Combined & Balancing \\
\hline \multirow{6}{*}{ 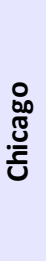 } & \multirow{2}{*}{ Healthcare } & Jan & no solution & $16.3 \%$ & $\mathrm{n} / \mathrm{a}$ & 31,078 \\
\hline & & July & $28.3 \%$ & $40.9 \%$ & 134,459 & 133,205 \\
\hline & \multirow{2}{*}{ Hotel } & Jan & $0.0 \%$ & $0.0 \%$ & 0 & 0 \\
\hline & & July & $21.0 \%$ & $29.8 \%$ & 89,390 & 88,659 \\
\hline & \multirow{2}{*}{ Office } & Jan & $3.0 \%$ & $2.9 \%$ & 6,411 & 4,635 \\
\hline & & July & $20.3 \%$ & $27.0 \%$ & 91,312 & 89,457 \\
\hline \multirow{6}{*}{$\begin{array}{l}\text { 옹 } \\
\text { ڤั } \\
\text { ํㅗ }\end{array}$} & \multirow{2}{*}{ Healthcare } & Jan & $30.9 \%$ & $37.4 \%$ & 123,790 & 119,126 \\
\hline & & July & $30.9 \%$ & $43.7 \%$ & 149,637 & 146,634 \\
\hline & \multirow{2}{*}{ Hotel } & Jan & $14.3 \%$ & $15.7 \%$ & 40,076 & 36,556 \\
\hline & & July & $24.1 \%$ & $34.2 \%$ & 105,850 & 104,468 \\
\hline & \multirow{2}{*}{ Office } & Jan & $16.1 \%$ & $17.7 \%$ & 50,401 & 45,808 \\
\hline & & July & $24.0 \%$ & $33.9 \%$ & 105,585 & 103,602 \\
\hline \multirow{6}{*}{$\begin{array}{l}\frac{1}{\vdots} \\
\frac{1}{2} \\
z \\
\text { z }\end{array}$} & \multirow{2}{*}{ Healthcare } & Jan & $14.0 \%$ & $17.1 \%$ & 34,349 & 34,723 \\
\hline & & July & $25.1 \%$ & $35.7 \%$ & 111,529 & 110,057 \\
\hline & \multirow{2}{*}{ Hotel } & Jan & $0.0 \%$ & $0.0 \%$ & 0 & 0 \\
\hline & & July & $20.3 \%$ & $28.7 \%$ & 86,188 & 85,337 \\
\hline & \multirow{2}{*}{ Office } & Jan & no solution & $4.8 \%$ & $\mathrm{n} / \mathrm{a}$ & 8,288 \\
\hline & & July & $19.6 \%$ & $26.3 \%$ & 86,000 & 83,948 \\
\hline \multirow{6}{*}{ 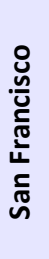 } & \multirow{2}{*}{ Healthcare } & Jan & $12.4 \%$ & $14.3 \%$ & 30,056 & 30,022 \\
\hline & & July & $22.0 \%$ & $24.3 \%$ & 90,149 & 76,543 \\
\hline & \multirow{2}{*}{ Hotel } & Jan & $<1.0 \%$ & $<1.0 \%$ & 86 & 0 \\
\hline & & July & $17.6 \%$ & $18.4 \%$ & 70,564 & 53,838 \\
\hline & \multirow{2}{*}{ Office } & Jan & no solution & $8.3 \%$ & $\mathrm{n} / \mathrm{a}$ & 14,883 \\
\hline & & July & $15.0 \%$ & $18.4 \%$ & 61,739 & 59,930 \\
\hline
\end{tabular}

The sum of squares (TSS) minimization result is an indication of the ice storage's ability to provide both balancing power and provide that power during the greatest imbalances; the peaks or troughs. Balancing served is the net reduction between the total balancing requirements from before and after the use of ice storage.

The balancing columns comes from the results in Section 3.2.10 Imbalance Sum of Squares Minimization Results. The combined columns are the results from cost minimization analysis using the combined arbitrage with balancing credits. 
By design, the balancing optimization finds the least sum of squares of the imbalances that can be obtained using ice storage. Its results are compared to the combined price cost minimization to evaluate its performance at balancing. Although the balancing provided is approximately the same for both methods (the last two columns of Table 11) for buildings and seasons with high heating loads, the cost minimization does a poor job of providing peak balancing. The solution tends to pick the price extremes and charge or discharge aggressively.

The difference is easiest to see in the Houston healthcare building shown in Figure 27 using results for July.
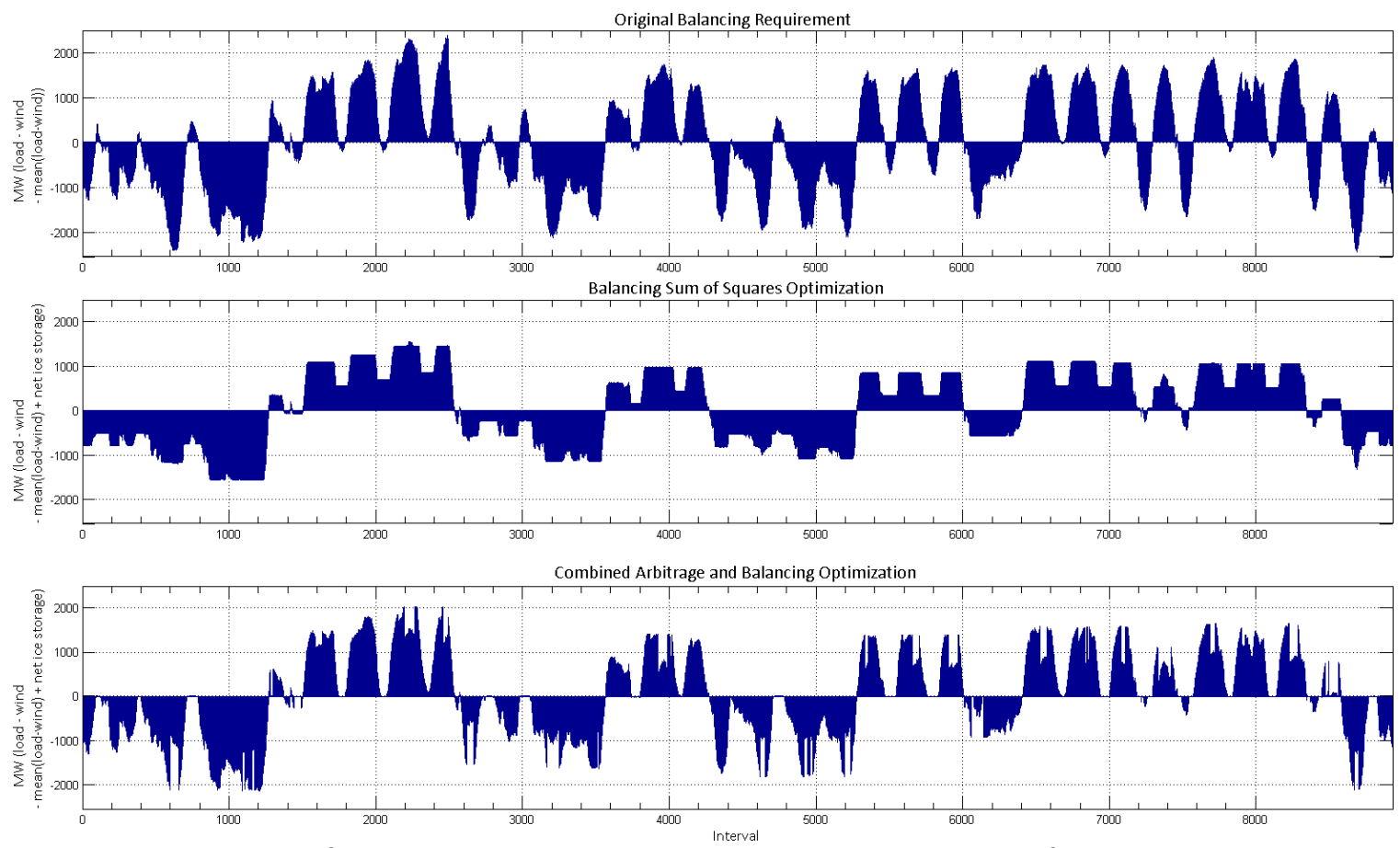

Figure 27: Net imbalances from combined price cost optimization versus balancing sum of squares

a) original balancing b) optimal sum of squares balancing c) balancing from combined arbitrage and balancing ancillary service credit.

Figure 27 shows that the peak imbalances are approximately $50 \%$ higher, and the balancing schedule contains more abrupt changes and more periods of no balancing compared to the sum of squares balancing in (c).

In summary, the cost minimization model can provide excellent total balancing energy; however, the power tends to ramp up and down quickly at high or low prices. A building owner providing balancing as an ancillary service would need to follow ramp rate limitations. The remaining balancing energy would be filled by traditional providers. 


\subsection{Energy Cost Savings Comparison}

The Section 4.2.1 Building Cost Savings and Storage Use demonstrated that providing a balancing ancillary service can reduce the building's net cost for energy. How does this cost reduction compare to the time of use price arbitrage of the traditional nighttime ice making and daytime ice cooling? Unfortunately, Chicago and Houston did not offer time of use pricing. The price difference between New York's peak and off-peak prices is below the differential required to overcome the coefficient of performance difference. This was also the case with San Francisco's winter time of use prices. That leave only San Francisco's summer rates with which to compare.

\subsubsection{Time of Use Load Shifting for Summer San Francisco}

A cost minimization for the time of use pricing alone (no credit for balancing ancillary service) was run. The cooling data is for a healthcare building in San Francisco in July. The storage and building characteristics are the standard ones listed in Table 8: Imbalance TSS minimization common parameters. The time of use price differential is barely more than what is required to cover coefficient of performance differences for building cooling and ice making.

The following figure shows the time of use pricing with the five peak prices during the weekdays. The building cooling load increases during the day and drops at night.
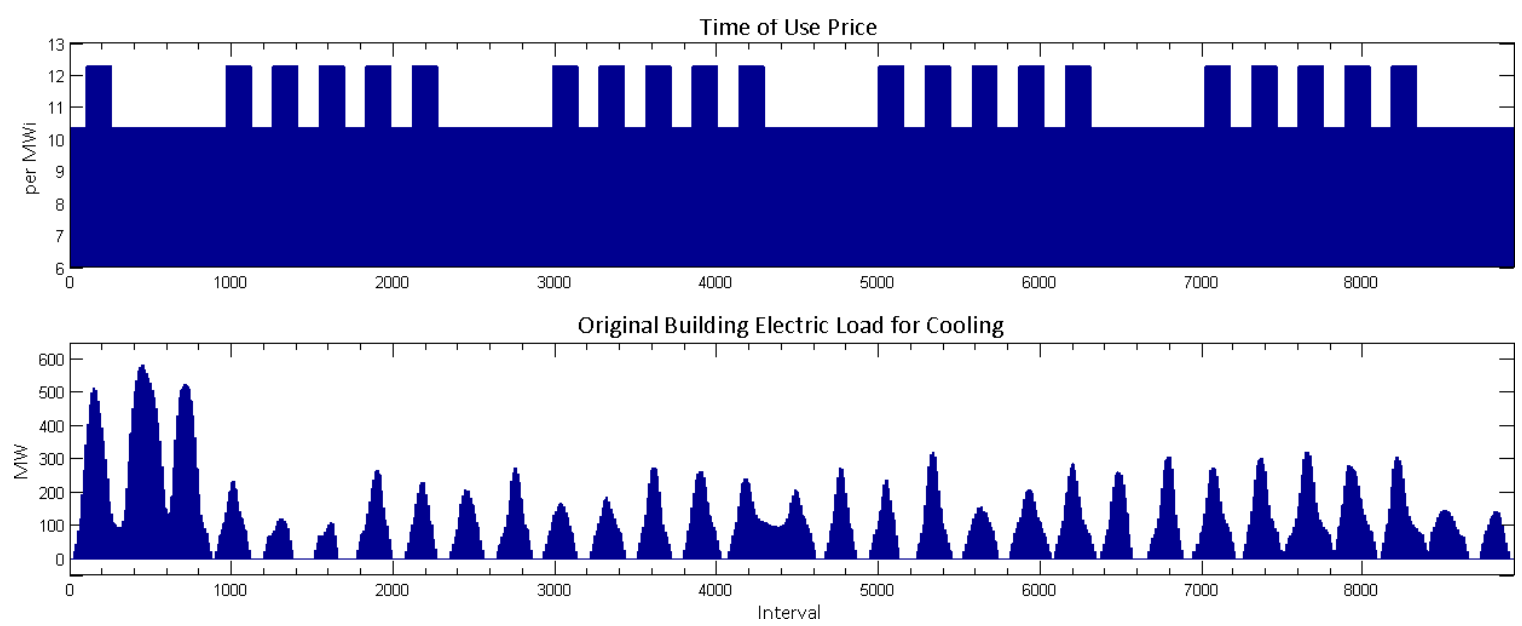

Figure 28: Time of use load shifting for summer San Francisco a) electricity price b) original building cooling 
The ice use for building cooling corresponds to the peak rates while the ice making occurs at night. These results are expected from a traditional load shifting use for ice storage.
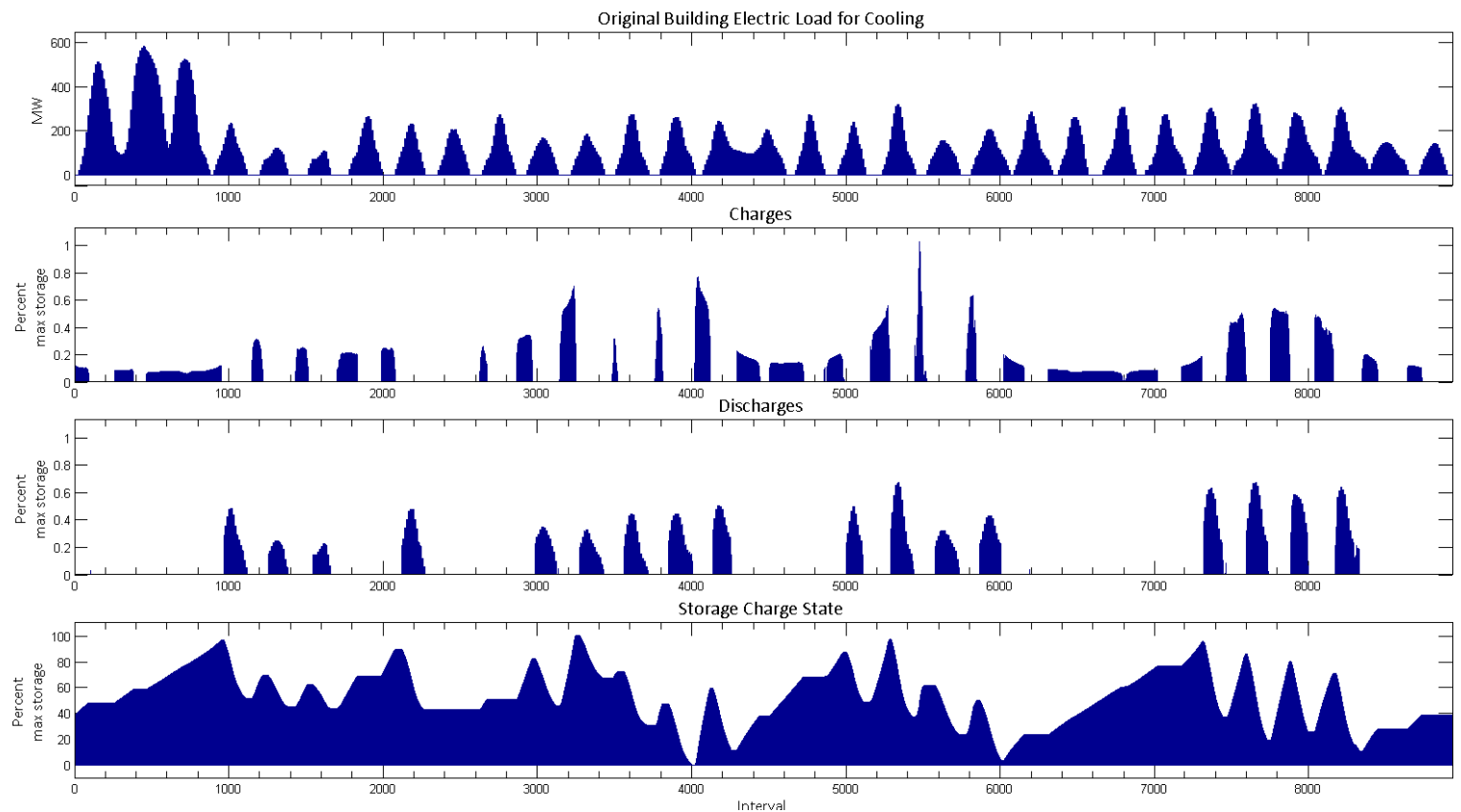

Figure 29: Storage use with load shifting for summer San Francisco

a) cooling load, c) charging, d) discharging and e) storage charge state

Because the price differential is so small, the cost reduction for a single building was $\$ 3.60$ for the month. This is compared to the $\$ 5016$ savings for the same building when using providing balancing ancillary service. 


\subsubsection{High Time of Use Price Differential's Effect on Cost Minimization}

The real-world cases leave unanswered the comparison between load shifting and load shifting with a balancing ancillary service credit when the time of use price difference is large compared to the balancing credit. We would like to know if the ice storage is used exclusively for load shifting or whether some balancing can be provided in addition. To explore this effect, a hypothetical case was created using the same healthcare facility from San Francisco, but the time of use pricing was changed.

Summer, July Hypothetical Pricing (cents/kWh):
17.70 Peak:
8:30 am to 9:30 pm, Monday through Friday
9.39 Off-Peak:
9:30 pm to 8:30 am, Monday through Friday and weekends

Electricity cost minimization was done using the time of use pricing arbitrage. A second minimization combined the time of use pricing attempting to provide balancing ancillary services. The results are summarized in Table 12.

\begin{tabular}{|c|c|c|c|c|c|c|c|}
\hline & \multicolumn{2}{|c|}{ Storage Only } & \multicolumn{2}{|c|}{ Balancing Effects } & \multicolumn{3}{|c|}{ Building Cooling } \\
\hline & $\begin{array}{c}\text { Energy } \\
\text { Consumed } \\
\text { (MWh) }\end{array}$ & $\begin{array}{c}\text { Energy } \\
\text { Provided } \\
\text { (MWh) }\end{array}$ & $\begin{array}{c}\% \text { TSS } \\
\text { Reduction }\end{array}$ & $\begin{array}{c}\text { Balancing } \\
\text { Served (MWh) }\end{array}$ & $\begin{array}{c}\text { Initial Cost } \\
\text { (thousands, \$) }\end{array}$ & $\begin{array}{c}\text { Final Cost } \\
\text { (thousands, \$) }\end{array}$ & $\begin{array}{l}\text { Savings per } \\
\text { Building (\$) }\end{array}$ \\
\hline Arbitrage & 35,131 & 29,659 & $14.3 \%$ & 64,790 & 12,104 & 10,153 & 1,951 \\
\hline Combined & 49,114 & 41,464 & $22.0 \%$ & 90,578 & 12,104 & 5,072 & 7,032 \\
\hline
\end{tabular}

The results indicate that balancing can be provided, increasing from 64,790 MWh to 90,578 MWh, while taking advantage of the time of use pricing. An additional \$5081 in electricity cost savings was captured for the owner. Because the ancillary service price function increases the price of electricity during intervals with excess load, the additional savings was not a foregone result. 


\section{Observations}

\subsection{Balancing Energy Maximums}

The building's total annual cooling load divided by the chiller COP for ice making is the maximum downward balancing (electric load increase) that can be provided. The same value divided by the chiller's COP for building cooling is the maximum upward balancing (load reduction).

There is more flexibility in providing downward balancing because ice-making can be done at any time. Upward balancing requires a building cooling load to coincide with the upward balancing requirement.

\subsection{Balancing Power Maximums}

The building chiller's rated maximum power is the downward balancing capacity. The building cooling load is the upward balancing capacity.

\subsection{Economic Benefits of Providing Balancing Ancillary Services}

Providing balancing ancillary services by using chiller demand response, in conjunction with ice storage, can reduce monthly building electricity costs by roughly $10-50 \%$ for buildings with yearround cooling requirements. Both flat electricity rate and time of use rate structures were evaluated. The real-world, peak to off-peak price differences tended to be small; therefore, a hypothetical rate structure was tested that involved a large price differential when compared to the value of the balancing services. Under these conditions, it was still possible to provide balancing services while shifting load from peak to off-peak times.

\subsection{The Essential Characteristics of Using a Sum of Squares Versus a Constrained Linear Minimization}

Minimizing imbalances caused by over-generation, by placing low prices on the energy, causes the chiller to run at full power. The increased load may cause imbalances in the other direction ( $a$ high-load imbalance). Two methods were considered to resolve this problem. The first method changes the problem to a sum of squares minimization on the imbalances, a non-linear problem. The second method keeps the problem linear, but adds a constraint to prevent the chiller and ice storage from creating any imbalances.

The sum of squares minimization reduces the magnitude of high and low imbalances evenly. 
Graphically, it reduces the high peaks and also fill in the troughs evenly. The method can also create small imbalances, while slowly charging the storage, in order to offset a large imbalance at some point in the future.

The constrained linear minimization picks the highest magnitude imbalances and reduces them by as much as possible, often to a zero imbalance. The total balancing energy provided is slightly more than the energy provided in the sum of squares approach. Rapid on/off cycles are the tendency in the constrained linear method. The constrained linear approach better reflects the ancillary services market where a balancing services market clearing price determined for each time period and all service providers are paid at that rate. Commercial buildings providing balancing ancillary services will need to follow ramp rate requirements set by the market.

\subsection{Comparable Demand Side Management}

Any power load capable of deferring its energy use may provide balancing services and can take advantage of load shifting. Similar parameters as those used for the building cooling optimization exist in these models as well, including COP (start-up/shutdown, added transportation cost), storage cost. Processes move from just-in-time energy use to increasing in-process energy inventory and associated carrying (storage) costs. 


\section{Future Work}

\subsection{Evaluate Composite Balancing Requirement}

This thesis examined the ability of load response from commercial buildings with thermal ice storage to provide ancillary services, specifically intrahour balancing. The imbalances considered were those created by the intermittent of wind generation. Other factors contribute to the imbalance signal, such as equipment outages, solar power and missed load forecasts. Future work should consider the composite imbalance signal and the use of building load to correct it. The balancing requirement should be available as market transaction histories.

\subsection{Economic Analysis for a Specific Region}

The analysis presented examines a broad number of buildings and regions using data sets that are both geographically and temporally unmatched. It also provides a good test case for the optimization toolkit. The next step would be to examine data from a specific region and time. There may be correlations between the daily temperatures that affect building cooling loads and wind generation from turbines. Using regional balancing requirements with weather and temperature data from the same region and time period would correct for these correlations.

\subsection{Consider Specific Building Types and Cities}

Preferred regions and building types were determined here based upon potential energy cost savings. Closely considering a few cities and building types would allow for accurate cost analysis, including utility demand and equipment charges, thermal storage capital costs and building floorspace opportunity costs. This data would make possible a cost-benefit analysis that could also evaluate chiller sizing and ice storage capacity sizing.

\subsection{Ramp Rate Control Utilizing Chiller-Cycling and Ice-Storage}

The total grid load minus the wind generation has been defined as the imbalance. The change in imbalance from one interval to the next is the ramp rate. Rapid changes in the ramp rate add instability risks and increase the need for stand-by generation or load shedding mechanisms that can act on short time frames. 
The ramp rates for the January BPA system load and wind generation data can be significant, as shown in Figure 30 and summarized in Table 13. The peaks range between -1102 MW/interval to $1240 \mathrm{MW} /$ interval. This indicates a shift of load and wind generation of more than one gigawatt in only five minutes.

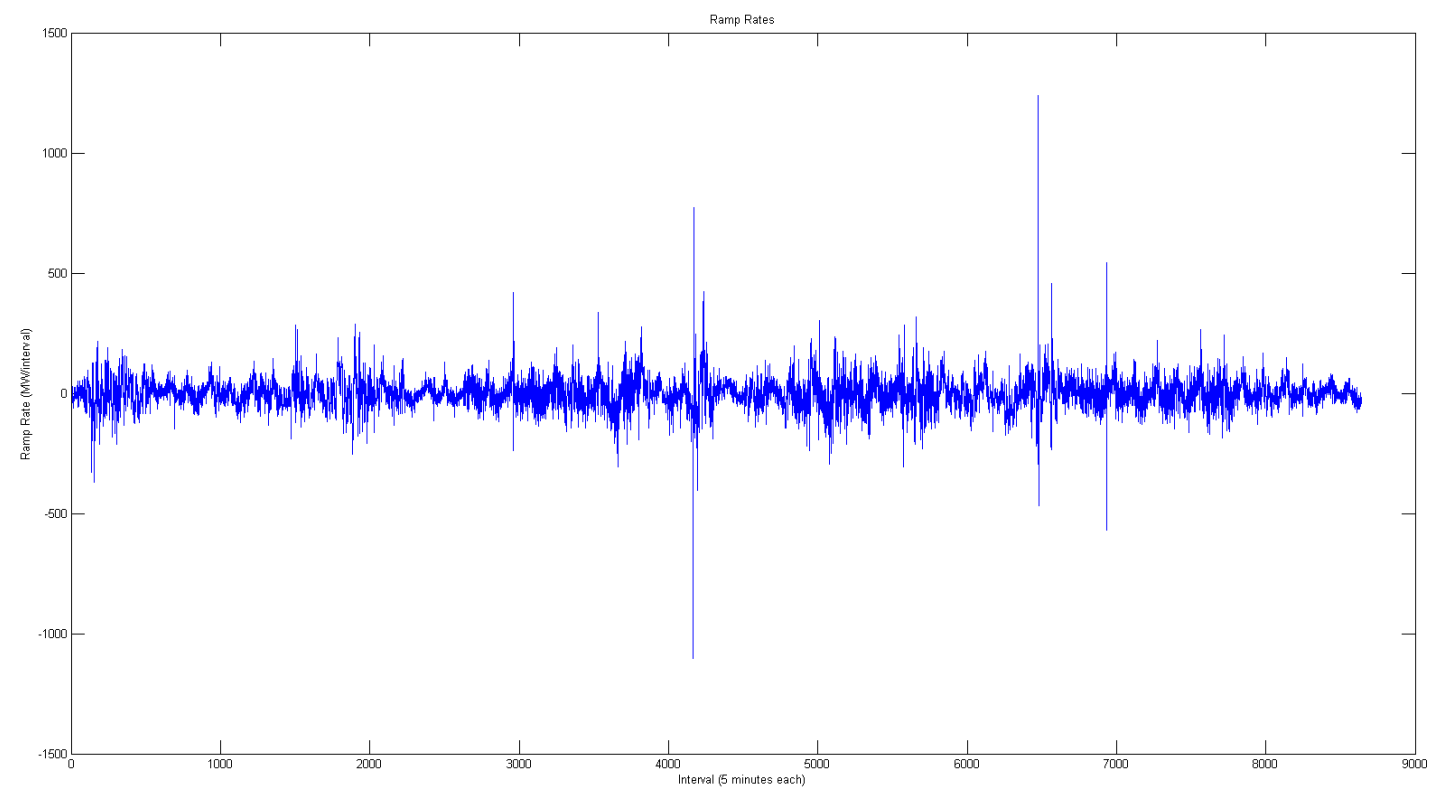

Figure 30: Ramp rates for the total system load minus wind generation

A building using a variable-speed compression chiller for cooling would be able to change its power draw from minimum operating capacity to rated capacity in 75 seconds to 6 minutes, as discussed in the Section 3.1 Regulation Services and Initial Results. It may be possible to moderate the balancing ramp rates using the compression chiller in combination with ice storage. The approximate quadratic optimization used to find an operating plan to moderate the imbalances might be used to find an optimal plan for moderating ramp rates. 


\subsubsection{Balancing Optimization's Effect on Ramp Rates}

After reducing the imbalances, using the sum of squares minimization, the ramp rates were also reduced. The peak, 5 minute ramp, went from $1240.0 \mathrm{MW}$ to $423.2 \mathrm{MW}$. The resulting ramp rates for the entire period are shown in Figure 31. The cooling load data came from the modeled healthcare building in Houston, see Section 1.3.2 Building Data.

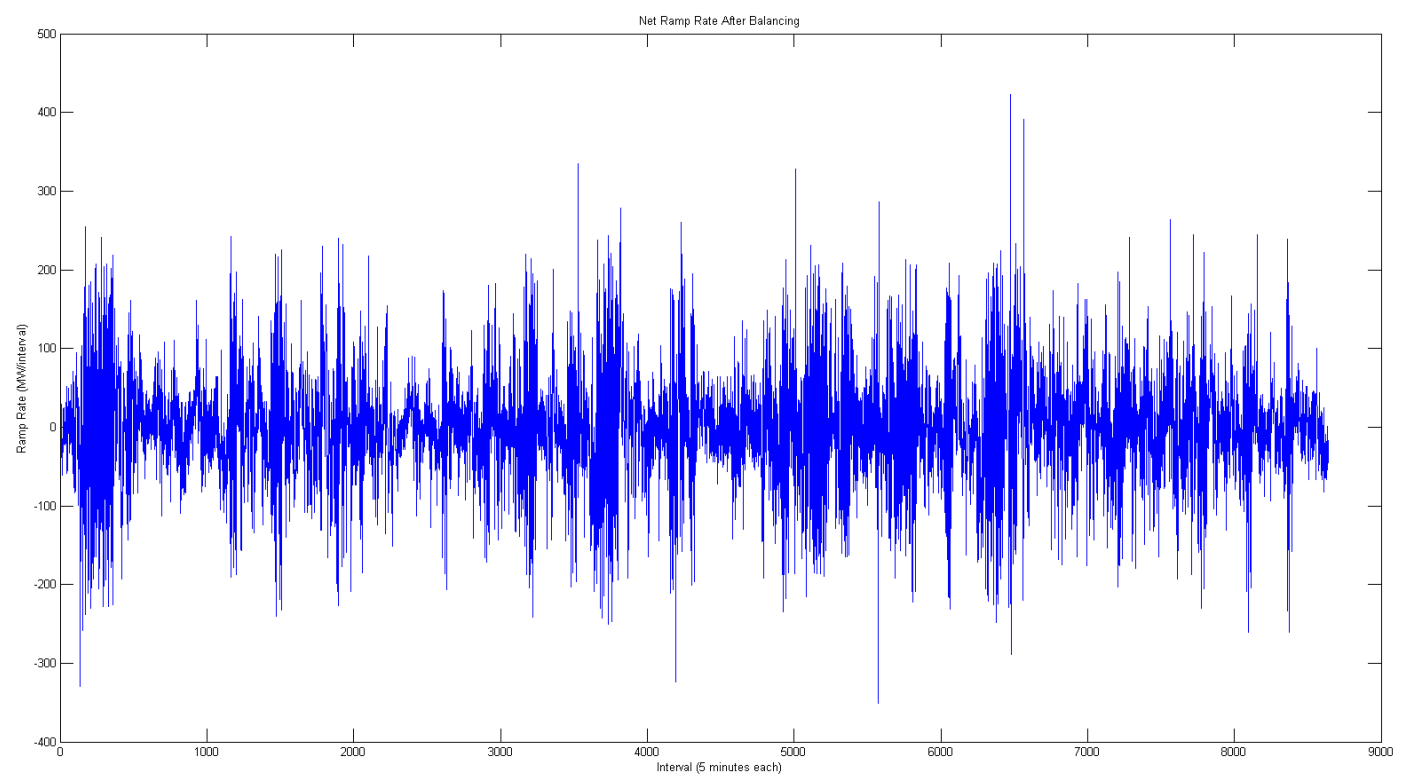

Figure 31: Resulting ramp rates after balancing optimization, 30 iterations

Using ice storage to reducing the imbalances also eliminates the major ramp peaks while slightly increasing the ramp rates on average, see Table 13.

Table 13: Ramp rates before and after balancing optimization

\begin{tabular}{|l|r|r|r|r|}
\cline { 2 - 5 } \multicolumn{1}{c|}{} & Mean of Abs olute & \multicolumn{1}{c|}{ M in } & Max & Standard Dev. \\
\hline Original & 46.2 & -1102.0 & 1240.0 & 66.2 \\
\hline Net & 49.4 & -351.0 & 423.2 & 68.6 \\
\hline
\end{tabular}

\subsubsection{Ramp Rate Optimization}

Managing the ice storage to specifically reduce the ramp rates would be interesting future work as the result could be compared to the ramp rates created by the combined price arbitrage/balancing services optimization. 


\section{Bibliography}

Black, Mary, and Goran Strbac. 2006. "Value of Storage in Providing Balancing Services for Electricity Generation Systems with High Wind Penetration." Journal of Power Sources 162 (2) (November 22): 949-953. doi:doi: 10.1016/j.jpowsour.2005.07.020.

CBECS Energy Information Administration (EIA). 2003. "CBECS." About the Commercial Buildings Energy Consumption Survey. http://www.eia.gov/consumption/commercial/about.cfm.

Consolidated Edison. 2013. "Con Edison: Customer Central - Market Supply Charge Calculator." Accessed August 9. https://apps1.coned.com/csol/msc_cc.asp.

Drees, Kirk, and James Braun. 1996. "Development and Evaluation of a Rule-Based Control Strategy for Ice Storage Systems." HVAC\&R Research 2 (October 1): 312-334. doi:10.1080/10789669.1996.10391352.

Heffner, Grayson, Chuck Goldman, Brendan J Kirby, and Michael Kintner-Meyer. 2007. "Loads Providing Ancillary Services: Review of International Experience."

http://www.osti.gov/bridge/servlets/purl/970866-I1qfEe/.

Henze, Gregor P., and Moncef Krarti. 2005. "Predictive Optimal Control of Active and Passive Building Thermal Storage Inventory." http://www.osti.gov/bridge/servlets/purl/894509GH9Mqf/.

Hoffman, Michael G, Michael CW Kintner-Meyer, Artyom Sadovsky, and John G DeSteese. 2010. "Analysis Tools for Sizing and Placement of Energy Storage for Grid Applications - A Literature Review." http://www.osti.gov/bridge/servlets/purl/990130-ppJvK9/.

Kintner-Meyer, M.C.W. 1994. "An Investigation of Optimal Sizing and Control of Air-conditioning Systems in Commercial Buildings". University of Washington. http://books.google.com/books?id=-sR8NwAACAAJ.

Kintner-Meyer, Michael, Patrick J Balducci, Chunlian Jin, Tony B Nguyen, Marcelo A Elizondo, Vilayanur V Viswanathan, Xinxin Guo, and Francis K Tuffner. 2010. "Energy Storage for Power Systems Applications: A Regional Assessment for the Northwest Power Pool (NWPP)." http://www.osti.gov/bridge/servlets/purl/991590-uRmJ3Q/.

Makarov, Yuri, Michael Cw Kintner-Meyer, and Howard Illian. 2010. "Optimal Size of Energy Storage to Accommodate High Penetration of Renewable Resources in WECC System." 2010 Innovative Smart Grid Technologies ISGT 60089: 1-5. doi:10.1109/ISGT.2010.5434768.

Makarov, Yuri V., Clyde Loutan, Jian Ma, and Phillip de Mello. 2009. "Operational Impacts of Wind Generation on California Power Systems." IEEE Transactions on Power Systems 24 (2): 1039-1050. 
Makarov, Yuri V., Clyde Loutan, Jian Ma, Phillip De Mello, and Shuai Lu. 2008. "Impacts of Wind Generation on Regulation and Load Following Requirements in the California System." In IEEE Power and Energy Society 2008 General Meeting: Conversion and Delivery of Electrical Energy in the 21st Century, PES, July 20, 2008 - July 24, 2008. IEEE Power and Energy Society 2008 General Meeting: Conversion and Delivery of Electrical Energy in the 21st Century, PES. Pittsburgh, PA, United states: Inst. of Elec. and Elec. Eng. Computer Society. http://dx.doi.org/10.1109/PES.2008.4596097.

Milligan, Michael R. 2010. "Benefit of Regional Energy Balancing Service on Wind Integration in the Western Interconnection of the United States : Preprint." In National Renewable Energy Laboratory: Golden, CO. http://www.nrel.gov/docs/fy11osti/49076.pdf.

NWPP Corporation. 2013. "NWPP Area Assessment of Reliability and Adequacy, 2013 Summer Operating Conditions.pdf." http://www.nwpp.org/our-resources/ReliabilityAssessments/Summer-2013.

Pratt, Robert G, Patrick J Balducci, Clint Gerkensmeyer, Srinivas Katipamula, Michael CW Kintner-Meyer, Thomas F Sanquist, Kevin P Schneider, and Thomas J Secrest. 2010. "The Smart Grid: An Estimation of the Energy and CO2 Benefits." http://www.osti.gov/bridge/servlets/purl/971445-kj4UwS/.

Sun, Changlin, Keith Temple, Todd Rossi, and James E. Braun. 2006. "RP-1252 -- Interaction Between Dynamic Electric Rates and Thermal Energy Storage Control". RP-1252. Atlanta, GA: American Society of Heating, Refrigerating and Air-Conditioning Engineers. http://rp.ashrae.biz/researchproject.php?rp_id=9.

U.S. Department of Energy, O.S.T.I. 2008. “20\% Wind Energy by 2030”. DOE/GO-102008-2567. http://www.osti.gov/bridge/servlets/purl/937007-eiac17/.

U.S. Energy Information Administration. 2013. "ESR - Table 5. Average Monthly Bill by Census Division, and State, 2009." Commercial Electric Sales, Revenue, and Price. Accessed August 5. http://www.eia.gov/cneaf/electricity/esr/table5.html.

West, J., and J. E Braun. 2000. "Modeling Partial Charging and Discharging of Area-constrained Ice Storage Tanks." In American Society of Heating, Refrigerating and Air-Conditioning Engineers, Inc., Atlanta, GA (US).

Wood, Allen J., and Bruce F. Wollenberg. 1996. Power Generation, Operation, and Control. 2nd ed. Wiley-Interscience.

Yang, Zhenguo, Jianlu Zhang, Michael C. W. Kintner-Meyer, Xiaochuan Lu, Daiwon Choi, John P. Lemmon, and Jun Liu. 2011. "Electrochemical Energy Storage for Green Grid." Chemical Reviews 111 (May 11): 3577-3613. doi:10.1021/cr100290v. 